Florida International University FIU Digital Commons

\title{
Morphology and anatomy of three common everglades utricularia species; U. Gibba, U. Cornuta, and U. Subulata
}

Theresa A. Meis Chormanski

Florida International University

DOI: $10.25148 /$ etd.FI15102723

Follow this and additional works at: https://digitalcommons.fiu.edu/etd

Part of the Biology Commons

\section{Recommended Citation}

Meis Chormanski, Theresa A., "Morphology and anatomy of three common everglades utricularia species; U. Gibba, U. Cornuta, and U. Subulata" (2007). FIU Electronic Theses and Dissertations. 2494.

https://digitalcommons.fiu.edu/etd/2494 


\section{FLORIDA INTERNATIONAL UNIVERSITY}

Miami, Florida

\section{MORPHOLOGY AND ANATOMY OF THREE COMMON EVERGLADES}

UTRICULARIA SPECIES; U. GIBBA, U. CORNUTA, AND U. SUBULATA

A thesis submitted in partial fulfillment of the

requirements for the degree of

MASTER OF SCIENCE

in

BIOLOGY

by

Theresa A.Meis Chormanski

2007 
To: Interim Dean Mark Szuchman

College of Arts and Sciences

This thesis, written by Theresa A. Meis Chormanski, and entitled Morphology and Anatomy of three common Everglades Utricularia species; U. gibba, U. cornuta, and $U$. subulata, having been approved in respect to style and intellectual content, is referred to you for judgment.

We have read this thesis and recommend that it be approved

David W. Lee

Jack B. Fisher

Jennifer H. Richards, Major Professor

Date of Defense: June 25, 2007

The thesis of Theresa A. Meis Chormanski is approved.

\begin{tabular}{r}
$\begin{array}{r}\text { Interim Dean Mark Szuchman } \\
\text { College of Arts and Sciences }\end{array}$ \\
\hline Dean George Walker \\
University Graduate School
\end{tabular}

Florida International University, 2007 


\section{ACKNOWLEDGMENTS}

I would like to thank my major professor and advisor Dr. Jennifer Richards for initiating my interest in plant morphology, teaching me the fundamentals of botany, and helping me understand the process of research. I am especially appreciative of her time and efforts in guiding my work so that it was both useful and constructive. I would also like to say thank you to my committee members Dr. Jack Fisher and Dr. David Lee for extending their expertise to helping find practical solutions to seemingly abstract problems. Finally, I would like to thank my friends, lab mates, and family members for their help with plant collections, laboratory work, and manuscript preparation. 


\begin{abstract}
OF THE THESIS
MORPHOLOGY AND ANATOMY OF THREE COMMON EVERGLADES

UTRICULARIA SPECIES; U. GIBBA, U. CORNUTA, AND U. SUBULATA

by
\end{abstract}

Theresa A. Meis Chormanski

Florida International University, 2007

Miami, Florida

Professor Jennifer H. Richards, Major Professor

Members of the aquatic plant genus Utricularia exhibit many unique characteristics: nutritional supplementation carried out by the most complex trapping mechanism of any carnivorous plant, extremely modified vegetative morphology, relaxed developmental constraints, high generic diversity, and fast genomic substitution rates. The vegetative morphology, anatomy and growth pattern of three species common to Florida's Everglades, $U$. gibba, U. cornuta, and $U$. subulata were analyzed in depth. Specimens were collected from different habitats in South Florida during both the wet and dry seasons. Light and scanning electron microscopy were used to quantify anatomical and morphological characteristics. A morphological model describing growth and the possible variations to the basic pattern was created for each of the three species, providing a framework for future ecological, physiological, and molecular studies.

Additional field and herbarium observations were made of the remaining eight taxa found in southern Florida and a species key was created for all eleven taxa. 


\section{TABLE OF CONTENTS}

CHAPTER

PAGE

I Morphology and Anatomy of Utricularia gibba, U. cornuta, and U. subulata ..... 1

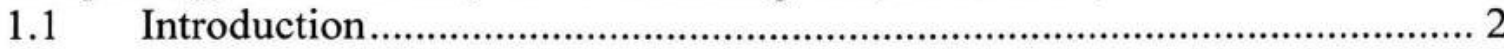

$1.2 \quad$ Materials and Methods ........................................................................ 7

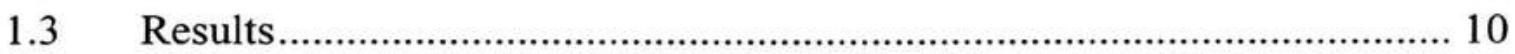

1.3a General morphological and anatomical characteristics of U. gibba ..................................................................................... 10

1.3b General morphological and anatomical characteristics of U. cornuta ............................................................................. 13

1.3c General morphological and anatomical characteristics of

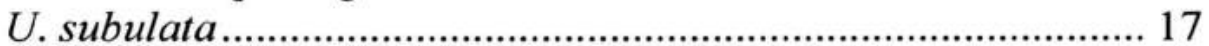

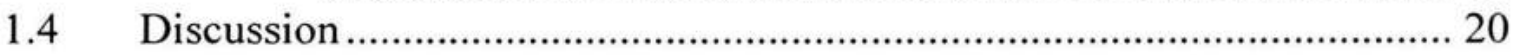

1.4a Architectural outline for U. gibba, U. cornuta, and

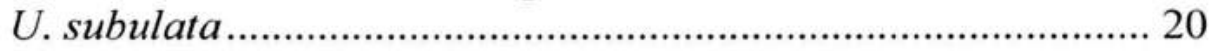

1.4b Plasticity of U. gibba, U. cornuta, and U. subulata between the dry and wet seasons ................................................................ 26

1.4c Inflorescence morphology of U. gibba, U. cornuta, and

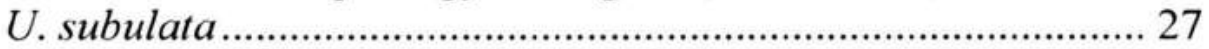

1.4d Relevance of Utricularia growth to future studies .................... 30

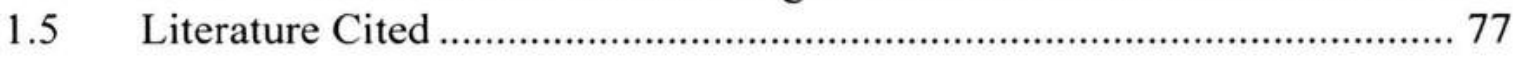

II A key for the Utricularia species of southern Florida using vegetative and floral

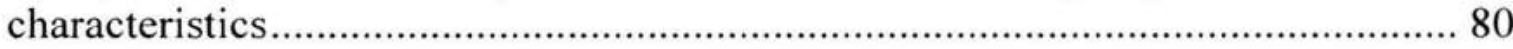

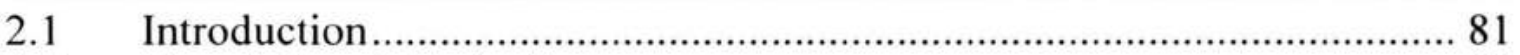

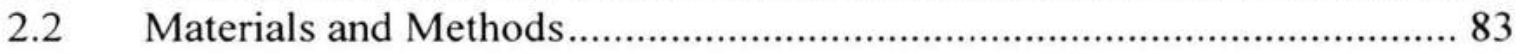

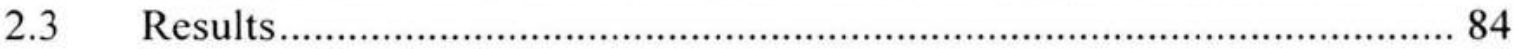

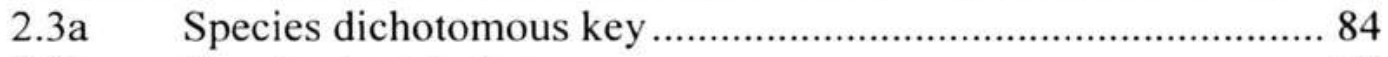

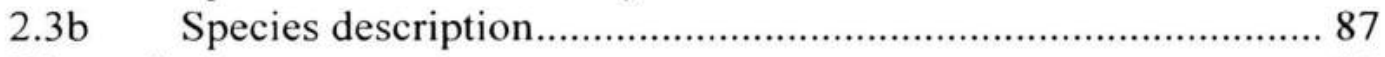

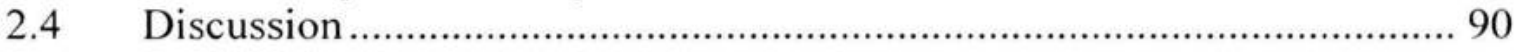

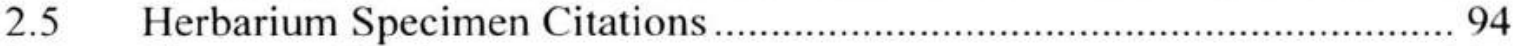

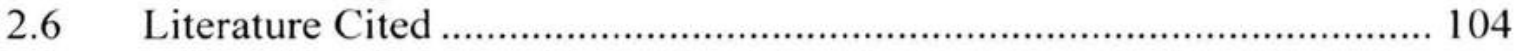




\section{LIST OF TABLES}

TABLE

PAGE

1.1 Summary of collection dates and locations ........................................................... 33

1.2. Description of terminology for the general organ types of $U$. gibba, U. cornuta, and U. subulata. 34

1.3. Plant organ location for U. gibba, U. cornuta, and U. subulata ......................... 35

1.4. Plant organ characteristics for U. gibba, U. cornuta, and U. subulata ................. 36

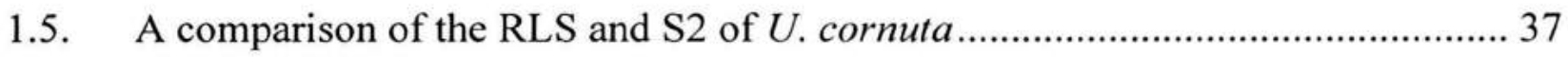

1.6. Summary of morphological measurements from field collected U. gibba plants. 38

1.7. Summary of morphological measurements from field collected $U$. cornuta plants

1.8. Summary of morphological measurements from field collected U. subulata plants 40

2.1. Field locations of Utricularia species in South Florida 96 


\section{LIST OF FIGURES}

FIGURE

PAGE

1.1. Phylogeny of selected members of Lentibulariaceae.......................................... 41

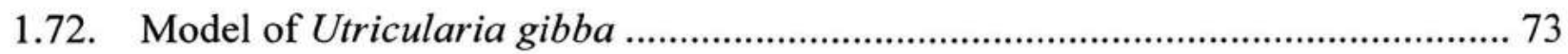

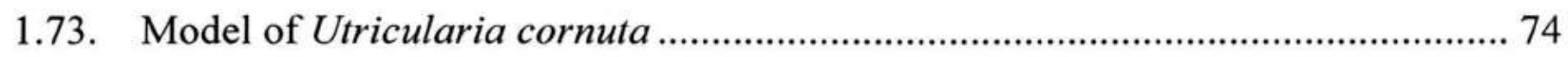

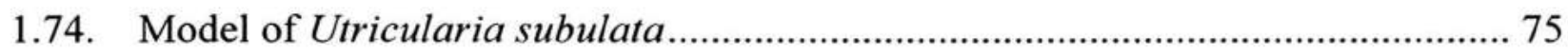

1.75. Hypothetical growth models for Utricularia cornuta .......................................... 76

2.1. Map of the counties where U. cornuta and $U$. juncea have been collected in

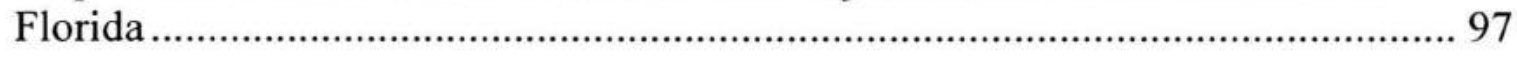




\section{LIST OF PLATES}

PLATE

PAGE

1.1. Figures 1.2-1.5. Habitat of Utricularia gibba from southern Florida .42

1.2. Figures 1.6-1.8. Habitat of Utricularia cornuta from southern Florida.......44

1.3. Figures 1.9-1.12. Habitat of Utricularia subulata from southern Florida .....46

1.4. Figures 1.13-1.18. Morphology of Utricularia gibba from southern Florida..48

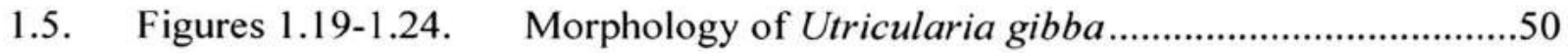

1.6. Figures 1.25-1.30. Paraplast sections of Utricularia gibba stained with hemotoxylin-safranin

1.7. Figures 1.31-1.36. Morphology of Utricularia cornuta from southern Florida

1.8. Figures 1.37-1.41. Morphology of Utricularia cornuta from southern Florida .56

1.9. Figures 1.42-1.49. Paraplast sections of Utricularia cornuta stained with hemotoxylin-safranin-fast-green... .58

1.10. Figure 1.50a-o. Utricularia cornuta paraffin sections through an apex of a primary stolon stained with hemotoxylin-safranin-fast-

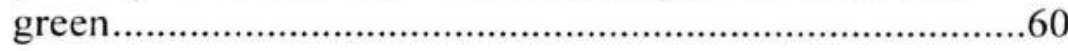

1.11. Figures 1.51-1.57. Utricularia subulata morphology ..................................62

1.12. Figures 1.58-1.61. Utricularia subulata paraplast sections stained with hemotoxylin-safranin-fast-green

1.13. Figures 1.62-1.63a-m. A sequence of paraplast sections through a stolon of Utricularia subulata stained with hemotoxylin-safraninfast-green.

1.14. Figure 1.63n-s. A sequence of paraplast sections through a stolon of Utricularia subulata stained with hemotoxylin-safraninfast-green.

1.15. Figures 1.64-1.67. Morphology of $U$. subulata and $U$. cornuta

1.16. Figures 1.68-1.69. SEM pictures of U. gibba 
2.1. Figures 2.2-2.10. Utricularia species of South Florida...............................98

2.2. Figures 2.11-2.18. Utricularia species of South Florida................................100

2.3. Figures 2.19-2.26. Utricularia species of South Florida...............................102 


\section{LIST OF ACRONYMS}

\section{ACRONYM}

Ia inflorescence appendages

Inf inflorescence

LLS leaf-like structure

S1 primary stolon

S2 secondary stolon

S3 tertiary stolon

Sm modified stolon

RLS rhizoid-like structure

SEM scanning electron microscope

T trap 


\section{Chapter 1}

Morphology and Anatomy of Utricularia gibba, U. cornuta, and U. subulata 


\section{INTRODUCTION}

Utricularia characteristics: The carnivorous plant family Lentibulariaceae includes a disproportionate (42\%) number of the earth's carnivorous plant species in three genera, Pinguicula, Genlesia, and Utricularia (Albert et al. 1992, Jobson et al. 2003, Müller et al. 2004, Müller et al. 2006). Utricularia, the largest and most evolutionarily derived genus of the family contains over 200 species (Taylor 1989) with unusual vegetative morphology and complex suction traps. Their carnivorous ability is a result of small, globose traps that function by actively expelling water, creating an internal lumen with negative pressure. The negative pressure allows the plant to ingest prey when external hairs are triggered by small aquatic organisms (Lloyd 1929, Lloyd 1942, Taylor 1989). Within the Lentibulariaceae, this trapping mechanism is unique to Utricularia species.

Besides exhibiting the unusual characteristic of carnivory, species of the genus Utricularia are unique because they have lost the typical angiosperm structure of roots, stems, and leaves, are highly plastic in their growth patterns, and display a range of vegetative morphological characters with uncertain homology. Unfortunately, this highly modified morphology prevents the plant organs of Utricularia species from being easily identified into particular organ categories by the rules of the classical model for angiosperm morphology. According to this model, most angiosperms have clearly defined stems, roots, and leaves that have a predicable relationship to each other and unique identifying characteristics including organ position, intermediate or transitional structures between unusual structures and ones that are more easily classified, and other special criteria. Utricularia species, on the other hand, lack identifiable roots at any 
ontogenetic stage, and the identity of the other two organs is not always obvious (Rutishauser and Sattler 1989, Rutishauser and Isler 2001). Hypotheses as to the identity of Utricularia species' unique organs have ranged from a more traditional approach that labels part of the plant as leaf-like and part as shoot-like (Goebel 1891, as described in Arber 1920), to labeling the plant as either wholly leaf-like (Kumazawa 1967), or wholly stem-like as a stem system (Godfrey and Wooten 1981). Even more radically, some authors have suggested that Utricularia species' plant body may be wholly root-like (Arber 1920). Rutishauser and Sattler (1989) have combined these theories and argue that in certain cases each plant structure can be interpreted as either stem or leaf, and therefore these authors have determined that individual plants are composed of stem-like leaves and leaf-like stems. Similar to the other vegetative structures, the homology of the traps is also uncertain. It is possible that the traps may be homologous to leaves since they develop in the same manner as epiascidiate leaves (Juniper et al. 1989). However, the traps, like the rest of the vegetative organs, are variable in their position, size, and location among the species. Thus, while the identity of Uticularia's organs has been studied in depth, a consensus does not exist on the categorical classification and homology of the vegetative organs.

The habit and vegetative morphology of different Utricularia species have been of interest since the late nineteenth century (Goebel 1891, Lloyd 1942, Taylor 1989, Rutishauser and Sattler 1989, Sattler and Rutishauser 1989, Rutishauser and Isler 2001). The habit of Utricularia is loosely divided into free-floating or affixed aquatics $(\sim 27 \%)$, terrestrials in moist soils ( $\sim 67 \%)$, and epiphytes, rheophytes, and lithophytes $(\sim 13 \%)$ (Taylor 1989). The aquatic species may become large; for example, U. purpurea may 
reach a length of one-half meter (Richards 2001) and individual $U$. foliosa plants may exceed two meters in length (Sattler and Rutishauser 1990). In contrast, most terrestrial species are small, with a maximum length of only a few centimeters (Lloyd 1942). This variation in size and habit is accommodated by the complex morphology of the genus. While most angiosperms are composed of a main axis with roots and leaves, Utricularia species are primarily composed of long, highly branched, horizontal stems, referred to as stolons (Taylor 1989). Stolons can be white and non-photosynthetic, as in terrestrials, or green and photosynthetic, as in most aquatic species. Other leaf-like photosynthetic structures, normally referred to simply as leaves, arise from the primary stolon. Lloyd 1942) suggests that branching tends to occur in the proximity of the "leaves" but not in he leaf axil, and therefore the branches do not represent branching via axillary buds. Ixillary buds or extra-axillary buds, however, can be seen in some species (Rutishauser nd Sattler 1989). Thus, branching from the stolon occurs in various positions, often, but ot necessarily, associated with axillary buds. The branches arising from the main axis zventually form both the dense, floating mats commonly seen in aquatic species and the complex matrix of plant segments that exist below the substrate in terrestrial species. Despite these non-conformist organ characteristics, each Utricularia species has vegetative structures with discernable and consistent qualities, allowing an architectural outline to be created for each individual species.

All species of the genus Utricularia lack true roots, even in embryonic stages, however, additional structures are often found on Utricularia plants, primary rhizoids and air shoots. The rhizoids, a misleading term, may help anchor the plant to the substrate or perform as a root substitute (Lloyd 1942, Taylor 1989). By technical definition, rhizoids 
in angiosperms represent a "root-like structure lacking conductive tissues" (Harris and Harris 2001). However, in Utricularia this term has been used to describe uncertain structures arising from the stolon, leaves, or inflorescence base. Taylor (1989) labels such structures rhizoids but acknowledges that they may not be homologous among Utricularia species. Aquatic Utricularia species usually do not require or possess rhizoids for anchorage, since they float on or close to the surface of the water; nonetheless, some aquatic species possess unattached rhizoids (Taylor 1989). Some of these rhizoids have specialized glands, possibly to help with additional nutrient acquisition. Utricularia species may also possess air shoots. These are organs of unknown function that arise from the stolon and have bract-like accessories on their distal end (Taylor 1989).

Although the vegetative morphology of Utricularia diverges from normal angiosperm morphology, the reproductive organs are standard angiosperm reproductive structures. When Utricularia species flower, the plants produce an axillary scape with distinct nodes, bracts or bracteoles, and axillary buds (Taylor 1989). Flowers can be solitary, clustered, or dispersed along the peduncle (Taylor 1989). The flowers are subtended by bracts and if the terminal flower is removed, the peduncle can branch from the nodal position to produce additional flowers (Kondo 1972). Each of the flowers consist of a two-lobed calyx and a two-lipped corolla. The lower lip of the corolla is often three lobed and elongates to form a spur, while the upper lip is entire. Two stamens are present and are positioned below a large, lobed stigma and short style resting on a single ovary (Godfrey and Wooten 1981, Taylor 1989). 
While we understand Utricularia does not follow the usual pattern of angiosperm morphology, good descriptions of the positional relationships and growth characteristics for most species occurring in this genus are lacking, particularly those based on fieldcollected plants. The aim of this study was to analyze the morphological and anatomical characteristics of Everglades Utricularia species through the quantification of phenotypic characters of field collected plants, paraplast sections, and scanning electron microscopy. This was carried out in order to gain a better understanding of their basic biology and growth patterns. The Everglades of South Florida is native to eleven Utricularia species (IRC 2007). Three of these species, U. purpurea, U. foliosa, and U. gibba, are among the 15 most common plant species in the Everglades (Stober et al. 1999 and 2005 REMAP surveys, J. H. Richards, FIU, personal communication). Utricularia species' abundance suggests they play an important role in this ecosystem. There have been studies on some of the free-floating aquatic species in this region (Richards 2001) but studies on the benthic and terrestrial species are lacking. Additional work on these species in the Everglades will lead to a better understanding of Utricularia species' growth, contributing to our knowledge of local Everglades taxa and to their role in this community. Utricularia gibba, U. cornuta, and U. subulata, were chosen for this study as representatives of native species of Utricularia in southern Florida. These species were identified as the focus of this study as all are common, occupy similar habitats, and are phylogenetically distributed within the genus (Jobson et al. 2003, Fig. 1.1).

Terminology: Due to the lack of understanding of structure homology for the plant organs in Utricularia, I have used neutral terminology to describe structures (Table 1.2). The largest horizontally growing stem on a plant is referred to as the primary stolon 
(S1). Branches from the primary stolon are referred to as secondary stolons (S2), branches from the secondary stolons are referred to as tertiary stolons (S3), and so forth. Branches arising from the base of the inflorescence are referred to as modified stolons (Sm). Two classes of lateral structures arise from the stolons; these include photosynthetic leaf-like structures (LLS) which are terete to flat, usually determinate or of limited growth, and photosynthetic, and rhizoid-like structures (RLS), thin, rounded, achlorophyllous, thread-like organs. The small organism trapping bladders with elaborate doors and glandular hairs found on the plant are called traps (T). Inflorescence (Inf) refers to the upright flowering stem and inflorescence appendage (Ia) refers to lateral organs that arise from the modified stolons at the base of the inflorescence. Similar terminology is necessary to describe and compare patterns between the species and is used here descriptively. However, the given terminology does not imply homology of the organs between the three species.

\section{MATERIALS AND METHODS}

Species description: Utricularia gibba is a small floating or benthic aquatic species (Figs. 1.2-1.5). Taylor (1989) and Jobson et al. (2003) placed this species in section Utricularia (Fig. 1.1), a large section of suspended or affixed aquatics, characterized morphologically by long stolons, two and four arm glands in the traps, circinnate vernation, and traps located only on their "leaves" (Taylor 1989). This species is abundant throughout the tropics, and can also be found in Europe, temperate North and South America, Asia, and Australia (Taylor 1989). Utricularia gibba historically was identified as U. biflora, U. pumila, U. fibrosa, and U. gibba proper; Taylor (1989) considered these to represent the same species and reduced them to the single species, $U$. 
gibba, but acknowledged significant morphological variation within the species. This variation has been confirmed in the floral characteristics, such as the size of the corolla and nectar spur; small, large and intermediate floral sizes are found in the species, however, it has not yet been documented in the vegetative structures (Taylor 1989). Taylor's description generally agrees with Lloyd (1942), who describes $U$. gibba as an aquatic with thread-like stolons bearing two-branch segments and traps with the stolon branching close to, but not in the leaf axils.

The second species chosen for this study, $U$. cornuta (Figs. 1.6-1.8), is placed in section Stomoisia (Fig. 1.1), a section characterized by small-to medium-sized terrestrials or subaquatics that grow embedded in moist soils (Taylor 1989). The two species in this section, $U$. cornuta and $U$. juncea, have plants with numerous rhizoids, linear leaves, and internal glands with one or two arms in the traps (Taylor 1989). Utricularia cornuta is not as widely distributed as U. gibba, being abundant in North American but with Cuba as the southern limit (Taylor 1989). Utricularia cornuta is morphologically very similar to $U$. juncea, and intermediate forms between the two species are common (Taylor 1989, Kondo 1972). Traps of $U$. cornuta are noteworthy in that they lack external appendages and instead possess a long entrance lined with glands (Fig. 1.33) (Lloyd 1942). The plant body of $U$. cornuta consists mainly of horizontal stolons with linear leaves and numerous rhizoids (Godfrey and Wooten 1981, Taylor 1989).

The third species studied, U. subulata, is a small, annual terrestrial in the section Setiscapella (Fig. 1.1). Section Setiscapella is characterized by plants possessing only a few rhizoids, linear leaves, and internal trap glands with two and four branches (Taylor 1989). The distribution of $U$. subulata is almost pan-tropical, and it is found throughout 
most of the United States, although it is threatened in several states (USDA, NRCS 2007). Utricularia subulata has a similar habit to $U$. cornuta, as both plants grow below the soil surface in moist, open areas with only linear green leaves growing above the surface (Figs. 1.9-1.12) (Godfrey and Wooten 1981). Morphologically, the principle plant body of $U$. subulata is composed of horizontal segments from which linear green leaves and rhizoids arise (Godfrey and Wooten 1981, Taylor 1989). Taylor (1989) suggests that U. subulata may be the same species as $U$. rendlei, although the matter is not resolved, as Lloyd considered them morphologically distinct enough to be considered two species (Lloyd 1935).

Determination of species morphology: In order to examine the differences in shoot architecture, morphological analysis was carried out for thirty plants of each species. Ten plants of each species were collected from three different field sites during the dry season (January to April 2006) and wet season (July to August 2006) (Table 1.1). Ten additional plants of $U$. gibba were collected from artificial fish pools on the roof of the HLSI building at FIU. The latter was not a field site, but provided an example of the morphology of a plant receiving high levels of nutrients. Plant segment length, distance between internodes, LLS length, and number and position of branches or axillary buds present were determined for all species. This data was used to model the architecture of each species.

Determination of species anatomy: Light microscopy of paraplast-embedded and stained tissue and scanning electron microscopy were used to study the morphology and development of the three species. Plants for these analyses were sampled from the FIU Singeltary property in Florida City, Florida and the Wildlife and Environmental 
Conservation Area in Homestead, Florida (Table 1.1). Plants were dissected into segments that included growing tips, nodal regions, lateral organs, primary stolons, and inflorescences. Dissected parts were then fixed in Craf III for 24 hours, washed in distilled water, and dehydrated with tertiary butyl alcohol (TBA) (Berlyn and Miksche 1976). The segments dehydrated in TBA were embedded in paraplast and sectioned with a microtome at $5 \mu \mathrm{m}$, stained with hemotoxylin-safranin (U. gibba), or hemotoxylinsafranin-fast green ( $U$. cornuta and $U$. subulata), to observe general anatomical characteristics. Fresh material was stained with Sudan IV to identify suberin, with toluidine blue to observe general characteristics, phloroglucinol and $\mathrm{HCl}$ to identify lignin, and with neutral red to determine vascular connections. Additional plant segments were first dehydrated in ethyl alcohol $(10 \%, 20 \%, 30 \%, 50 \%, 70 \%, 95 \%, 100 \%)$, then critical point-dried with hexamethyldisilazane (HMDS) (100\% ethanol, $100 \%$ acetone, $100 \%$ HMDS series) using the protocol of E. Capitano, Y. Bootwala, and J. Prince (U. of Miami), sputter-coated (Au/Pd), and examined using a JOEL JSM 5900LV (Peabody, MA, USA) scanning electron microscope at the FIU Center for Analytical Electron Microscopy.

\section{RESULTS}

\section{General morphological and anatomical characteristics of $U$. gibba}

Structural characteristics and positional relationships: Utricularia gibba plants grow individually or form mats on the water surface, grow as suspended fragments below the water surface, or form mats in moist soils. The vegetative organs of $U$. gibba include primary stolons (S1), secondary stolons (S2), modified stolons (Sm), inflorescences (I), inflorescence appendages (Ia), dichotomously branched filiform leaf-like structures 
(LLS), and traps (T) (Tables 1.2-1.4). Stolons of $U$. gibba grow horizontally and have circinnate vernation and a terminal apical meristem (Figs. 1.13-1.14). The primary stolon (S1) is the oldest or largest horizontal stolon found on each plant segment (Figs. 1.131.14). The secondary stolons ( $\mathrm{S} 2)$ and tertiary stolons ( $\mathrm{S} 3$ ) are stolons that arise in the axils of the leaf-like structures (LLS) (Figs. 1.13, 1.22, 1.69). S2s are usually smaller in diameter than the primary stolon but can also be or appear equal in diameter (Fig. 1.22). S2s have apical meristems with circinnate vernation and are architecturally identical to the primary stolon. LLS are lateral organs that share some characteristics with true leaves; namely, they appear to be determinate and often have axillary buds (Figs. 1.18, $1.25,1.68,1.71)$. A second type of stolon is seen in $U$. gibba, defined here as a modified stolon (Sm). Sms occur only at the base of the inflorescence, arising directly from the inflorescence axis (Fig. 1.70) and are similar to the S1 in that they have circinnate vernation and apical meristems. However the modified stolons do not reiterate the primary stolon structure. Instead of bearing LLS, they have unique lateral structures which I call inflorescence appendages (Ia) (Figs. 1.15, 1.17, 1.19-1.21, 1.23-1.24) that are born on the proximal end of the Sm. The Sm are achlorphyllous and can be densely covered in traps at the distal ends (Fig. 1.16), features not typically seen on the S1 or S2. The Ia are claw-like, multifid structures occurring in the same position on the modified stolons that the LLS occupy on the S1 or S2 (Fig. 1.17). No roots, root-like structures, or rhizoids are found on $U$. gibba.

Organ growth pattern: Each individual plant, identified as a plant segment (Figs. 1.13-1.14), showed a monopodial growth pattern with the terminal apex growing continuously and the older parts of the plant segment breaking off or dying. LLS are 
initiated at the apical meristem with an alternating phylotaxis (Fig. 1.30) and are arranged spirally along the S1. The LLS, which are the trap-bearing organs, were observed to branch dichotomously up to four times in my plant collections. Axillary buds were found in the axils of the LLS in $35 \%$ of the nodes of the total plant segments measured (Table 1.6). Multiple S2s can arise in a LLS axil from supernumerary or accessory axillary buds (Figs. 1.18, 1.71). The buds can grow out into S2, reiterating the S1 architecture (Fig. $1.13,1.69)$. Higher order branching occurs from the secondary stolons, presumably creating the thick mats found in the field or breaking off to form clones of the parent plant.

Plasticity of the vegetative organs: Plant segment lengths from field collected plants during both the wet and dry season ranged from $30 \mathrm{~mm}$ to $407.2 \mathrm{~mm}$ with a mean value of $117.1 \pm 76.4 \mathrm{~mm}$. LLS lengths from field collected plants ranged from $0.5 \mathrm{~mm}$ to $12 \mathrm{~mm}$ with a mean value of $4.6 \pm 2.9 \mathrm{~mm}$. All morphological measurements, including plant segment length, internode length, LLS length, and the percentage of LLS with axillary buds from plants collected during the dry season were significantly different from plants collected during the wet season (Table 1.6).

Inflorescence morphology: The inflorescence grows orthotropically, projecting above the substrate or water. It is initiated at a node in the axil of a LLS from either the primary axillary bud or an accessory axillary bud. One or two inflorescences can be produced in the same LLS axil (Figs. 1.19-1.20, 1.24). Inflorescence height ranged from 4.5-9.4 cm with a mean value of $5.9 \pm 2.1 \mathrm{~cm}$ (Table 1.6). Sm form at the base of the inflorescence, directly from the inflorescence axis (Figs. 1.19-1.20, 1.24, 1.70). Traps and/or inflorescence appendages (Ia) arise from the modified stolons (Sm) and are 
arranged alternately (Figs. 1.16, 1.17, and 1.20). The inflorescence appendages ranged from 0.5-1.1 $\mathrm{mm}$ long and 0.6-1.2 $\mathrm{mm}$ wide (Table 1.6).

Anatomical characteristics: Anatomically, U. gibba is very simple. The primary stolon (S1) is composed of epidermal cells containing chloroplasts surrounding a region of aerenchyma and a central vascular bundle (Fig. 1.28). Sections made through the two types of lateral organs, leaf-like structures and inflorescence appendages, showed some similar characteristics. The leaves do not have a bifacial internal anatomy, but resemble the primary stolon in that they contain epidermal cells with chloroplasts surrounding aerenchyma and a central vascular bundle (Fig. 1.29). The inflorescence appendages differ anatomically from both the leaves and the stolons in that they do not contain aerenchyma, are solid tissue throughout with a central vascular bundle, and have an epidermal layer with densely aggregated glandular projections (Figs.1.27). Sections stained in hematoxalyin and safranin show a band of epidermal cells that stain darker than the surrounding cells, indicating the presence of suberin, cutin, or lignin; (Figs. 1.26). The glandular projections on the Ia are composed of three different types of cells: a cell continuous with the epidermis, a flattened central cell, and a hemispherical terminal cell (Figs. 1.26-1.27). The central cell has thickened cell walls (Figs. 1.26). These glandular projections absorb stain when exposed to toluidine blue (Fig. 1.21) and neutral red (Fig. 1.23).

\section{General morphological and anatomical characteristics of $U$. cornuta}

Structural characteristics and positional relationships: Utricularia cornuta is classified by Taylor (1989) as a terrestrial and grows embedded in wet soils or periphyton mats in southern Florida (Figs. 1.6-1.8). The vegetative organs of U. cornuta include 
primary stolons (S1), secondary stolons (S2), modified stolons (Sm), rhizoid-like structures (RLS), leaf-like structures (LLS), traps (T), and inflorescence appendages (Ia) (Tables 1.2-1.4). The primary stolon ( $\mathrm{S} 1)$ of $U$. cornuta is a horizontally growing stem with a terminal apex that initiates lateral organs in an alternating, almost distichous pattern (Figs. 1.31, 1.36). The lateral organs arising off the primary stolon (S1) include secondary stolons (S2), leaf-like structures (LLS), and rhizoid-like structures (RLS). A node is defined by the position of the LLS because the LLS position is more consistent than the position of the RLS or the S2. The LLS are linear, strap-shaped, and highly variable in their length. These organs are phototropic and therefore grow orthotropically in natural settings. The LLS often have thin, hair-like structures at their base and traps (T) along their entire lengths (Figs. 1.31, 1.36). The secondary stolons (S2) occur approximately opposite the LLS (Fig. 1.36) and their growth appears to reiterate the growth of the primary stolon (S1).

Utricularia cornuta has previously been described as bearing numerous rhizoids (Taylor 1989) and it does have several organs that could be referred to as rhizoid-like structures, each with different characteristics, depending upon the portion of the plant where the structure occurs (Table 1.4). Among these unknown structures are the thin, linear, and often thread-like organs found on all structures of the plant; they can be found growing off the primary stolon (Fig. 1.35) or growing at the base of the leaf-like structures (Fig. 1.36). Although the RLSs may appear at a node, in a position also characteristic of the secondary stolons, the RLSs are distinguishable by their tapered tip, multitude of traps, and hair-like outgrowths along their length. Additionally, the RLSs 
only initiate traps as lateral structures, while S2 can initiate LLS, RLS, or additional S2 (Fig. 1.35) (Table 1.5).

Modified stolons (Sm), termed so because they have different lateral organs than $\mathrm{S} 1$ or S2, arise from the base of the inflorescence (Figs. 1.37, 1.40). Instead of LLS, RLS, or S2, the lateral organs of the Sm are inflorescence appendages (Ia), which are small, linear, glandular appendages found only on the modified stolons at the base of the inflorescence (Figs. 1.38).

Organ growth pattern: Each individual plant, identified as a plant segment, grows monopodially from the tip and dies at the opposite end. Morphologically, three structures arise off the primary stolon (S1): leaf-like structures (LLS), secondary stolons (S2), and rhizoid-like structures (RLS) (Tables 1.2-1.4). The LLS and the S2 always appear at nodes, while the RLS may appear at nodes, along an internode, or at the base of the LLSs (Table 1.3). All structures are initiated from the apical meristem in an alternate pattern but may come to appear opposite (Fig. 1.39). Sequential sections through the apex show that the organs are not inserted in the same phylotaxis, instead they are inserted at different positions along the $\mathrm{S} 1$, indicated by the spaces between the lateral organs in the sequential sections. (Fig. 1.50). A LLS is present at every node with either a S2 or a RLS appearing opposite the LLS. Additional secondary stolons (S2) can form at the nodes, either in the axil of a LLS or S2 or centrally located between the two structures at the node (Fig. 1.67).

Plasticity of the vegetative organs: Plant segment lengths from field collected plants ranged from $11 \mathrm{~mm}$ to $107 \mathrm{~mm}$ in length with a mean value of $48.8 \pm 24.1 \mathrm{~mm}$. The LLS ranged from $5 \mathrm{~mm}$ to $50 \mathrm{~mm}$ in length with an average of $26.1 \pm 9.3 \mathrm{~mm}$ in 
length. The RLS of $U$. cornuta are highly variable in length, and because of their tapering tips, are often broken at the end. Therefore, lengths were not measured for this structure. A comparison of the seasonal variation in segment length and the percentage of nodes with axillary buds in $U$. cornuta did not show a significant difference between the dry and wet seasons. The variation in internode length and LLS length between the wet and dry season was significantly different between the two seasons (Table 1.7).

Inflorescence morphology: The inflorescence stalk of $U$. cornuta projects above the substrate and is red due to anthocyanins in the epidermis (Figs. 1.37, 1.40). Each inflorescence is initiated at a node, in the axil of a LLS (Fig. 1.34). Inflorescence height ranged from 18.5-38.2 $\mathrm{cm}$ with a mean value of $28 \mathrm{~cm} \pm 6.9 \mathrm{~cm}$ (Table 1.7). The base of the inflorescence has numerous Sm that bear lateral Ia. Each Ia has vascular tissue (Fig. 1.45 ) and is covered in glandular projections (Figs. 1.38, 1.48). These glandular projections have a structure similar to the glandular projections found on $U$. gibba; that is, they are composed of three cells, the basal cell continuous with the epidermis, a central cell, and a terminal globose cell (Figs. 1.49). Like $U$. gibba, the central cell stains with safranin, indicating suberin, cutin, or lignin (Figs. 1.46, 1.49) and these glandular projections readily absorb toluidine blue dye (Figs. 1.38, 1.47). Although these glandular projections are most densely aggregated on the inflorescence appendages, they are found sparsely distributed on all plant organs, including the leaf-like structures (Fig. 1.46).

Anatomical characteristics: Meristematic areas found regularly along the surface of the LLS and along the surface of the RLS initiate traps (Fig. 1.44). These meristematic areas show an organizational pattern of one epidermal or tunica layer above a corpus, or body of cells, which divide to create the bulk of the trap. Apical meristems show a similar 
organizational pattern of one tunica layer over a corpus of dividing cells except the epidermal cells appear to be vacuolated (Fig. 1.43).

Transverse sections of two types of lateral organs, LLS and Ia, show similar characteristics. The LLS and Ia are both symmetrical, terete, and composed of tissue throughout (Figs. 1.42, 1.48). Glandular projections are seen on both structures; however, they are denser on the inflorescence appendages than the leaf-like structures.

Utricularia cornuta shows additional suberization in addition to the thickening of the central cell of the glandular projections. When stained with Sudan IV, bands of suberized tissue are exposed on the LLS, RLS, and S2 where the lateral organs attach to the primary stolon (Fig. 1.32). This suberized band is also seen in paraplast sections (Fig. $1.50 \mathrm{~d}, \mathrm{f}-\mathrm{h}, \mathrm{k}-\mathrm{l})$. Phloroglucinol staining of this region indicated a lignified layer.

\section{General morphological and anatomical characteristics of $U$. subulata}

Structural characteristics and positional relationship: $U$. subulata is a small, annual terrestrial that grows embedded in wet soils or periphyton mats in South Florida, a habitat similar to that of $U$. cornuta (Figs. 1.9-1.12). The vegetative organs of $U$. subulata include primary stolons (S1), secondary stolons (S2), modified stolons (Sm), leaf-like structures (LLS), rhizoid-like structures (RLS), inflorescence appendages (Ia) and traps (T) (Tables 1.2-1.4). The primary stolon (S1) of $U$. subulata, similar to $U$. cornuta, is a horizontally growing stolon with a terminal apical meristem that bears lateral organs (Fig. 1.51). Although it appears that all organs are initiated at a node at the same time in a whorled pattern, sequential sections through the apex and SEM pictures show that the lateral organs are inserted at different locations along the stolon (Figs. 1.63, 1.66). The 
lateral organs arising from the primary stolon (S1) of U. subulata are LLS, RLS, S2, traps, and inflorescences (Tables 1.2-1.4).

Each type of lateral organ, LLS or RLS, arising from the primary stolon has unique characteristics. The LLSs are terete, narrow, and linear to narrowly spatulate, often with a curved tip (Fig. 1.51). All LLSs contain chloroplasts at the distal end and central portion and show positive phototropism. Additionally, the LLS may have anthocyanins in the terminal end, creating a distinctly reddish tip. The RLSs are linear, thin organs lacking chloroplasts that arise at the nodes. At least one RLS is always present at every node, and plants collected in this study almost always had two RLSs at each node (Figs. 1.51-1.52). Traps may be present as lateral appendages on all structures of $U$. subulata. Secondary stolons (S2) are stolons arising from the primary axis in the axils of the LLS that reiterate the primary stolon morphology (Figs. 1.51-1.52).

Organ growth pattern: Each individual plant consists of a segment that grows monopodially from the plant tip and dies or breaks at the opposite end. LLSs arise off the stolon and identify the nodal position. Usually two or sometimes only one RLSs are born on the stolon at the node, appearing opposite the LLSs. Although it appears that the two RLS are initiated at the same time and that they are initiated at the same time as the LLS, SEM pictures and sequential sections through the apex show that they are inserted at different positions along the S1 (Figs. 1.63a-s, 1.66). From the sequence, the two RLS are inserted first (Fig. 1.63a-k, RLS 1; and 1.631-p, RLS 2) and the LLS is inserted after the two RLSs (Fig. 1.63q-s). Sequential sections through a mature nodal region the sections show the same results: first two RLSs are inserted and then the LLS is inserted along the S1 (Fig. 1.62a-c). Structures resembling axillary buds are found in the axil of the LLS 
(Figs. 1.56, 1.65) and give rise to the $\mathrm{S} 2$ (Fig. 1.52). Occasionally, U. subulata appear to form small rosettes of leaves at each node. These rosettes are formed when a $\mathrm{S} 2$ forms in the axil of the LLS with condensed internodes. The LLSs and RLSs are positioned along this shortened S2, creating what appears to be a rosette of LLSs (1.64). S2 forming in the axil of the LLS can also elongate, again repeating the morphology of the primary stolon (Fig. 1.51).

Plasticity of the vegetative organs: $U$. subulata is classified as an annual and plants could only be found for a short time during the dry season from December to early April. Utricularia subulata plant segments collected in the field ranged from $4-42 \mathrm{~mm}$ with a mean sample length of $16.4 \pm 9.1 \mathrm{~mm}$ (Table 1.8). Leaf-like structures had lengths ranging from $3 \mathrm{~mm}$ to $33 \mathrm{~mm}$ and a mean value of $13.6 \pm 8.6 \mathrm{~mm}$. Like $U$. cornuta, RLS are highly variable in length and exact lengths were not obtained (Table 1.8).

Inflorescence morphology: Wiry inflorescences form in the axil of a LLS and grow orthotropically, rising out of the substrate, often comprising the only above-ground and visible part of the plant (Figs. 1.9, 1.12). Inflorescence height ranged from $26-75 \mathrm{~mm}$ with a mean value of $4.3 \pm 1.3 \mathrm{~cm}$ (Table 1.8). Modified stolons form at the base of the inflorescence (Fig. 1.57), directly from the inflorescence tissue, and bear inflorescence appendages; lateral appendages on the Sm that are densely covered in glandular projections (Figs. 1.53-1.54). The inflorescence appendages of $U$. subulata are similar to the inflorescence appendages of $U$. gibba and $U$. cornuta in that they are also densely covered with glandular projections. As in the other two species, these projections are found on all plant organs, but are aggregated densely on the inflorescence appendage tips and are displayed in a pattern similar to $U$. cornuta (Fig. 1.53-1.54). These glandular 
projections are also composed of three cells: a cell continuous with the epidermis, a central cell, and a globose terminal cell (Figs. 1.55, 1.58). The central cell stains darkly with Sudan IV (Fig. 1.53) and safranin (Fig. 1.58), indicating the presence of suberin in this cell.

Anatomical characteristics: The LLS, RLS, and inflorescence projections of $U$. subulata show similar subizerization patterns to $U$. cornuta. The LLS and the RLS of $U$. subulata both have a band around the base that stained with safranin, most likely indicating suberization of the cell walls within this region (Fig. 1.62a-c). Suberin was confirmed in the inflorescence appendages when live tissue of $U$. subulata is stained with Sudan IV (Fig. 1.53). U. subulata shows additional cell thickenings that appear to be unique to $U$. subulata. These thickened cells were found under the epidermal layer of the inflorescence appendage (Fig. 1.59) and the RLS (Figs. 1.60-1.61). Another structure revealed by the plant sections were small granules under the lateral organs, apparently more densely aggregated on the side of the stolon located toward the lateral organ (Fig. $1.58)$.

\section{DISCUSSION}

\section{Architectural outline for $U$. gibba, U. cornuta, and $U$. subulata}

In addition to their carnivorous ability, Utricularia species are often recognized for their lack of conformity to plant morphological rules and our inability to label their plant organs definitively as roots, shoots, or leaves. Despite the ambiguous nature of the plant organs, a morphological pattern can be recognized for each species regardless of organ identification and homology. Three Utricularia species, U. gibba, U. cornuta, and 
U. subulata, all common in the Florida Everglades, were chosen for this study. Organ categories were defined for each species and their morphology was mapped.

Utricularia gibba is classified as an affixed aquatic (Taylor 1983) but the plant can also be found as a free floating aquatic, a suspended aquatic, or embedded in moist soils. The vegetative portion of $U$. gibba is composed of different types of stolons (S1, S2, and Sm), dichotomously branched leaf-like structures (LLS), and traps (T). The basic unit of $U . g i b b a$ is the primary stolon with one LLS branched dichotomously into two segments (Fig. 1.72, A, step 1). All other structures are modifications of this basic unit (Fig. 1.72, steps 2-6). Figure 1.72 shows the different identified variations generally seen for U. gibba in this study. Part A shows the basic unit, the primary stolon and a LLS that has divided once. Simple modifications of the LLS include an increase in the number of dichotomous branches on the LLS, however, the number of dichotomous branching events was limited to four in this study (Fig. 1.72, steps 2 and 3). Secondary stolons (S2) can form in the axil of a LLS (Fig. 1.72, step 4) and multiple secondary stolons (S2) can also be found in the LLS axil (Fig. 1.72, step 5). The location of the axillary bud in $U$. gibba is consistently in the LLS axil. SEM pictures of the axil of $U$. gibba show the presence of multiple axillary buds in the node (Fig. 1.71) Thus, in U. gibba, LLS are borne on the primary stolon and stolons are borne in the axil of a LLS. Inflorescences are also formed at the nodal position in the axil of a LLS (Fig. 1.72, step 6) and multiple inflorescences and S2s can also form in a single axil (Figs. 1.19-1.20, 1.24). Modified stolons (Sm) are formed around the base of the inflorescence and may provide support for the upright inflorescence (Fig. 1.72, step 6). Inflorescence appendages and traps form on 
the modified stolons (Sm) (Fig. 1.72, step 6). Like other members of section Utricularia, the traps of $U$. gibba are only formed on the LLS (Taylor 1989).

Like $U$. gibba, the vegetative portion of $U$. cornuta follows an architectural outline with various modifications at the nodal position. The basic unit of $U$. cornuta consists of a primary stolon (S1) with a leaf-like structure (LLS) and a rhizoid-like structure (RLS) located at the nodal position (Fig. 1.73, A and step 1). The nodal position is defined by the location of the LLS since its location is less variable than the RLS or S2. Secondary stolons (S2) can replace the position of the RLS across from the LLS at the nodal position (Fig. 1.73, step 2). The S2 will initiate lateral organs, primarily LLS and RLS, repeating the morphology of the S1. Thus, a LLS is always present at every node and, minimally, is either paired with a RLS or a S2. In addition to the basic LLS-RLS pair or LLS-S2 pair, secondary stolons can also be formed at two locations at the nodal position. The first is in the axil of the leaf-like structures and the second is from a position centrally located between the LLS and the RLS on the primary stolon (S1) (Fig. 1.73 , step 3). These structures arise from an axillary bud either in the axil of the LLS or S2 or centrally located between the lateral organs (Fig. 1.67). Another oddity sometimes seen when the apex of the leaf-like structure is damaged is that leaf-like structures may also bear additional LLS or RLS (Fig. 1.73, step 4). While the S2 seems to be limited to the nodal position, appearing either across from the LLS in the axil of one of the nodal organs or centrally between the two organs, the RLS are not limited to the nodal position and can be located along an internode (Fig. 1.73, step 5). Inflorescences are formed in the axil of a LLS or, like the S2, can be positioned centrally on the primary stolon (Fig. 1.73, step 6). Sm are found at the base of the inflorescence. The Sm at the base of the 
inflorescence also bears inflorescence appendages (Fig. 1.73, step 6), identified by their dense cover of glandular projections. Unlike the floating or suspended aquatic Utricularia species, all structures, including the primary stolon, can initiate traps on $U$. cornuta.

The vegetative portion of $U$. subulata has an architectural plan similar to $U$. cornuta. The basic unit of $U$. subulata, from one internode to the next, will consists of at least one leaf-like structure (LLS) and one or two rhizoid-like structures (RLS) (Fig. 1.74, A or step 1). S2s form in the LLS axils, repeating the structure of the S1 (Fig. 1.74, step 3). Often, the nodes of $U$. subulata appear to have small rosettes of LLS. This appearance is due to additional LLSs initiated along a S2 with condensed internodes that has formed in the axil of a LLS, producing a shortened S2 with numerous leaf-like structures (Fig. 1.74, step 2). The S2 are always initiated in the axil of a LLS and reiterate the structure of the primary stolon. As in $U$. cornuta and $U$. gibba, the inflorescence of $U$. subulata forms in a LLS axil. Numerous Sm are also found at the base of the inflorescence (Fig. 1.74, step 5). As in $U$. cornuta, inflorescence appendages form on the modified stolons at the inflorescence base and are distinguished by their dense cover of glandular projections. The traps of $U$. subulata are not limited to the LLS but are found on all the plant organs. When the traps are initiated on the LLS, they can appear to form in linear rows, a characteristic potentially unique to $U$. subulata.

Comparison of growth morphology and organ determination: Taxonomically, these three species are placed in different sections (Jobson and Albert 2002, Jobson et al. 2003, Müller and Borsch 2005, Taylor 1989). Taylor (1989) placed the species in different sections because of differences in trap and internal gland structure. Jobson and 
Albert (2002) and Jobson et al. (2003) agreed with Taylor (1989) and suggested that form and function may be highly correlated in Utricularia, demonstrating that molecular and morphological characteristics align to distinguish the different groups (Fig. 1.1). Müller and Borsch (2005) suggested a few changes to this phylogeny including three subgenera and the placement $U$. subulata and $U$. gibba together in subgenus Utricularia, despite their habitat and morphological differences and U. cornuta in Biovalva, a more basal subgenus.

Utricularia cornuta and $U$. subulata are both terrestrial species with morphological similarities, yet, no phylogenetic study placed $U$. subulata and $U$. cornuta in the same section, despite their architectural and habitat similarities. Morphological similarities between $U$. subulata and $U$. cornuta include non-photosynthetic horizontal stolons embedded in wet sand or soils, linear photosynthetic leaf-like structures, and nonphotosynthetic rhizoid-like structures initiated around a nodal position and appearing opposite to the LLS. Additionally, the growing tips of the two species are similar in that they are not circinnate, as in U. gibba and some other Utricularia species, and in that the tips of the primary stolon resemble the tips of the secondary stolons. Since the two species are not placed in the same section taxonomically, it is possible that the growth patterns of the two species have converged as a result of their similar habitats or that these growth patterns are commonly seen in the non-floating species.

Although $U$. cornuta and $U$. subulata appear simpler in their morphology than $U$. gibba and other Utricularia species, organ determination poses several problems with regard to these species. Primarily, the organs in $U$. cornuta and $U$. subulata are more flexible in their growth patterns and the distinction between organs is sometimes 
ambiguous. For example, instead of an S2 or RLS forming at the nodal position across from the LLS, rarely, a long, thickened stolon will form instead. This stolon appears to have the potential to become a S2, yet, no lateral organs are initiated. Another difficulty with organ determination in these two species is that the LLS can occasionally branch. In addition to challenges with organ determination, the factors that determine organ initiation at each node of $U$. cornuta are obscure. For example, the appearance of either a RLS or a S2 at each node in $U$. cornuta does not seem to follow a regular pattern and the decision to form either a RLS or a S2 across from a LLS at each node appears random. One hypothesis regarding their order of appearance is that the structures are first initiated as a RLS and then meristematic areas on the RLS become lateral organs, changing the RLS into a S2. However, several observations indicate that this is not the case. If this were true, one would expect to see a S2 at the older portion of the primary segment and a RLS at the growing end of the primary segment; in fact, both structures are seen throughout the plant segment in random order. This suggests that the appearance of the S2 or RLS is controlled by environmental variables. Additional observations support this conclusion. On an individual plant segment, LLS are seen arising facing the light, always with a RLS or S2 appearing opposite, but never with a LLS opposite another LLS. Several explanations for this observation are possible. One is that the stolon twisted as it grew through the soil so that the LLS always appears on the side of the stolon facing the light. This means that the plant has an alternate phyllotaxy of LLS initiation; as the LLS grows positively phototropically, the primary stolon is twisted, causing all the LLS to appear on one side of the plant (Fig. 1.75a). Another possible explanation is that the fate of the lateral organ is determined by environmental factors 
when it is initiated. For example, if the lateral organ is initiated on the part of the stolon towards the sun, this organ will develop into a LLS containing chloroplasts (Fig. 1.75b). Again, although this study mapped the morphology of these two species, further experimental studies should be carried out to determine what causes the morphological variation.

$U$. subulata also expresses some ambiguity of organ determination at the nodes. For example, it does not consistently have two RLS per node, instead having one or two RLS per node. Additionally, axillary buds found in the axil of the lateral organs can either become a condensed S2 (Fig. 1.64), giving the node a rosette-like appearance, or elongate (Fig. 1.51) to appear more like a typical secondary stolon. These organ determination decisions may be correlated to environmental conditions.

Plasticity of $U$. gibba, $U$. cornuta, and $U$. subulata between the dry and wet seasons Utricularia gibba showed increased plant segment lengths, internode lengths, LLS lengths, and percent of axillary buds per node in wet season compared to the dry season. This difference could be due to the disparity in the habitat between the two seasons. Given the higher water levels in the wet season, $U$. gibba was collected as a floating or attached aquatic, whereas with the dry season's lower water levels, U. gibba was collected as a benthic species growing in the periphyton mats or in muddy soils. Significant variation in $U$. cornuta is seen in differences in the internode lengths and the LLS lengths between the dry and wet season. This variation could also be related to the water level in the surrounding environment. Kondo (1972) noticed this when he grew $U$. cornuta under controlled conditions. Specifically, he saw that the leaves (LLS) were twice as long when the plants grew under water than when the plants grew in drier 
environments. Utricularia subulata is an annual and therefore any plasticity observed may be due to local environmental conditions and not seasonal variations.

\section{Inflorescence morphology of $U$. gibba, $U$. cornuta, and $U$. subulata}

Although the vegetative morphology of Utricularia has deviated from the typical angiosperm growth pattern, the reproductive structures of this genus have a traditional pattern with easily distinguishable organs. The inflorescences of all three species grow orthotropically, are racemes, and are formed in the axil of a LLS and the primary stolon. The inflorescence structure of the three species is more closely related to a traditional stem having bracts at defined nodal positions with axillary buds present in the bracts. Additional structures found on all three species, which I have referred to as modified stolons (Sm) (Table 1.2-1.4), are formed directly from inflorescence tissue. These modified stolons may help to hold the inflorescence erect or provide nutritional support to the plant. Despite differences in morphology, the stolons formed at the base of the inflorescence all have appendages, referred to as inflorescence appendages in this study, that are covered in glandular projections.

The glandular projections covering the inflorescence appendages are not unique to these appendages and have been mentioned in other studies of trap architecture. Fineran (1985) reviewed the structure and function of the different types of glands on the $U$. monanthos trap and identified one gland that appears similar in structure to the glandular projections of the three species in this study. The glands he identified were distributed on the external surface of the trap and among the epidermal cells of the other plant organs, similar in location to the glands in this study. Fineran (1985) performed light and scanning electron microscopy on the external and internal linings of these glands and 
observed thickened outer cell walls and wall ingrowths on the central cell. From these observations, he suggested that these globose cells would function in absorbing solutes and ions from the external environment during the early stages of the gland ontogeny. Fineran (1985) also suggests that the gland would then perform a different function at a later time; as the glands aged, structural remodeling would cause the cells to change roles and begin functioning to expel water. Nonetheless, the absorption of toluidine blue and neutral red by the glands observed on live tissue in this study suggests that they absorb solutes, possibly allowing them to function as a root substitute to absorb additional nutrients from the surrounding medium. The increased density of these glands on the inflorescence may increase the ability of the plants to absorb nutrients via the inflorescence appendages, supporting growth of the relatively large inflorescence on the proportionally small plants. Alternately, the plant may be receiving adequate nutrition from carnivory or from solutes in the surrounding medium and the glands on the inflorescence appendage could be used to pull water up the inflorescence, helping to keep the inflorescence upright.

The inflorescence appendages of $U$. gibba are not only unusual in that they are densely covered with these glandular projections, but also in that they are curved, clawlike, and multifid (Figs. 1.21, 1.23). Their position on the modified stolon is the same as the position of the LLS on the primary or secondary stolons, suggesting that they may be homologous to the LLS. Moreover, transitional structures combining the characteristics of a LLS and an inflorescence appendage have been observed (Fig. 1.15). The inflorescence appendages have often been referred to as rhizoids in previous studies and available literature, possibly for lack of a better name (Taylor 1989). Other terms 
encountered include lateral appendages or glove-shaped appendages (Salmon 2001). In typical angiosperm morphological descriptions the term rhizoid is usually given to a structure that lacks conductive tissue and has a root-like function. These structures, however, do have vascular tissue and their function is not known, indicating that "rhizoid" may not be the appropriate terminology to use for these structures. On the other hand, the glandular projections quickly and selectively absorb dyes, indicating that their function may be absorption of nutrients from the surrounding medium, a function that parallels one function of true roots. These glands also appear to have a layer of suberized tissue surrounding the central cells that shows clearly when the plant is stained with Sudan IV. This layer looks similar to the casparian strip around the endodermis of a typical root and therefore may function as a barrier to allow only select solutes into the plant. Thus, because of the confusion with the various meaning of the term "rhizoid" and the unusual characteristics of these structures, it is here suggested that these structures be referred to as inflorescence appendages or lateral appendages.

The suberization of these three Utricularia species is odd and merits further discussion. $U$. gibba appears to have suberization only around the central cell of the glandular projections, but $U$. cornuta and $U$. subulata have suberization surrounding the base of the lateral organs (Figs. 1.32, 1.62a-c). The function of this suberization is not known, but one potential use could be to provide a seal after lateral organs have fallen off. This suberization in the lateral organs of these aquatic plants is potentially be for additional support, or it could be used to limit solute flow into or out of the plant, or the entrance of pathogens. 


\section{Relevance of Utricularia growth to future studies}

The true nature of Utricularia vegetative morphology, with respect to the homology of the organs, may be more problematic than any other extant angiosperm. A morphological pattern can nevertheless be discerned for each species and in this study I have mapped a pattern for $U$. gibba, U. cornuta, and $U$. subulata. Because of the ambiguity of the organ classification, it was necessary to define each organ category for each given species before an architectural model could be created (Table 1.2). Although there appears to be a limited amount of variation in the plant growth pattern, the tissues of Utricularia species remain meristematic and can develop into new structures, or into entirely new plants (Fig. 1.41). For example, the leaf-like structures of all three species appear to reach a point where they become determinate, but if part of the LLS is destroyed or broken from the primary stolon, it can initiate a new plant, which may not appear to follow the architectural rules at first, but will ultimately return to the growth pattern for that species.

The unique characteristics of Utricularia as a genus - the complex traps (Lloyd 1942, Sydenham and Findlay 1973), extremely modified vegetative morphology (Arber 1920, Rutishauser and Sattler 1989, Sattler and Rutishauser 1990, Taylor 1989), relaxed developmental constraints (Müller et al. 2006), high generic diversity (Albert et al. 1992), and fast genomic substitution rates (Jobson and Albert 2002, Jobson et al. 2004, Müller and Borsch 2005, Müller et al. 2006) - indicate that members of this genus would be good model species for physiological, ecological, and evolutionary studies. Previous phylogenetic studies of carnivorous plants have emphasized the divergence and evolutionary significance of the different methods of trapping prey and their 
corresponding structures (Albert et al. 1992, Jobson and Albert 2002, Jobson et al. 2003, Jobson et al. 2004, Müller et al. 2004, Müller et al. 2005). These studies agree that the genus Utricularia has the most evolutionarily advanced trap structure and function in addition to its loss of a distinct shoot-root growth pattern. Discovering the patterns that led to the establishment of these two atypical features could help uncover the evolutionary significance of different genes in development of plant morphology.

Molecular work suggests that the characteristic free-form growth pattern Utricularia species exhibit may have been the result of a deletion, mutation, or other alteration of genomic regulatory controls. Recent studies have shown that Utricularia species do possess a faster nucleotide substitution rate (Jobson and Albert 2002, Jobson et al. 2004), possibly leading to increased cladogenesis, more diversity within the genus, and a morphological distancing from the typical angiosperm structure. Additionally, the Utricularia species have small genomes - U. gibba has the third smallest angiosperm genome thus far identified (Greilhuber et a. 2006) - implying that portions of the genome has been lost. Other molecular studies of angiosperms with divergent or odd morphology and studies of Arabidopsis mutants have increased the understanding of regulatory gene control in plant development (Byrne et al. 2003 and Harrison et al. 2005). One of these classes of regulatory genes, knottedl-like homeobox (KNOX) genes, has been identified as the class of genes responsible for indeterminate apical growth (Jackson et al. 1994), thus, repression of $K N O X$ activity contributes to the determinacy of leaf growth (Lincoln et al. 1994, Hofer et al. 1996). The patterns of expression and repression of this group of genes in Utricularia species would provide insight into plant determinacy regulatory control mechanisms since identification of determinate organs is not always obvious, and 
the organs which may appear determinate, have the ability to return to active growth at some level.

Additional phylogenetic and morphological studies could increase the understanding of the mechanisms used by Utricularia to release these plants from preestablished angiosperm growth rules. In addition to, or a potential cause of this lack of constraint to the typical angiosperm growth pattern, Utricularia species show an increase in their genomic substitution rates across several loci (Jobson and Albert 2002) resulting in alterations in cellular functions (Jobson et al. 2004). Thus, the ambiguity of Utricularia species' organs, the complex trapping structure, unique physiology, and high genomic substitution rates suggest Uticularia species may make good models to determine which genes play important roles in angiosperm root-shoot determination and how these genes are affected by environmental studies.

Utricularia is a large genus with 217 unique species recognized by Taylor (1989). Ten extant species and one potentially extinct species of Utricularia are present in South Florida, providing a high diversity of Utricularia species in a relatively small area. This work provided a morphological model for three Utricularia species common to the Everglades region, but the distribution and abundance of the members of this species suggest the probability that a similar model could be created for other South Florida Utricularia species, allowing them to be useful for studying in plant evolution, physiology, and ecology. 
Table 1.1. Summary of collection dates and locations.

\begin{tabular}{|l|l|l|l|l|}
\hline Species & Site & Dry Season Date & Wet Season Date & UTM \\
\hline U. gibba & Singeltary, Florida City & April 2006 & July 2006 & 17R 0550213, 2847738 \\
\hline & Henington Pond, FIU & April 2006 & July 2006 & 17R 0562313, 2849027 \\
\hline & Wildlife and Environmental Area & April 2006 & July 2006 & 17R 0543841, 2800748 \\
\hline & Fish Pools & April 2006 & July 2006 & FIU campus \\
\hline U. cornuta & Singeltary, Florida City & April 2006 & July 2006 & 17R 0553416, 2810337 \\
\hline & Wildlife and Environmental Area & March 2006 & July 2006 & 17R 0543841, 2800748 \\
\hline & $\begin{array}{l}\text { Mahogany Hammock, ENP } \\
\text { EVER-2005-SCI-0065) }\end{array}$ & January 2006 & July 2006 & 17R 0518369, 2802552 \\
\hline U. subulata & Singeltary, Florida City & April 2006 & July 2006 & 17R 0553461, 2810305 \\
\hline & Wildlife and Environmental Area & March 2006 & July 2006 & 17R 0543841, 2800748 \\
\hline & Mahogany Hammock, ENP & January 2006 & July 2006 & 17R 0518369, 2802552 \\
\hline
\end{tabular}


Table 1.2. Description of terminology for the general organ types of U. gibba, U. cornuta, and U. subulata

\begin{tabular}{|l|l|}
\hline PLANT ORGAN & DEFINITION \\
\hline primary stolon (S1) & $\begin{array}{l}\text { largest horizontally growing stem (stolon) in a plant } \\
\text { segment }\end{array}$ \\
\hline secondary and tertiary stolons (S2 and S3) & $\begin{array}{l}\text { branch-like stolons arising from the main plant axis } \\
\text { that reiterate the structure of that primary stolon }\end{array}$ \\
\hline leaf-like structure (LLS) & $\begin{array}{l}\text { chloroplast-containing structures arising from the } \\
\text { rimary stolon }\end{array}$ \\
\hline rhizoid-like structures (RLS) & thin, linear, thread-like organs lacking chloroplasts \\
\hline inflorescence & flowering stem \\
\hline modified stolons (Sm) & $\begin{array}{l}\text { horizontally growing stems (stolons) with different } \\
\text { lateral appendages than the primary stolon }\end{array}$ \\
\hline inflorescence appendage & $\begin{array}{l}\text { small, lateral appendage of a modified stolon densely } \\
\text { covered with glands }\end{array}$ \\
\hline traps & prey capturing organ \\
\hline node & point of LLS initiation \\
\hline
\end{tabular}


Table 1.3. Plant organ location for U. gibba, U. cornuta, and U. subulata.

\begin{tabular}{|c|c|c|c|}
\hline PLANT ORGAN & $\begin{array}{c}U . g i b b a \\
\text { ORGAN POSITION }\end{array}$ & $\begin{array}{c}\text { U. cornuta } \\
\text { ORGAN POSITION } \\
\end{array}$ & $\begin{array}{c}\text { U. subulata } \\
\text { ORGAN POSITION }\end{array}$ \\
\hline primary stolon (S1) & center axis & center axis & center axis \\
\hline $\begin{array}{l}\text { secondary and tertiary stolons } \\
\text { (S2 and S3) }\end{array}$ & $\begin{array}{l}\text { lateral from the primary } \\
\text { stolon in the axil of the LLS }\end{array}$ & $\begin{array}{l}\text { lateral from the primary } \\
\text { stolon appearing across from } \\
\text { the LLS (most common } \\
\text { position), in the LLS axils, or } \\
\text { appearing at the central } \\
\text { portion of the node }\end{array}$ & $\begin{array}{l}\text { lateral from the primary } \\
\text { stolon in the LLS axils }\end{array}$ \\
\hline leaf-like structure (LLS) & $\begin{array}{l}\text { lateral appendage of the S1, } \\
\text { the position of the LLS } \\
\text { identifies the nodal position }\end{array}$ & $\begin{array}{l}\text { lateral appendage of the S1, } \\
\text { the position of the LLS } \\
\text { identifies the nodal position }\end{array}$ & $\begin{array}{l}\text { lateral appendage of the S, } \\
\text { the position of the LLS } \\
\text { identifies the nodal position }\end{array}$ \\
\hline rhizoid-like str:- ures (RLS) & not present & $\begin{array}{l}\text { usually fo: }-1 \text { on all } \\
\text { structures of the plant }\end{array}$ & $\begin{array}{l}\text { lateral appendage of the } S 1 \text { at } \\
\text { the nodes across from the } \\
\text { LLS, } 1-2 \text { present per node, } \\
\text { may also be found at the base } \\
\text { of the LLS }\end{array}$ \\
\hline inflorescence & axil of a LLS & $\begin{array}{l}\text { axil of the LLS or the central } \\
\text { portion of the node }\end{array}$ & axil of a LLS \\
\hline modified stolons (Sm) & base of the inflorescence & base of the inflorescence & base of the inflorescence \\
\hline inflorescence appendage & lateral appendage of the Sm & lateral appendage of the $\mathrm{Sm}$ & lateral appendage of the $\mathrm{Sm}$ \\
\hline traps & form only on the LLS & found on LLS, RLS, stolons & found on LLS, RLS, stolons \\
\hline
\end{tabular}


Table 1.4. Plant organ characteristics for $U$. gibba, U. cornuta, and U. subulata.

\begin{tabular}{|c|c|c|c|}
\hline \begin{tabular}{|l|} 
PLANT \\
ORGAN \\
\end{tabular} & $\begin{array}{l}\text { U. gibba } \\
\text { CHARACTERISTICS }\end{array}$ & $\begin{array}{l}\text { U. cornuta } \\
\text { CHARACTERISTICS }\end{array}$ & $\begin{array}{l}\text { U. subulata } \\
\text { CHARACTERISTICS } \\
\end{array}$ \\
\hline $\begin{array}{l}\text { primary stolon } \\
\text { (S1) }\end{array}$ & $\begin{array}{l}\text { horizontal stolon, circinnate } \\
\text { vernation, contains } \\
\text { chloroplasts, thin, grows } \\
\text { from the apex while drying } \\
\text { from the opposite end }\end{array}$ & $\begin{array}{l}\text { horizontal stolon, lacks } \\
\text { chloroplasts, grows from the } \\
\text { apex while drying from the } \\
\text { opposite end }\end{array}$ & $\begin{array}{l}\text { horizontally growing stolon, } \\
\text { lacks chloroplasts, grows } \\
\text { from the apex while drying } \\
\text { from the opposite end }\end{array}$ \\
\hline $\begin{array}{l}\text { secondary and } \\
\text { tertiary stolons } \\
\text { (S2 and S3) }\end{array}$ & $\begin{array}{l}\text { stolons arising from the } \\
\text { primary stolon, in the LLS } \\
\text { axils, identical in structure to } \\
\text { the S1, contains chloroplasts }\end{array}$ & $\begin{array}{l}\text { stolons arising from the } \\
\text { primary stolon at a node in } \\
\text { the axil of the LLS or in the } \\
\text { central portion of the nodal } \\
\text { area, identical in structure to } \\
\text { the S1, lack chloroplasts } \\
\text { except on the LLS }\end{array}$ & $\begin{array}{l}\text { stolons arising from the } \\
\text { primary stolon in the axil of } \\
\text { a LLS, identical in structure } \\
\text { to the S1, stolons may have } \\
\text { condensed internodes } \\
\text { causing them to appear } \\
\text { shorter, lack chloroplasts } \\
\text { except on the LLS }\end{array}$ \\
\hline $\begin{array}{l}\text { leaf-like } \\
\text { structure (LLS) }\end{array}$ & $\begin{array}{l}\text { dichotomously divided ( } 1-4 \\
\text { times), contain chloroplasts, } \\
\text { primary lateral structures of } \\
\text { the S1 }\end{array}$ & $\begin{array}{l}\text { linear, strap-shaped, } \\
\text { phototropic, contain } \\
\text { chloroplasts in the distal } \\
\text { region }\end{array}$ & $\begin{array}{l}\text { terete, narrow, linear to } \\
\text { spatulate, tip may be curved, } \\
\text { contain chloroplasts } \\
\text { throughout and often } \\
\text { anthrocyanins in the tip }\end{array}$ \\
\hline $\begin{array}{l}\text { rhizoid-like } \\
\text { structures (RLS) }\end{array}$ & not present & $\begin{array}{l}\text { thin, linear, often thread-like } \\
\text { organs, highly variable in } \\
\text { length, tapering at the tip, } \\
\text { appear determinate, hair-like } \\
\text { organs sometimes present } \\
\text { along basal portions, lack } \\
\text { chloroplasts }\end{array}$ & linear, thin, lack chloroplasts \\
\hline inflorescence & $\begin{array}{l}\text { formed in the axil of the } \\
\text { LLS, two types of stolons } \\
\text { form at the base, S1 and Sm }\end{array}$ & $\begin{array}{l}\text { Form in the axil of the LLS } \\
\text { or the central portion of the } \\
\text { nodal region }\end{array}$ & form in the axil of a LLS \\
\hline $\begin{array}{l}\text { modified stolons } \\
(\mathrm{Sm})\end{array}$ & $\begin{array}{l}\text { stolons formed at the base of } \\
\text { the inflorescence, circinnate } \\
\text { vernation, lack chloroplasts }\end{array}$ & $\begin{array}{l}\text { short stolons formed at the } \\
\text { base of the inflorescence, } \\
\text { lack chloroplasts }\end{array}$ & $\begin{array}{l}\text { short stolons formed at the } \\
\text { base of the inflorescence, } \\
\text { lack chloroplasts }\end{array}$ \\
\hline $\begin{array}{l}\text { inflorescence } \\
\text { appendage }\end{array}$ & $\begin{array}{l}\text { multified, claw-like } \\
\text { structures, covered in } \\
\text { glandular cells }\end{array}$ & $\begin{array}{l}\text { linear, short, occasionally } \\
\text { divided into two segments, } \\
\text { covered in glandular cells }\end{array}$ & $\begin{array}{l}\text { linear, short, covered in } \\
\text { glandular cells }\end{array}$ \\
\hline traps & $\begin{array}{l}\text { small, globose, trap } \\
\text { appendages by door } \\
\text { branched, various shades of } \\
\text { color between pale green and } \\
\text { black }\end{array}$ & $\begin{array}{l}\text { small, globose, lacking trap } \\
\text { appendages, elongated } \\
\text { "nose" present, lack color, } \\
\text { often anthrocyanins present } \\
\text { in nose }\end{array}$ & $\begin{array}{l}\text { small, globose, trap } \\
\text { appendages thickened and } \\
\text { sparsely branched, no } \\
\text { pigments present }\end{array}$ \\
\hline
\end{tabular}


Table 1.5. A comparison of the RLS and S2 of $U$. cornuta.

\begin{tabular}{|c|c|c|}
\hline $\begin{array}{l}\text { Lateral Organ } \\
\text { Characteristic }\end{array}$ & RLS & S2 \\
\hline description & thin, linear, thread-like organs, lack chloroplasts & $\begin{array}{l}\text { branch-like stolons that reiterate the structure of } \\
\text { that primary stolon, lack chloroplasts except in } \\
\text { the LLS born on the S2 }\end{array}$ \\
\hline $\begin{array}{l}\text { lateral } \\
\text { structures }\end{array}$ & traps, hair-like structure & LLS, RLS, S3, traps \\
\hline $\begin{array}{l}\text { position on } \\
\text { main stolon }\end{array}$ & $\begin{array}{l}\text { lateral, either appearing across from the LLS or } \\
\text { in the internodal region }\end{array}$ & $\begin{array}{l}\text { lateral, appearing across from the LLS (most } \\
\text { common position), in the LLS axils, or appearing } \\
\text { at the central portion of the nodal area }\end{array}$ \\
\hline length & $\begin{array}{l}\text { various, sometimes long and short RLS are } \\
\text { found on the same plant, older RLS are not } \\
\text { necessarily longer }\end{array}$ & $\begin{array}{l}\text { older S2 are longer than younger S2 on the same } \\
\text { plant segment, S2 is usually shorter than S1 } \\
\text { unless the S1 is broken }\end{array}$ \\
\hline apex & tapers, or thins to fine points & does not taper, appears the same as the S1 apex \\
\hline
\end{tabular}


Table 1.6. Summary of measurements from field collected U. gibba plants. One set of measurements was taken on plants collected during the dry season and one set of measurements was taken on plants collected during the wet season.

\begin{tabular}{|c|c|c|c|c|c|}
\hline U. gibba & & $\mathbf{N}$ & Mean士 S.D. & Range & Significance \\
\hline \multirow{3}{*}{$\begin{array}{l}\text { Segment Length (mm) } \\
\qquad \mathrm{N}=\text { number of plants }\end{array}$} & Dry Season & 40 & $83.9 \pm 29.9$ & $30-146$ & \\
\hline & Wet Season & 30 & $161.2 \pm 95.6$ & $55.1-407.2$ & 0.0002 \\
\hline & Overall & 70 & $117.1 \pm 76.4$ & $30-407.2$ & \\
\hline \multirow{3}{*}{$\begin{array}{l}\text { Internode Length }(\mathrm{mm}) \\
\qquad \mathrm{N}=\text { number of internodes }\end{array}$} & Dry Season & 771 & $4.4 \pm 2.5$ & $0.3-18$ & \\
\hline & Wet Season & 846 & $5.6 \pm 2.3$ & $0.9-16.5$ & 0 \\
\hline & Overall & $\overline{1617}$ & $5.1 \pm 2.5$ & $0.3-18$ & \\
\hline \multirow{3}{*}{$\begin{array}{l}\text { LLS Length }(\mathrm{mm}) \\
\qquad \mathrm{N}=\text { number of LLS }\end{array}$} & Dry Season & 241 & $5.1 \pm 3.2$ & $0.5-12$ & \\
\hline & Wet Season & 174 & $3.9 \pm 2.4$ & $0.5-12$ & 0 \\
\hline & Overall & 415 & $4.6 \pm 2.9$ & $0.5-12$ & \\
\hline Inflorescence (cm) & & 5 & $5.9 \pm 2.1$ & $4.5-9.4$ & \\
\hline \multirow{2}{*}{$\begin{array}{l}\text { Inflorescence Appendages (mm) } \\
\mathrm{N}=\text { number of Inf appendages }\end{array}$} & Width & 10 & $0.9 \pm 0.2$ & $0.6-1.2$ & \\
\hline & Length & 10 & $0.8 \pm 0.2$ & $0.5-1.1$ & \\
\hline \multirow{2}{*}{$\begin{array}{l}\text { axillary buds/node } \\
\qquad \mathrm{N}=\text { number of plants }\end{array}$} & Dry Season & 40 & $0.4 \pm 0.2$ & $0.1-0.8$ & \\
\hline & Wet Season & 30 & $0.3 \pm 0.2$ & $0.1-0.7$ & 0.0121 \\
\hline
\end{tabular}


Table 1.7. Summary of measurements from field collected $U$. cornuta plants. One set of measurements was taken on plants collected during the dry season and one set of measurements was taken on plants collected during the wet season.

\begin{tabular}{|c|c|c|c|c|c|}
\hline U. cornuta & & $\mathbf{N}$ & Mean \pm S.D. & Range & Significance \\
\hline \multirow{3}{*}{$\begin{array}{l}\text { Segment Length }(\mathrm{mm}) \\
\qquad N=\text { number of plants }\end{array}$} & Dry Season & 30 & $54.6 \pm 26.6$ & $11.5-88$ & \\
\hline & Wet Season & 30 & $43.1 \pm 20$ & $11-97.9$ & 0.0641 \\
\hline & Overall & 60 & $48.8 \pm 24.1$ & $11-107$ & \\
\hline \multirow{3}{*}{$\begin{array}{l}\text { Internode Length }(\mathrm{mm}) \\
\qquad \mathrm{N}=\text { number of internodes }\end{array}$} & Dry Season & 264 & $6.2 \pm 2.7$ & $1-17$ & \\
\hline & Wet Season & 218 & $5.6 \pm 2.1$ & $0.8-12$ & 0.0001 \\
\hline & Overall & 482 & $5.8 \pm 2.5$ & $0.8-17$ & \\
\hline \multirow{3}{*}{$\begin{array}{l}\text { LLS Length }(\mathrm{mm}) \\
\qquad \mathrm{N}=\text { number of LLS }\end{array}$} & Dry Season & 74 & $23.2 \pm 8.8$ & $5-45$ & \\
\hline & Wet Season & 92 & $28.4 \pm 9.1$ & $13-50$ & 0.0003 \\
\hline & Overall & 166 & $26.1 \pm 9.3$ & $5-50$ & \\
\hline Inflorescence $(\mathrm{cm})$ & & 6 & $28 \pm 6.9$ & $18.5-38.2$ & \\
\hline $\begin{array}{l}\text { Inflorescence Appendages (mm) } \\
\mathrm{N}=\text { number of Inf appendayes }\end{array}$ & & 10 & $1.8 \pm 0.6$ & $1.1-2.8$ & \\
\hline axillary buds/node & Dry Season & 30 & $0.05 \pm 0.1$ & $0-0.05$ & \\
\hline $\mathrm{N}=$ number of plants & Wet Season & 30 & $0.05 \pm 0.1$ & $0-0.05$ & 0.8537 \\
\hline
\end{tabular}


Table 1.8. Summary of measurements from field collected U. subulata plants. Measurements were taken on plants collected during the dry season only.

\begin{tabular}{|c|c|c|c|c|c|}
\hline U. subulata & & $\mathbf{N}$ & Mean \pm S.D. & Range & Significance \\
\hline \multirow{2}{*}{$\begin{array}{l}\text { Segment Length (mm) } \\
\qquad \mathrm{N}=\text { number of plants }\end{array}$} & Dry Season & 27 & $16.2 \pm 9.1$ & $4-42$ & \\
\hline & Wet Season & $\mathrm{N} / \mathrm{A}$ & & & \\
\hline \multirow{2}{*}{$\begin{array}{l}\text { Internode Length }(\mathrm{mm}) \\
\qquad \mathrm{N}=\text { number of internodes }\end{array}$} & Dry Season & 125 & $3.6 \pm 1.2$ & $1-6$ & \\
\hline & Wet Season & $\mathrm{N} / \mathrm{A}$ & & & \\
\hline \multirow{2}{*}{$\begin{array}{l}\text { LLS Length }(\mathrm{mm}) \\
\qquad \mathrm{N}=\text { number of LLS }\end{array}$} & Dry Season & 78 & $13.6 \pm 8.6$ & $3-33$ & \\
\hline & Wet Season & N/A & & & \\
\hline Inflorescence $(\mathrm{cm})$ & & 8 & $4.3 \pm 1.3$ & $2.6-7.5$ & \\
\hline \multirow{2}{*}{$\begin{array}{l}\text { axillary buds/node } \\
\qquad \mathrm{N}=\text { number of plants }\end{array}$} & Dry Season & 28 & $0.3 \pm 0.2$ & $0-0.7$ & \\
\hline & Wet Season & $\mathrm{N} / \mathrm{A}$ & & & \\
\hline
\end{tabular}




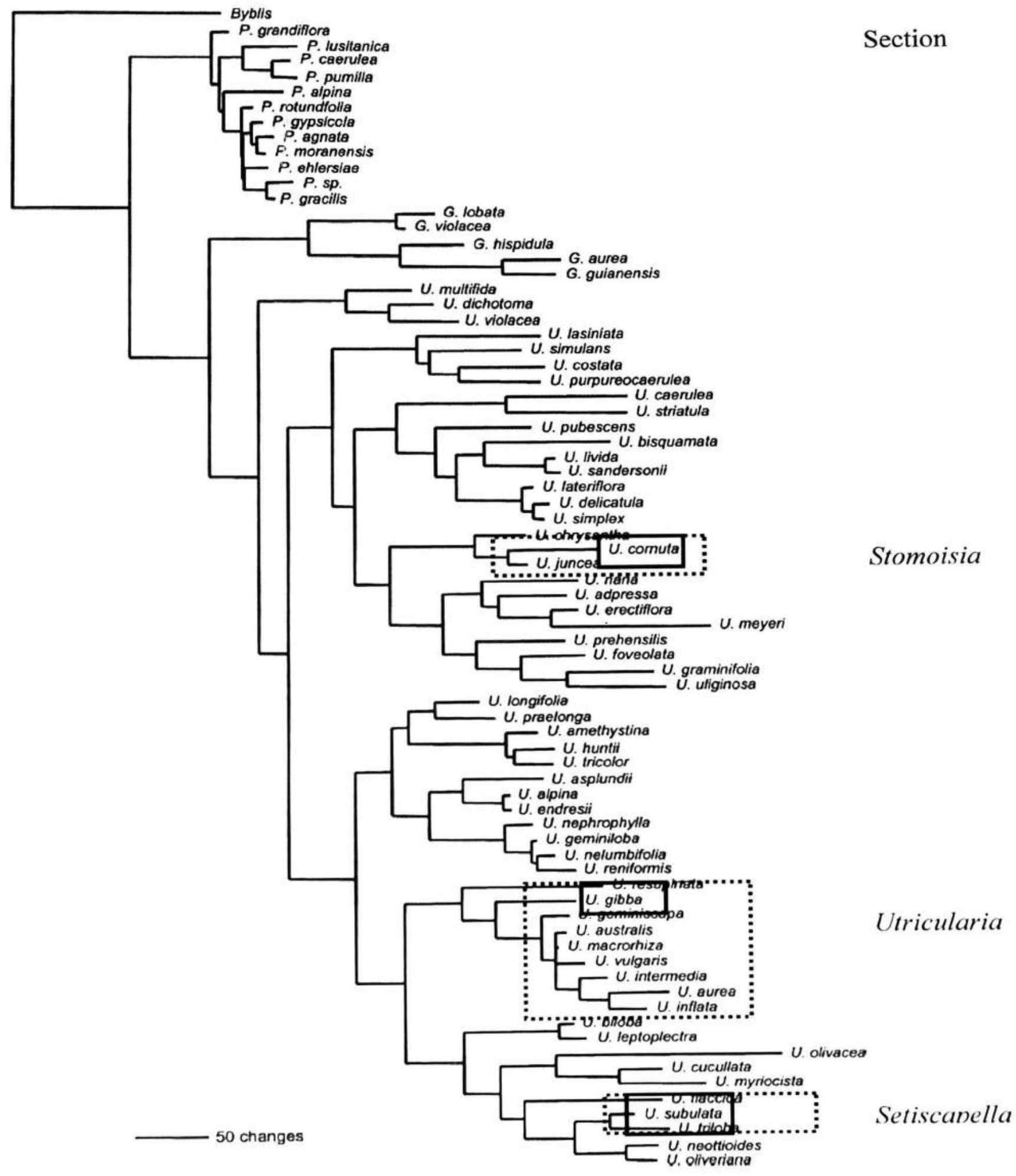

Figure 1.1. The phylogeny of selected members of the Lentibulariaceae from Jobson et al. 2003 based on plastid rps 16 intron and $\operatorname{rn} \mathrm{L}-\mathrm{F}$ DNA sequences. The positions of $U$. cornuta, U. gibha, and $U$. subulata are highlighted with boxes. 


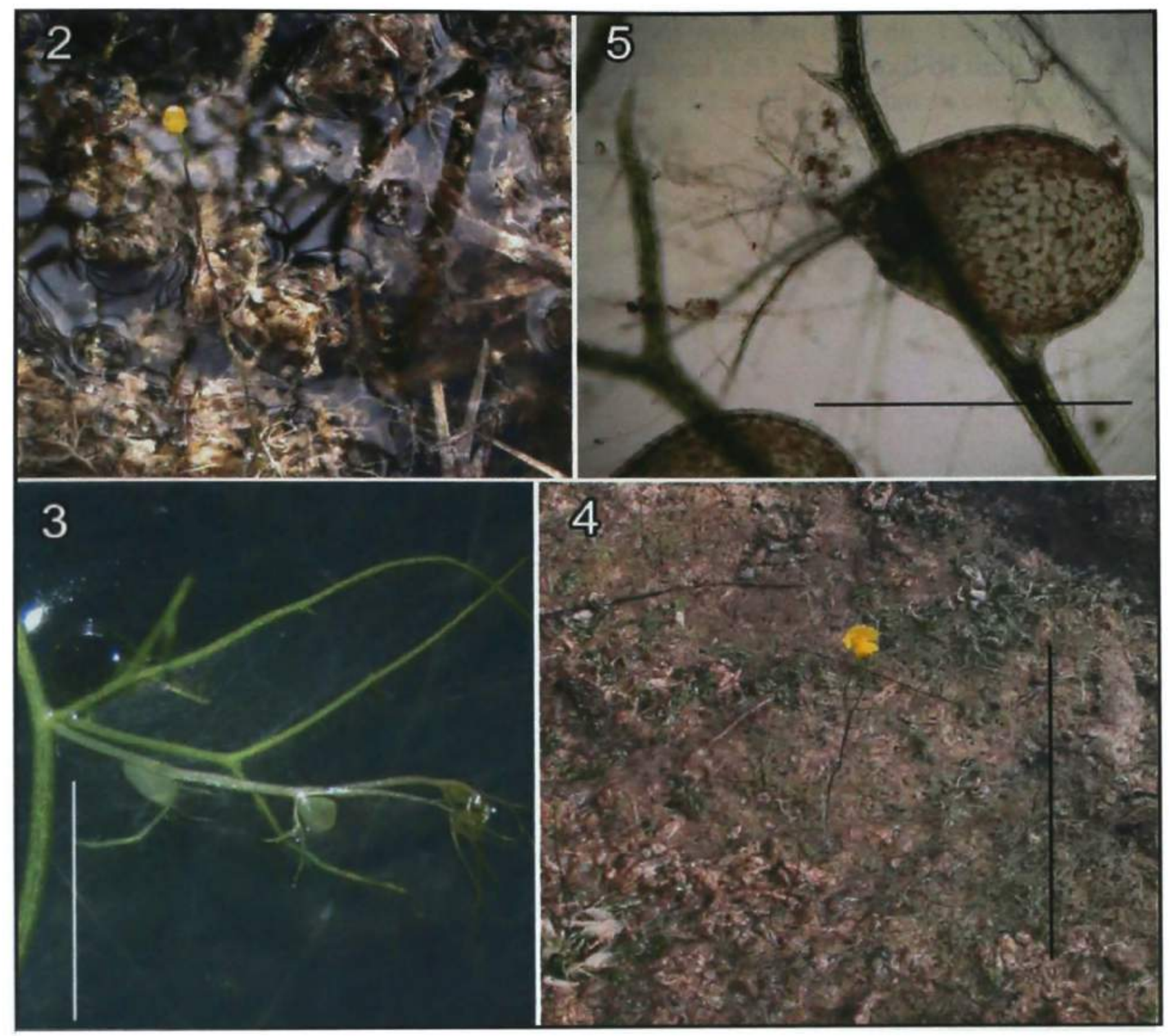




\section{Plate 1.1}

Figures 1.2-1.5. Habitat of Utricularia gibba from southern Florida. 1.2. U. gibba as a floating aquatic; flowering. 1.3. A LLS with traps and a S2 in the axil of the LLS. 1.4. $U$. gibba as a bethic aquatic; flowering. 1.5. Trap on a LLS. Fig. 1.3, bar $=\mathrm{cm}$; Fig. 1.4, bar $=8 \mathrm{~cm}$; Fig. 1.5 , bar $=1 \mathrm{~mm}$. 


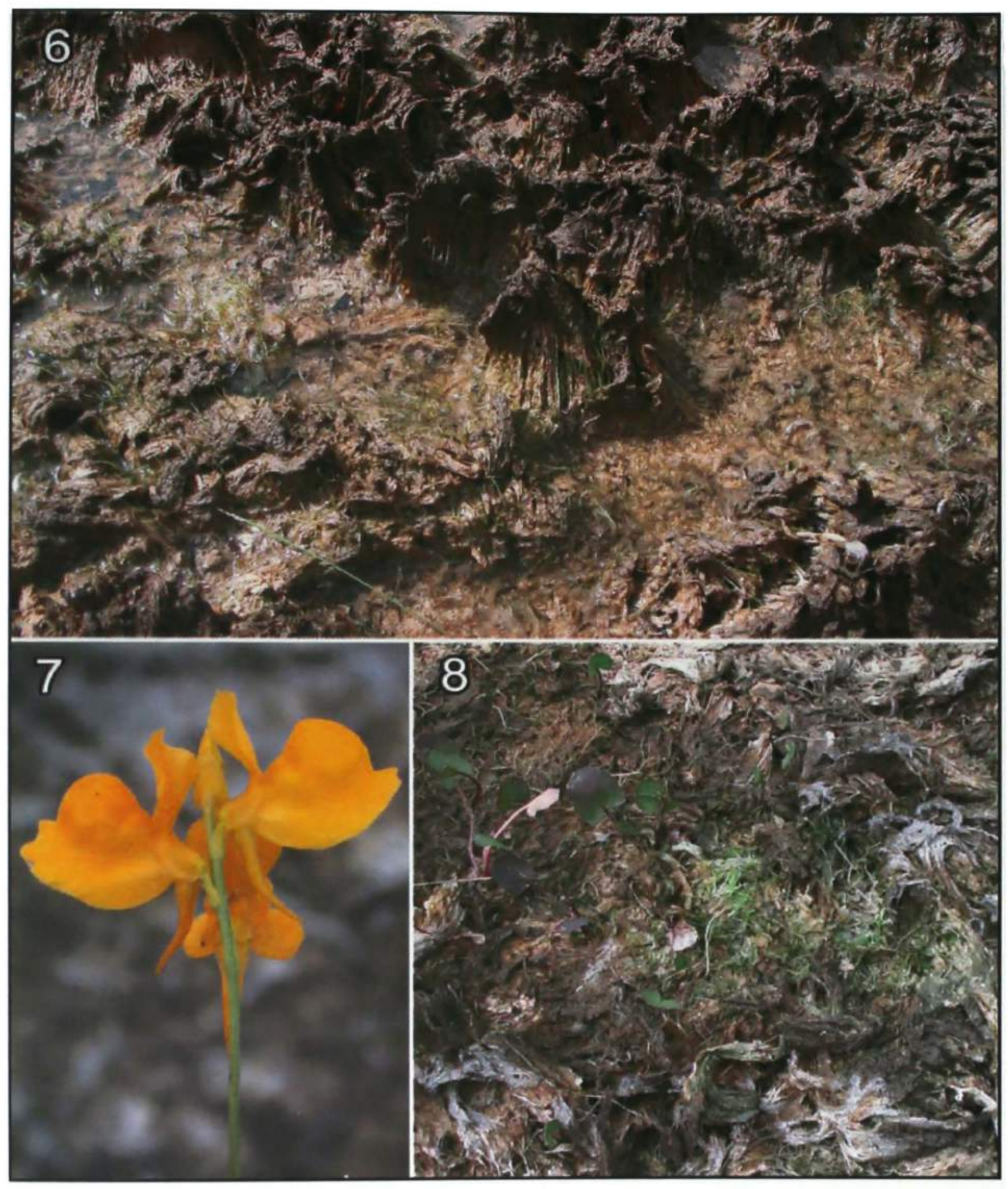




\section{Plate 1.2}

Figures 1.6-1.8. Habitat of Utricularia cornuta from southern Florida. 1.6. U. cornuta growing in the periphyton mat. 1.7. U. cornuta flowers. 1.8. U. cornuta growing in the periphyton mat. 


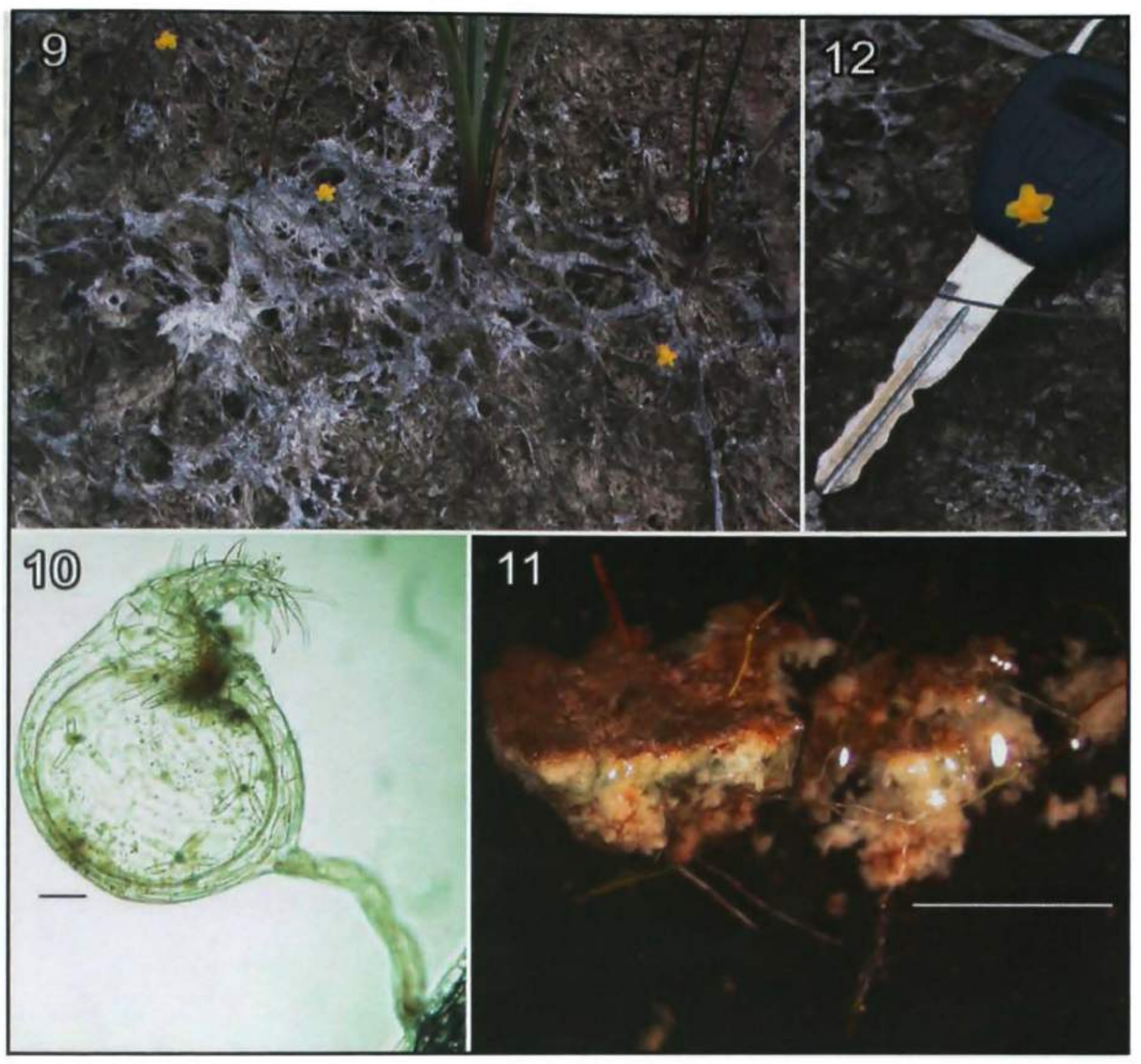




\section{Plate 1.3}

Figures 1.9-1.12. Habitat of Utricularia subulata from southern Florida. 1.9. U. subulata growing in the periphyton mat; flowering. 1.10. U. subulata trap. 1.11. One U. subulata plant embedded in the periphyton mat. 1.12. U. subulata inflorescence. Fig. 1.10, bar = $0.2 \mathrm{~mm}$; Fig. 1.11, bar $=0.5 \mathrm{~cm}$. 


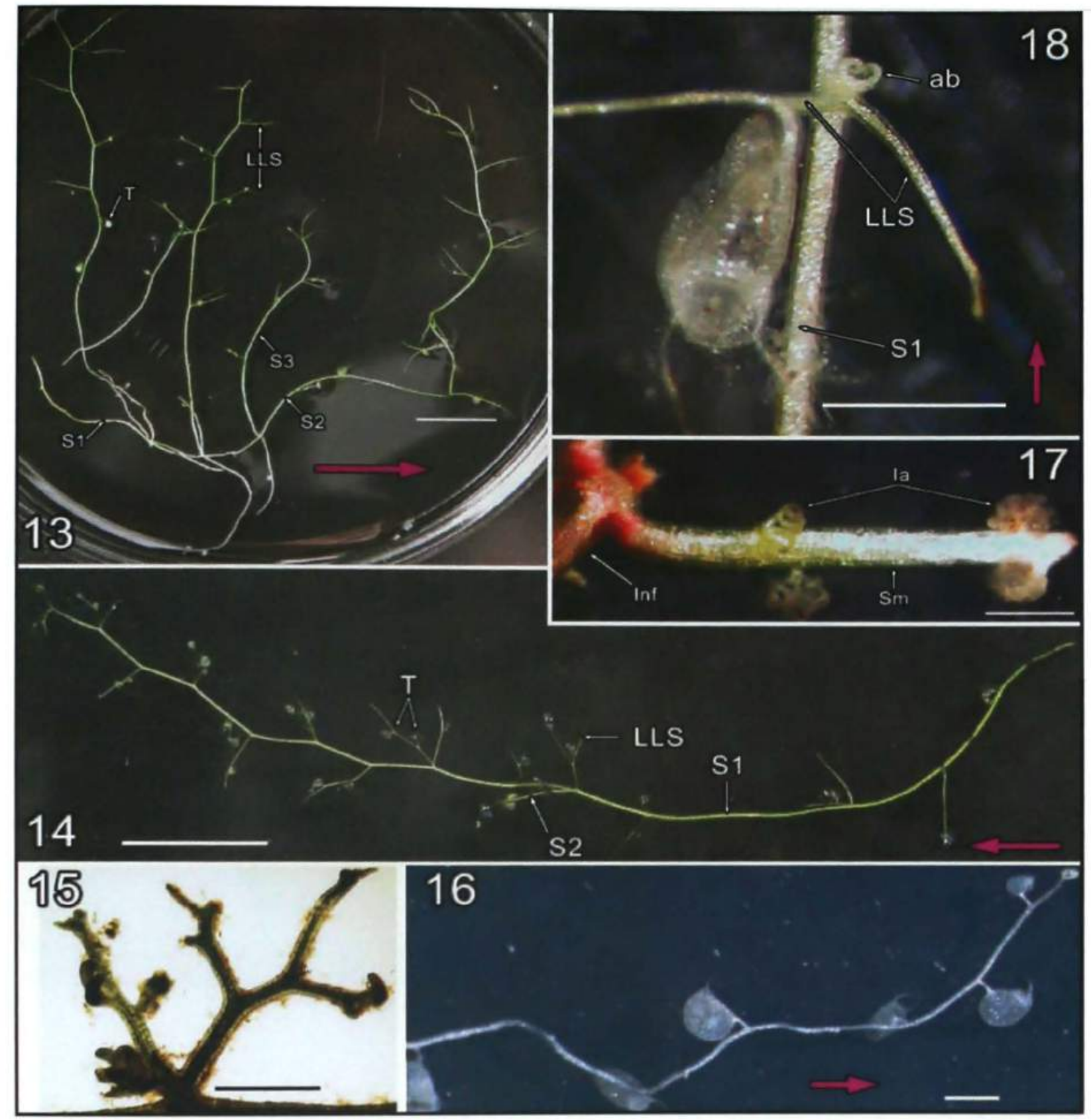




\section{Plate 1.4}

Figures 1.13-1.18. Morphology of Utricularia gibba from southern Florida. 1.13. One plant of $U$. gibba showing a dying S1 with multiple S2 and S3 growing out from the axils of the LLSs. All stolons show circinnate vernation, dichotomously branched LLS, and traps. 1.14. An unbranched plant segment of $U$. gibba, the terminal apex growing while the older portion of the segment is dying. 1.15. An intermediate structure between a LLS and an Ia. The organ has the basic shape of the LLS, but the tips are covered in glands and curved similar to an Ia. This intermediate structure was located on a Sm. 1.16. Part of a $\mathrm{Sm}$ in $U$. gibba lacking LLS. This type of stolon is rarely found at the base of the inflorescence 1.17. The $\mathrm{Sm}$ at the base of the inflorescence with a claw shaped, multified Ia. 1.18. A portion of the $S 1$ with a LLS, a $T$, and two ab. Figs. 1.13-1.14, bar $=1 \mathrm{~cm}$; Figs. 1.15-1.18, bar $=1 \mathrm{~mm}$. Figure abbreviations: ab, axillary bud; Ia, inflorescence appendage; Inf, inflorescence; LLS, leaf-like structure; S1, primary stolon; S2, secondary stolon; S3, tertiary stolon; Sm, modified stolon; pink arrow, direction of growth of S1. 


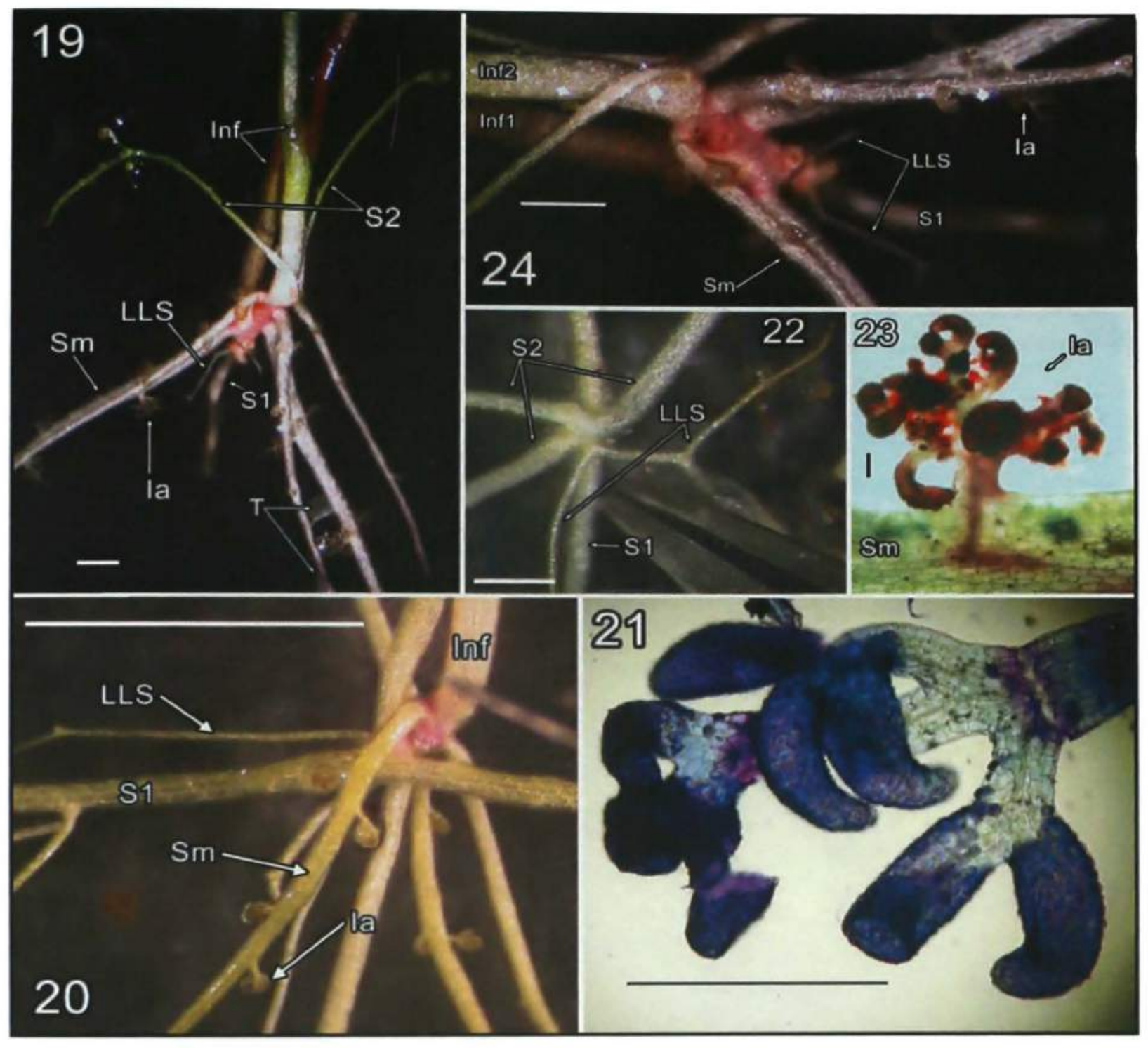




\section{Plate 1.5}

Figures 1.19-1.24. Morphology of Utricularia gibba. 1.19. Two inflorescence bases of $U$. gibba showing the two types of stolons ( $\mathrm{Sm}$ and $\mathrm{S} 2$ ) emerging from the peduncle. The inflorescence in the background is in the axil of the LLS of S1 and the S1 has broken off. Ias are formed on each Sm. 1.20. Inflorescence base in the axil of a LLS. 1.21. Ia dyed with toluidine blue to emphasize the dense covering of the glandular projections. 1.22. Plant segment with multiple S2s arising in the axil of a dichotomously branched LLS. $16 \mathrm{x}, 1 \mathrm{~mm}$. 1.23. Ia dyed with neutral red. 1.24. Figure 1.19 with increased magnification. Scars show position of removed Sm. Figs. 1.19, 1.22, 1.24, bar $=1 \mathrm{~mm}$; Fig. 1.20, bar $=$ $0.5 \mathrm{~cm}$; Fig. 1.21 , bar $=0.5 \mathrm{~mm}$; Fig. 1.23 , bar $=0.05 \mathrm{~mm}$. Figure abbreviations: Ia, inflorescence appendage; Inf, inflorescence; LLS, leaf-like structures; S1, primary stolon; $\mathrm{S} 2$, secondary stolon; Sm, modified stolon. 


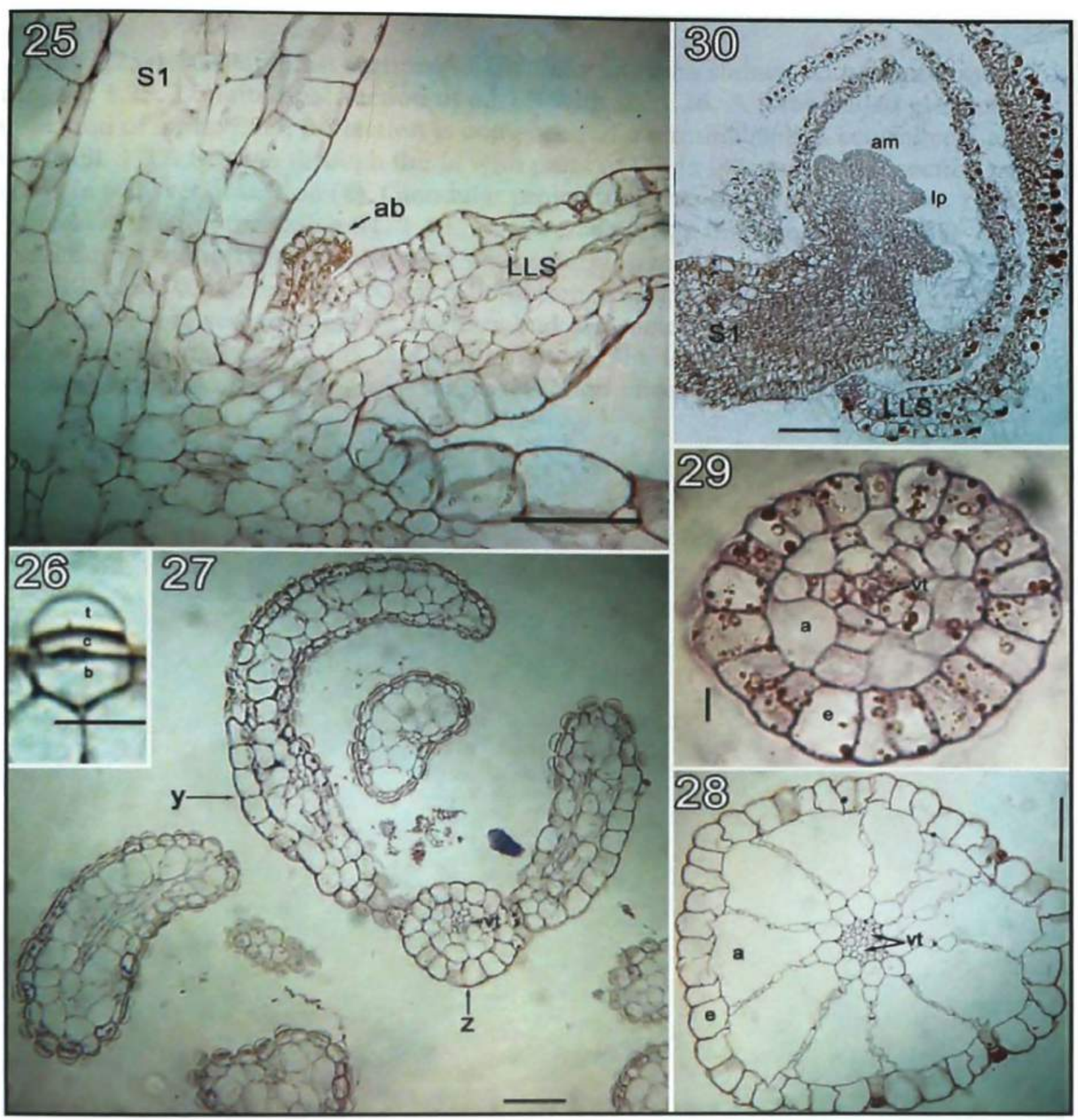




\section{Plate 1.6}

Figures 1.25-1.30. Paraplast sections of Utricularia gibba stained with hemotoxylinsafranin. 1.25. Longitudinal section of a LLS with ab. 1.26. A three-celled glandular projection of an Ia. Each projection is composed of a terminal cell, a central cell, and a basal cell. 1.27. Section through the Ia with parts of the Ia in longitudinal section (y) and others in transverse section (z). Glandular projections line the edges of the Ias. 1.28. Transverse section through a S1. 1.29. Transverse section through a LLS. 1.30.

Longitudinal section through the apex with emerging leaf primoridia. Figs. 1.25, 1.27, $1.28,30$, bar $=0.05 \mathrm{~mm}$; Fig. 26, bar $=0.005 \mathrm{~mm}$, Fig. $29=0.01 \mathrm{~mm}$. Figure

abbreviations: a, aerenchyma; ab, axillary bud; am, apical meristem; b, basal cell; c, central cell; e, epidermis; LLS, leaf-like structures; lp, leaf primordium; S1, primary stolon; $\mathrm{t}$, terminal cell; vt, vascular tissue; $\mathrm{y}$, longitudinal section; $\mathrm{z}$, transverse section. 


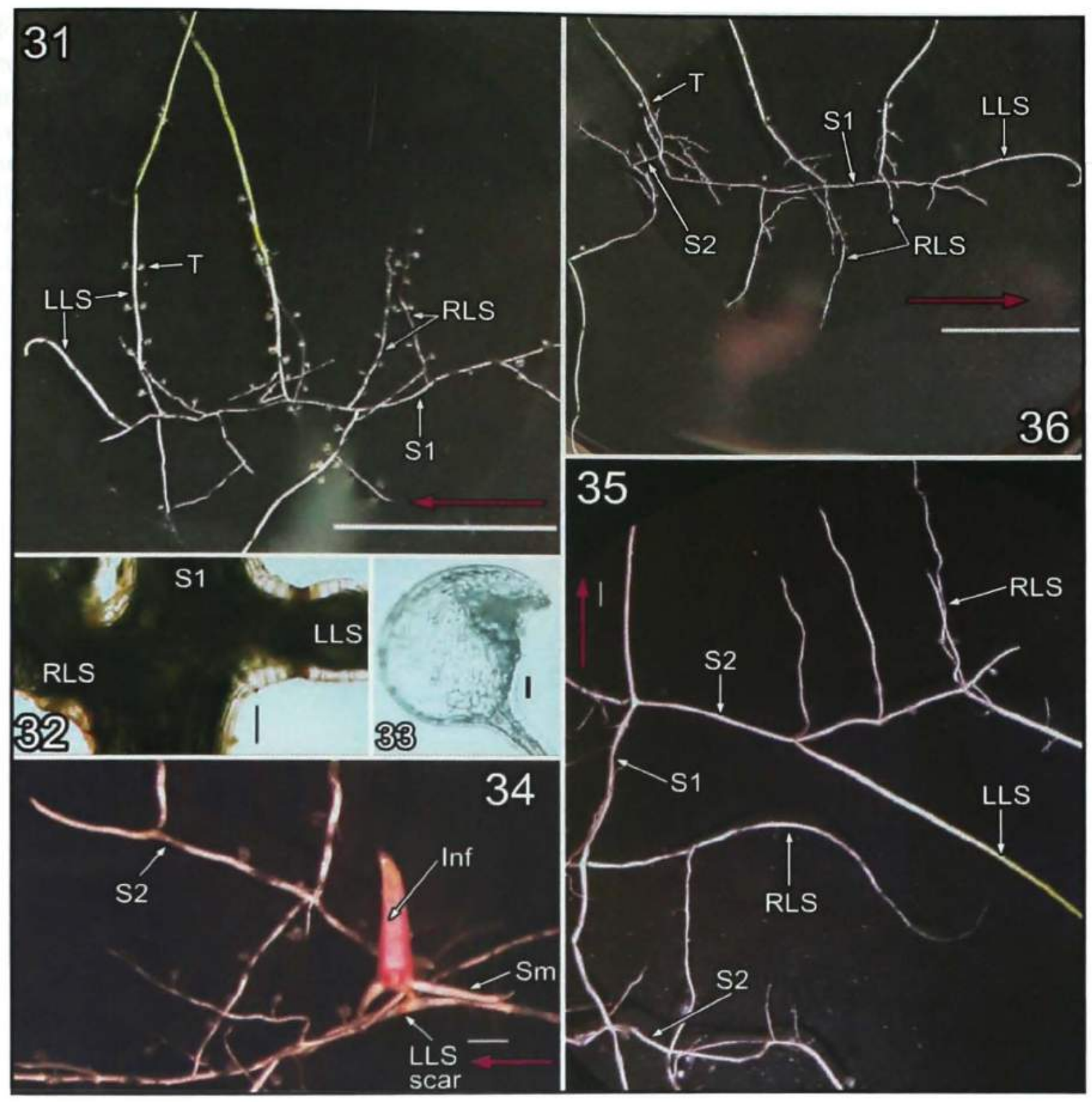




\section{Plate 1.7}

Figures 1.31-1.36. Morphology of Utricularia cornuta from southern Florida. 1.31. Plant segment and lateral organs. 1.32. Lateral organs, a LLS and a RLS stained with Sudan VI indicating a band of suberized tissue between the $\mathrm{S} 1$ and each lateral organ. 1.33. $U$. cornuta trap. 1.34. Plant segment forming an inflorescence at a node between a LLS scar and a S2. Sm are forming from the base of the inflorescence. 1.35. S1 with a S2 at the first node and a RLS at the next consecutive node. The S2 apex and lateral organs reiterate the primary stolon while the RLS has a different appearance. 1.36. Plant segment and lateral organs. Figs. 1.31, 1.36, bar $=1 \mathrm{~cm}$; Figs. 1.32, 1.33, bar $=0.05 \mathrm{~mm}$; Figs. $1.34,1.35$, bar $=1 \mathrm{~mm}$. Figure abbreviations: Inf, inflorescence; LLS, leaf-like structures; RLS, rhizoid-like structures, S1, primary stolon; S2, secondary stolon; Sm, modified stolon; pink arrow, direction of growth of S1. 


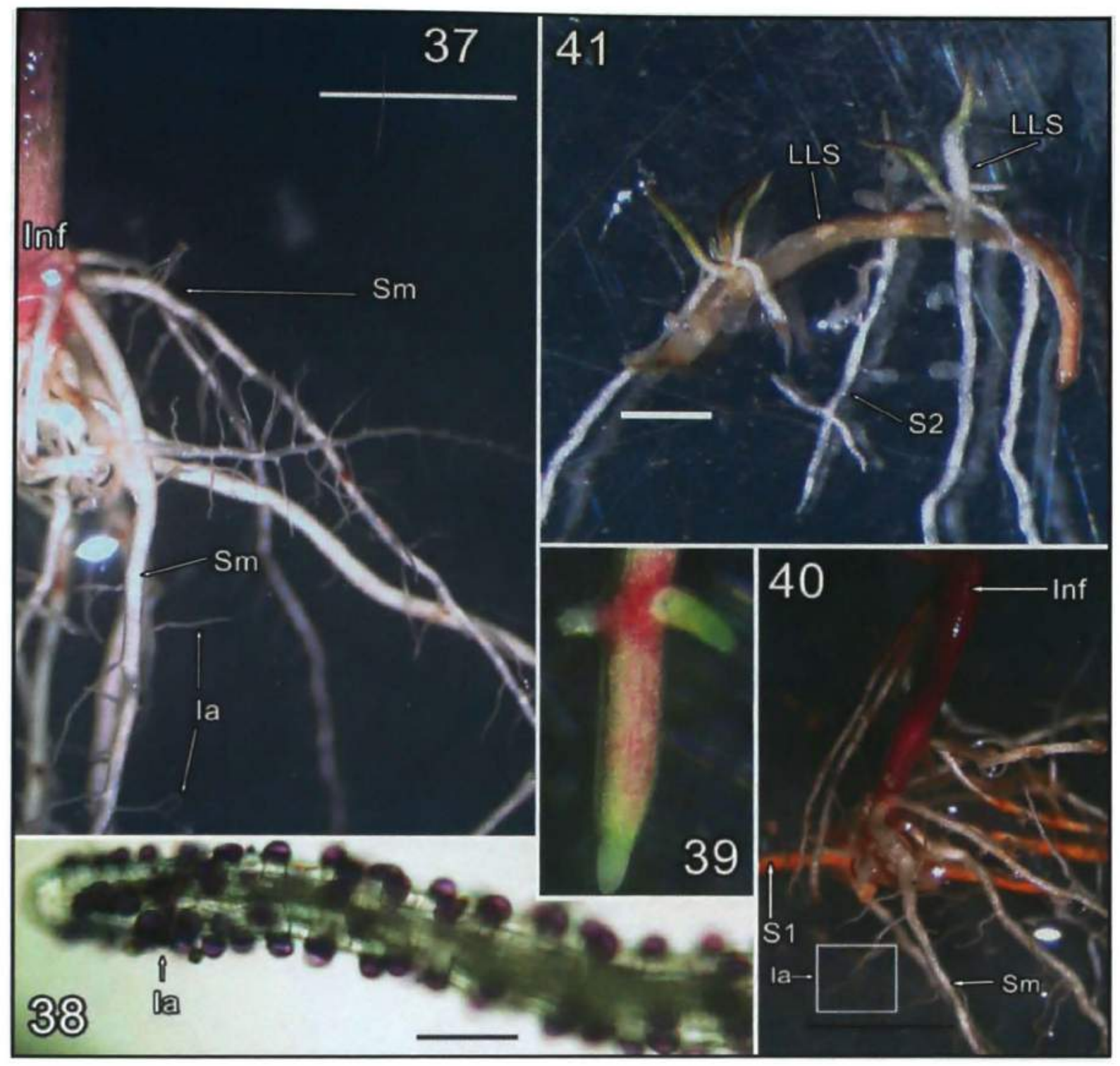




\section{Plate 1.8}

Figures 1.37-1.41. Morphology of Utricularia cornuta from southern Florida. 1.37. Inflorescence base with Sm and Ia. 1.38. The tip of an Ia stained with toluidine blue to show the glandular projections. 1.39. The apex of a $\mathrm{S} 1$ with the first lateral organs. 1.40. Inflorescence base with a Sm and Ia. 1.41. New growth from an older LLS. Each new growth area represents a condensed $\mathrm{S} 1$ which is alternately initiating pairs of LLS and RLS or LLS and S2. Figs. 37, 41 bar $=5 \mathrm{~mm}$; Fig. 38, bar $=0.05 \mathrm{~mm}$; Fig. 40, bar $=1 \mathrm{~mm}$. Figure abbreviations: Ia, inflorescence appendage; Inf, inflorescence; LLS, leaf-like structures; S2, secondary stolon, Sm, modified stolon 


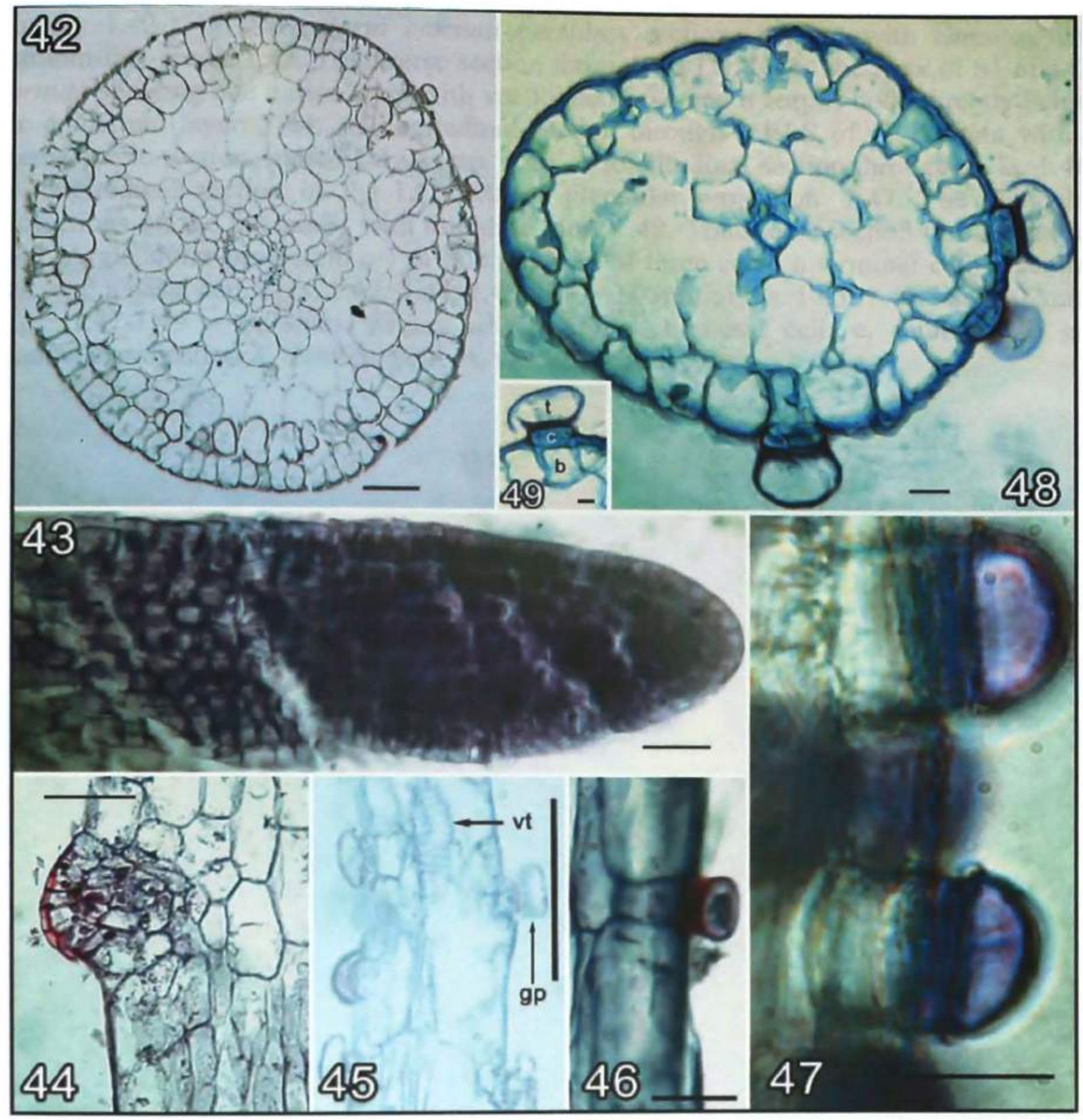




\section{Plate 1.9}

Figures 1.42-1.49. Utricularia cornuta paraplast sections stained with hemotoxylinsafranin-fast-green. 1.42. Transverse section through a LLS. 1.43. The apex of S1 of a $U$. cornuta showing one tunica layer with vacuolated cells and a corpus body directly below the epidermal layer. 1.44. A longitudinal section through a RLS of $U$. cornuta with a meristematic section, most likely a trap. 1.45. A longitudinal section through an Ia. 1.46. A longitudinal section of the LLS with a glandular projection. 1.47. The glandular projections on the Ia stained with toluidine blue. 1.48. Transverse section through an Ia. 1.49. A glandular projection on an Ia composed of three cells: a terminal cell, a central cell, and a basal cell. Figs. $1.42,1.44,1.45$, bar $=0.05 \mathrm{~mm}$; Figs. $1.43,1.46$, bar $=.02 \mathrm{~mm}$, Figs. $1.47-1.49=0.01 \mathrm{~mm}$. Figure abbreviations: b, basal cell; c, central cell; gp, glandular projection; t, terminal cell; vt, vascular tissue. 


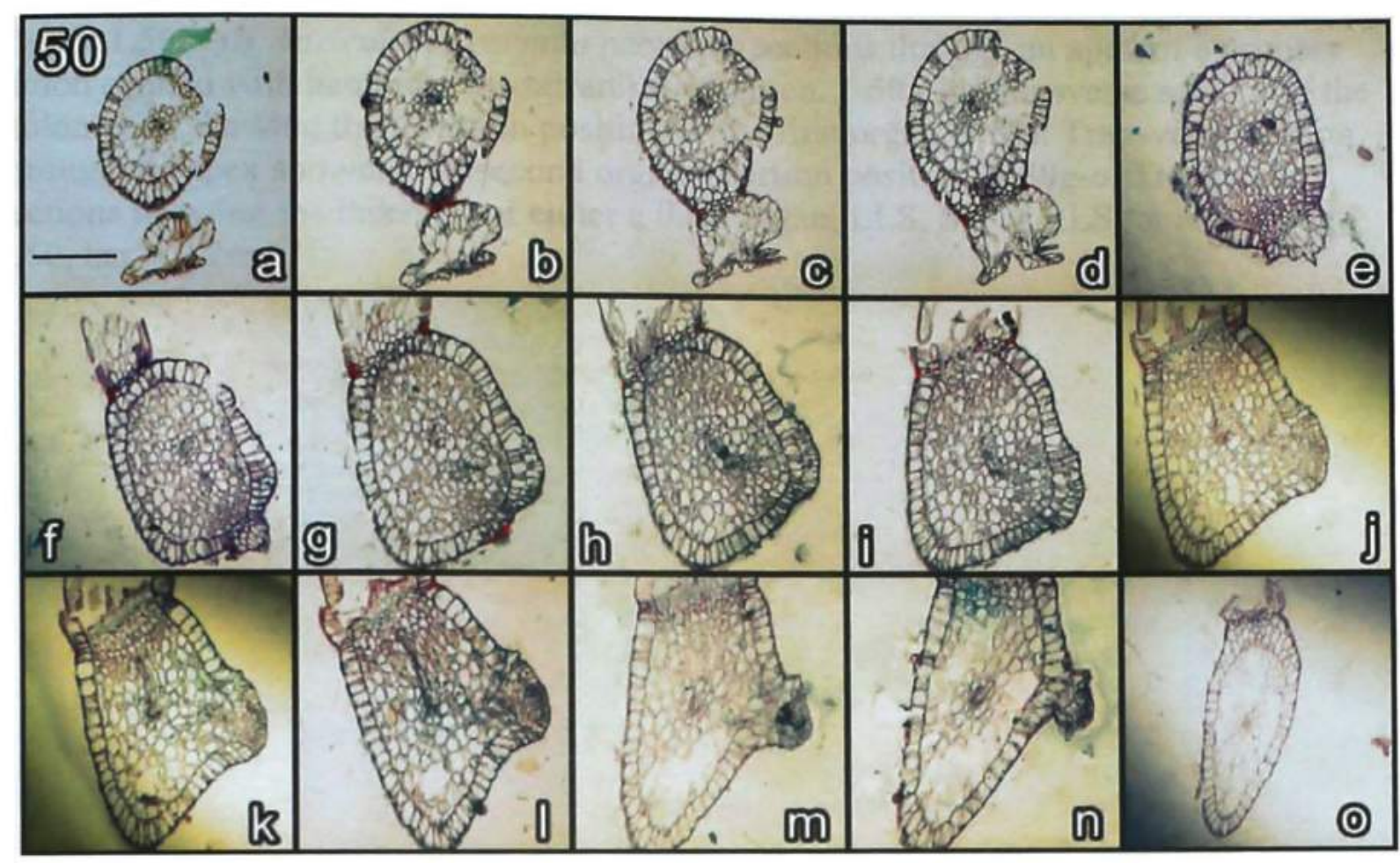




\section{Plate 1.10}

Figure 1.50(a-o). Utricularia cornuta paraplast sections through an apex of a primary stolon stained with hemotoxylin-safranin-fast-green. 1.50a-e. Transverse section of the stolon apex showing the insertion position of the first organ. 1.50f. Transverse section through the apex showing the second organ insertion position. 1.50g-o. Transverse sections showing the insertion of either a third organ, LLS, S2, or RLS, or a trap. Fig. 1.50 , bar $=0.2 \mathrm{~mm}$. 


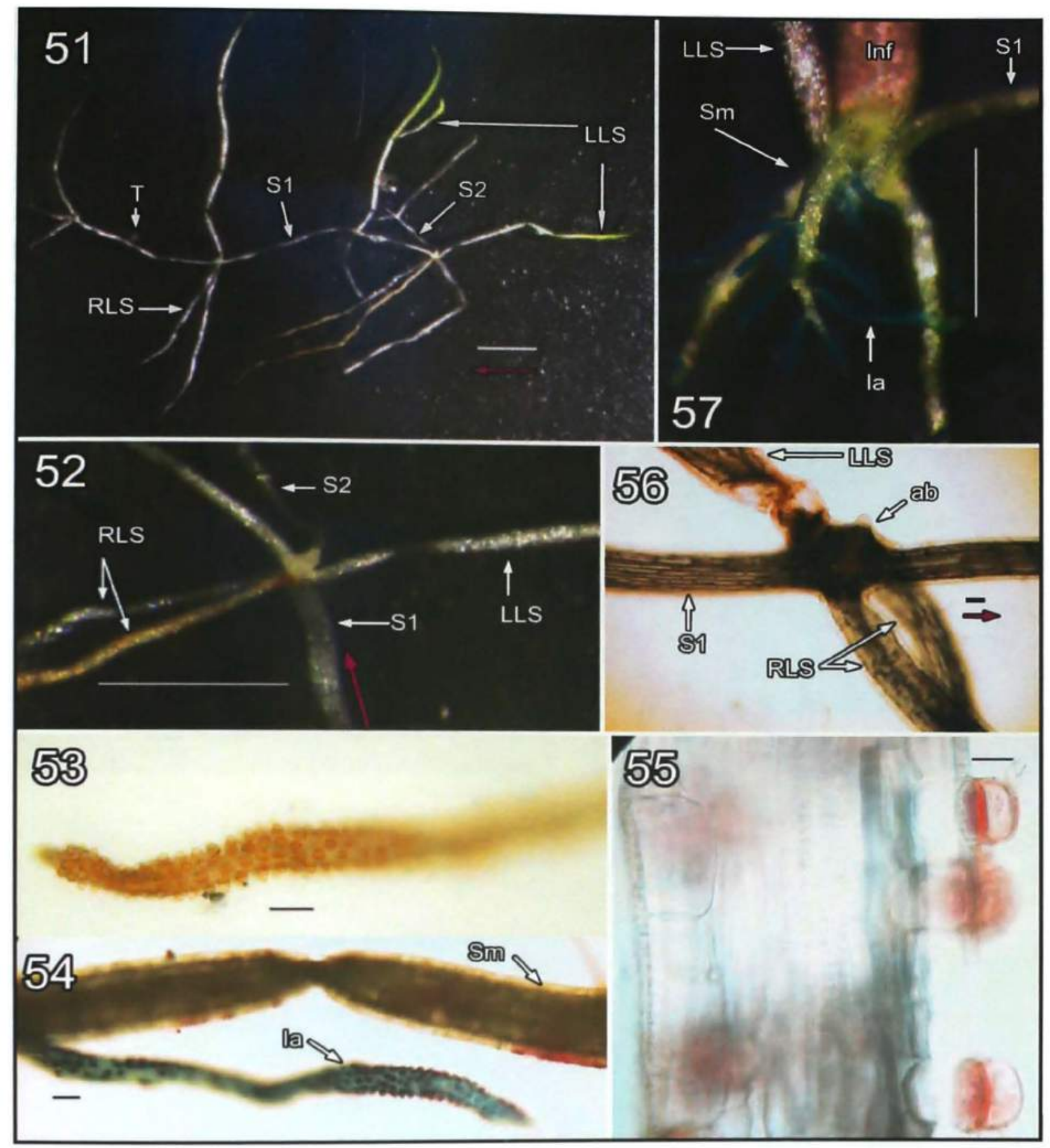




\section{Plate 1.11}

Figure 1.51-1.57. Utricularia subulata morphology. 1.51. Plant segment and lateral organs. One of the LLS has branched; a rare occurrence. 1.52. A S2 inserted on the S1 in the axil of a LLS. 1.53. Ia dyed with Sudan IV. 1.54. Sm with Ia dyed with toluidine blue. 1.55. Glandular projections dyed with Sudan IV. The central cell shows suberized tissue. 1.56. A nodal area with an axillary bud in the axil of a LLS. 1.57. Inflorescence in the axil of a LLS. Sm with lateral Ias forming at the base of the Inf. This plant was removed from the periphyton mat and was sitting in a dish of DI water for two days. No dye was applied but the Ias turned blue. Figs. 1.51-1.52, 1.56-1.57, bar = 1mm; Figs. 1.53-1.55 bar $=0.05 \mathrm{~mm}$. Figure abbreviations: Ia, inflorescence appendage; Inf, inflorescence; LLS, leaf-like structures; RLS, rhizoid-like structures, S1, primary stolon; S2, secondary stolon; Sm, modified stolon; pink arrow, direction of growth of S1. 


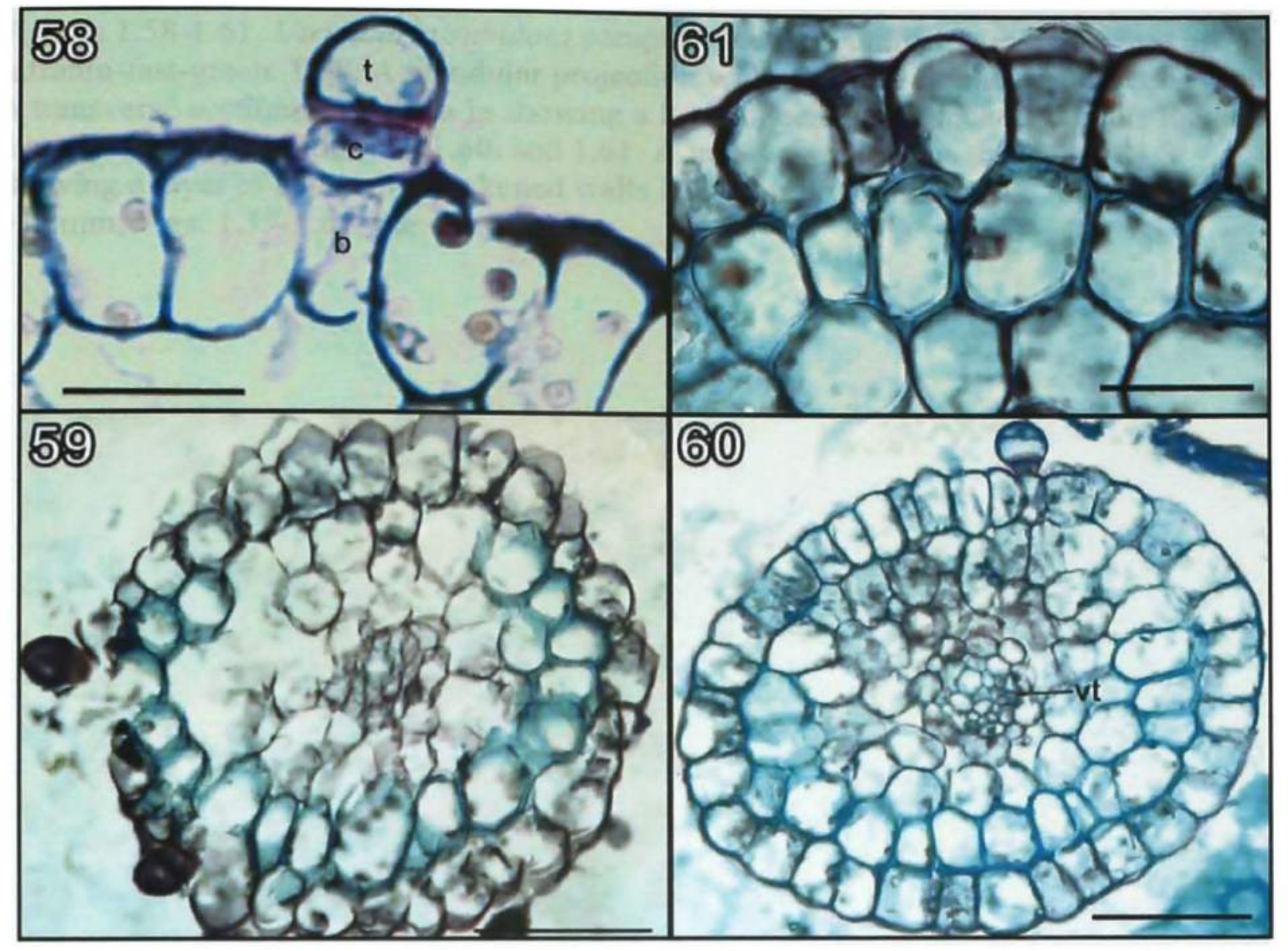




\section{Plate 1.12}

Figures 1.58-1.61. Utricularia subulata paraplast sections stained with hemotoxylinsafranin-fast-green. 1.58. A glandular projection with the three characteristics cells. 1.59. A transverse section through an Ia showing a layer of cells with thickened walls located directly below the epidermis. 1.60. and 1.61. A transverse sections through a RLS showing a layer of cells with thickened walls and central vascular tissue. Fig. 1.58, bar = $0.02 \mathrm{~mm}$; Figs. $1.59-1.61, \mathrm{bar}=0.05 \mathrm{~mm}$. 


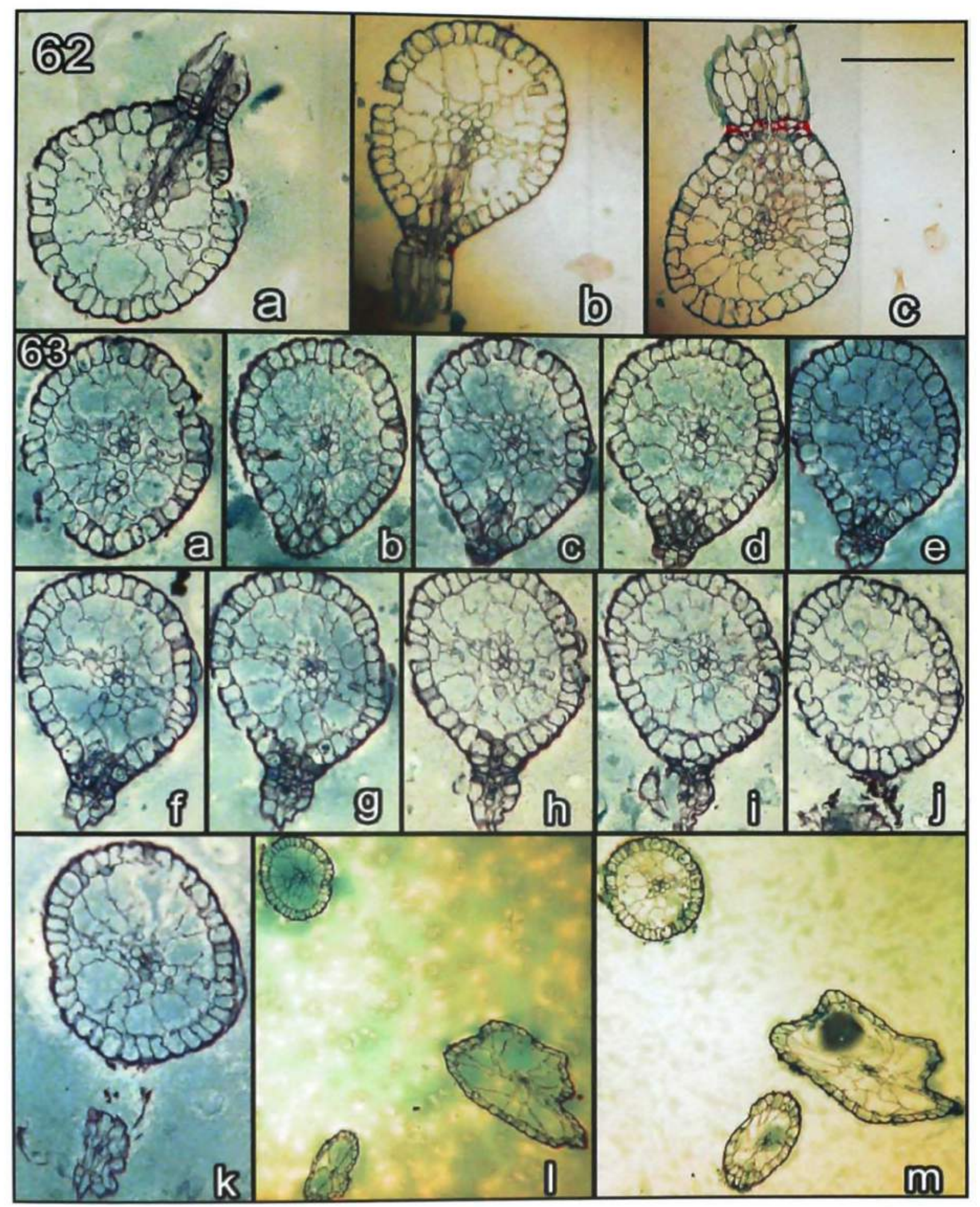




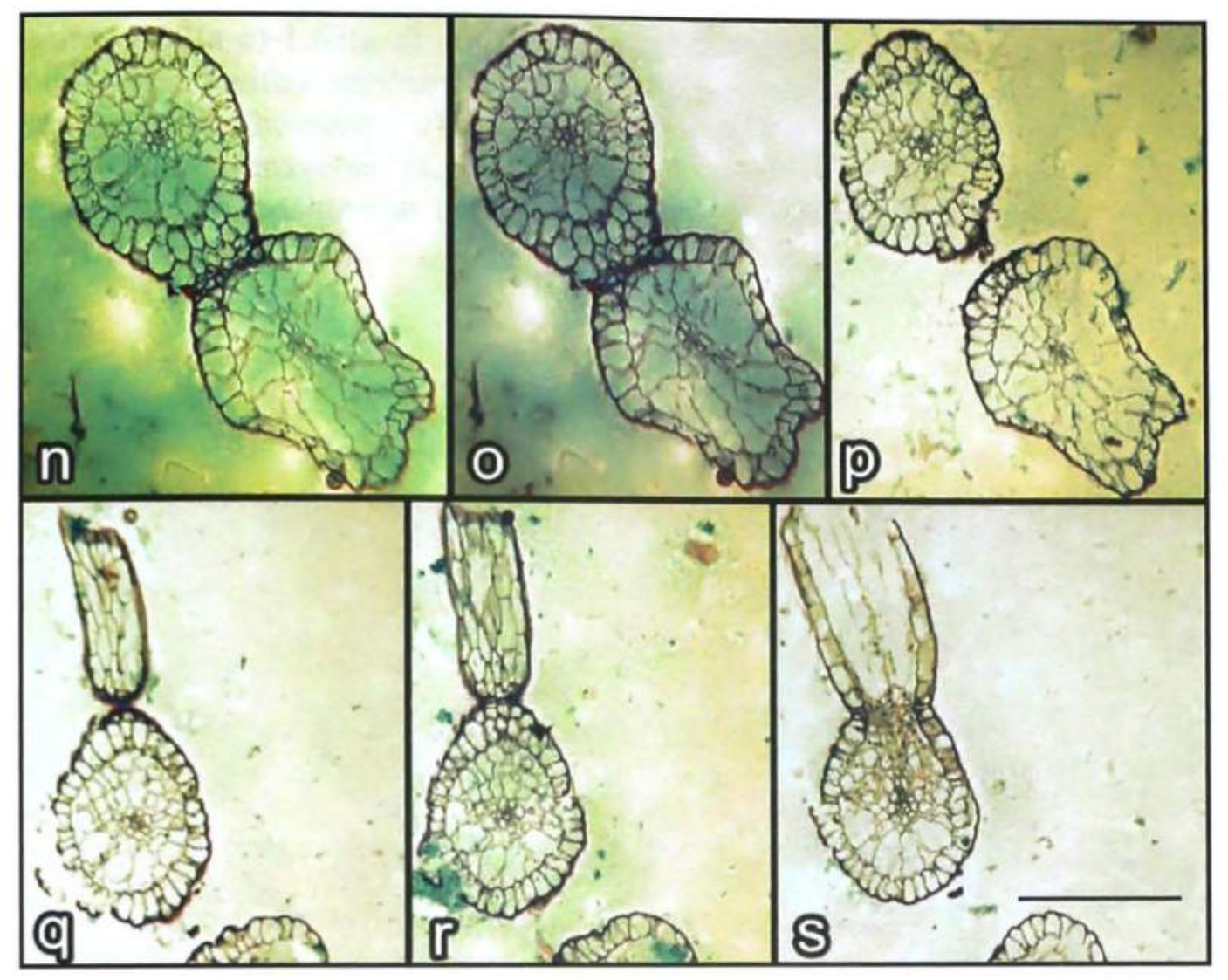




\section{Plates 1.13 and 1.14}

Figures 1.62(a-c)-1.63(a-s). Utricularia subulata paraplast sections through the primary stolon stained with hemotoxylin-safranin-fast-green. 1.62a-c. Transverse sections through a mature node showing the order of organ insertion pattern as RLS (a) -RLS (b) -LLS (c). 1.63a-s. Transverse sections through the apex of the primary stolon showing the organ insertion position at the first node as RLS (a-j), RLS (k-p), and LLS (q-s). Fig. $1.62-1.63$, bar $=0.2 \mathrm{~mm}$. 


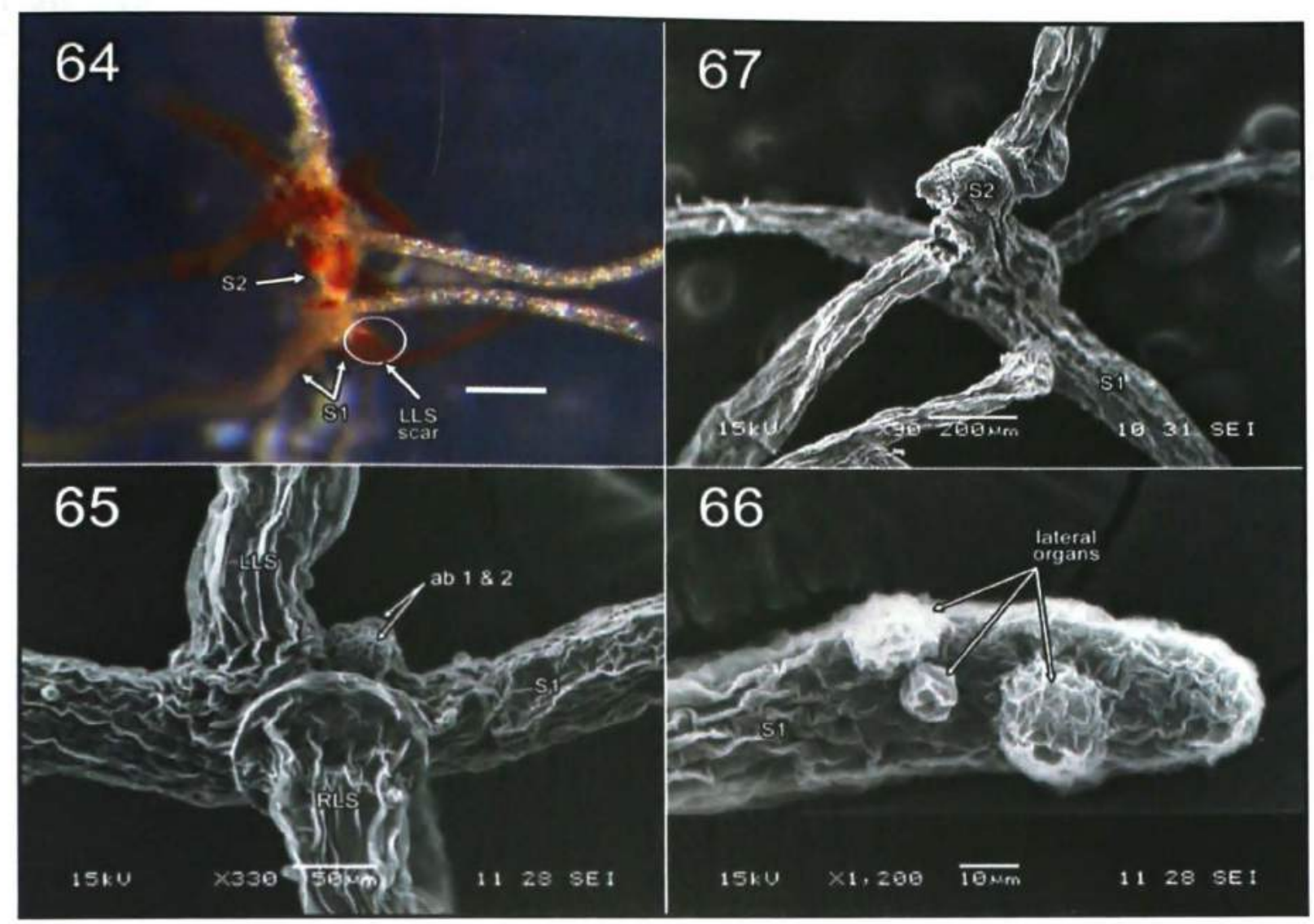




\section{Plate 1.15}

Figures 1.64-1.67. Morphology of $U$. subulata and $U$. cornuta. 1.64. S2 with condensed internodes in the axil of a LLS scar. The condensed S2 initiates organs in a similar pattern to the primary stolon but the condensed internodes cause its appearance to resemble a small rosette. 1.65. SEM of multiple axillary buds in the axil of the LLS of $U$. subulata. 1.66. Terminal tip of $U$. subulata indicating early lateral organ positions. 1.67. $U$. cornuta nodal region. A S2 is located in the axil of a LLS. Fig. 1.64, bar $=1 \mathrm{~mm}$. Figure abbreviations: ab, axillary bud; LLS, leaf-like structures; RLS, rhizoid-like structures S1, primary stolon; S2, secondary stolon. 


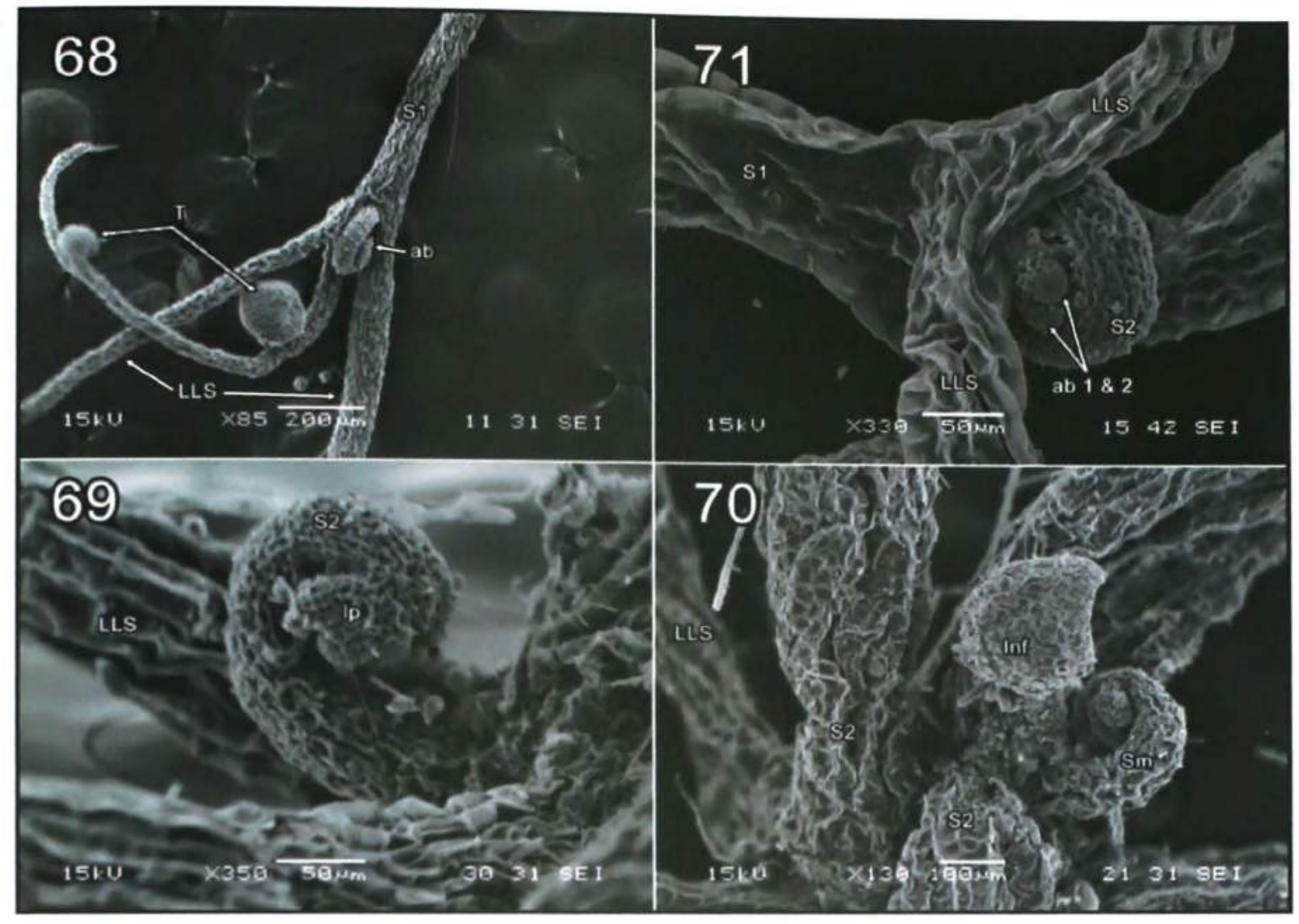




\section{Plate 1.16}

Figures 1.68-1.71. SEM pictures of $U$. gibba. 1.68. Axillary bud in the axil of a LLS. 1. 69. Secondary stolon in the axil of a LLS. 1.70. Young inflorescence in the axil of a LLS. The inflorescence is surrounded by stolons that have formed first in the axil of the LLS. A modified stolon is forming from the inflorescence tissue. 1.71. Multiple axillary buds in the axil of a LLS. Figure abbreviations: ab, axillary bud; Inf, inflorescence; lp, leaf primordium, LLS, leaf-like structures; S1, primary stolon; S2, secondary stolon; Sm, modified stolon; T, trap. 


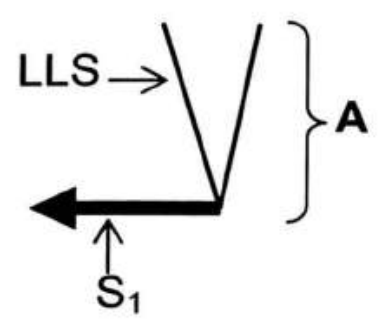

13

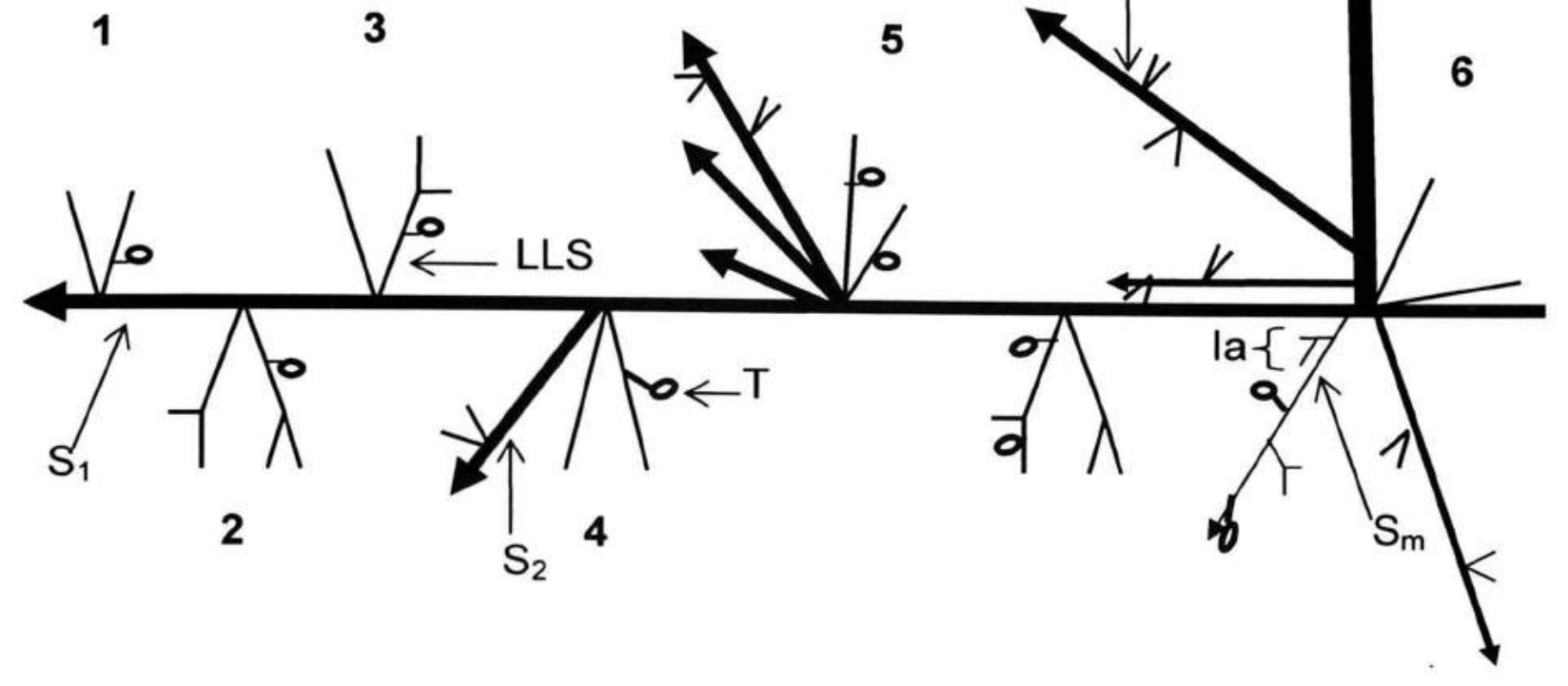

Figure 1.72. Model of Utricularia gibba. A represents the simplest unit of $U$. gibba in a plant segment. Multiples of these simple units combine together to make a plant segment. Steps 1-6 represent the possible modifications of unit A found in $U$. gibba plants. The arrow points indicate the locations of plant apices and the direction of growth. The basic unit of the plant (A and step 1) consists of a primary stolon and one LLS branched dichotomously once. Modifications include: additional dichotomous branching of the terminal ends of the LLS (steps 2 and 3), the presence and outgrowth of an axillary bud (step 4), the presence and outgrowth of multiple axillary buds (step 5), and the presence of an inflorescence (step 6). Two types of branches arise off of the inflorescence peduncle, one, the secondary stolon (S2), a reiteration of the primary stolon (S1) and the second, the modified stolon (Sm), a stolon with unique lateral organs, inflorescence appendages (Ia), and traps. 


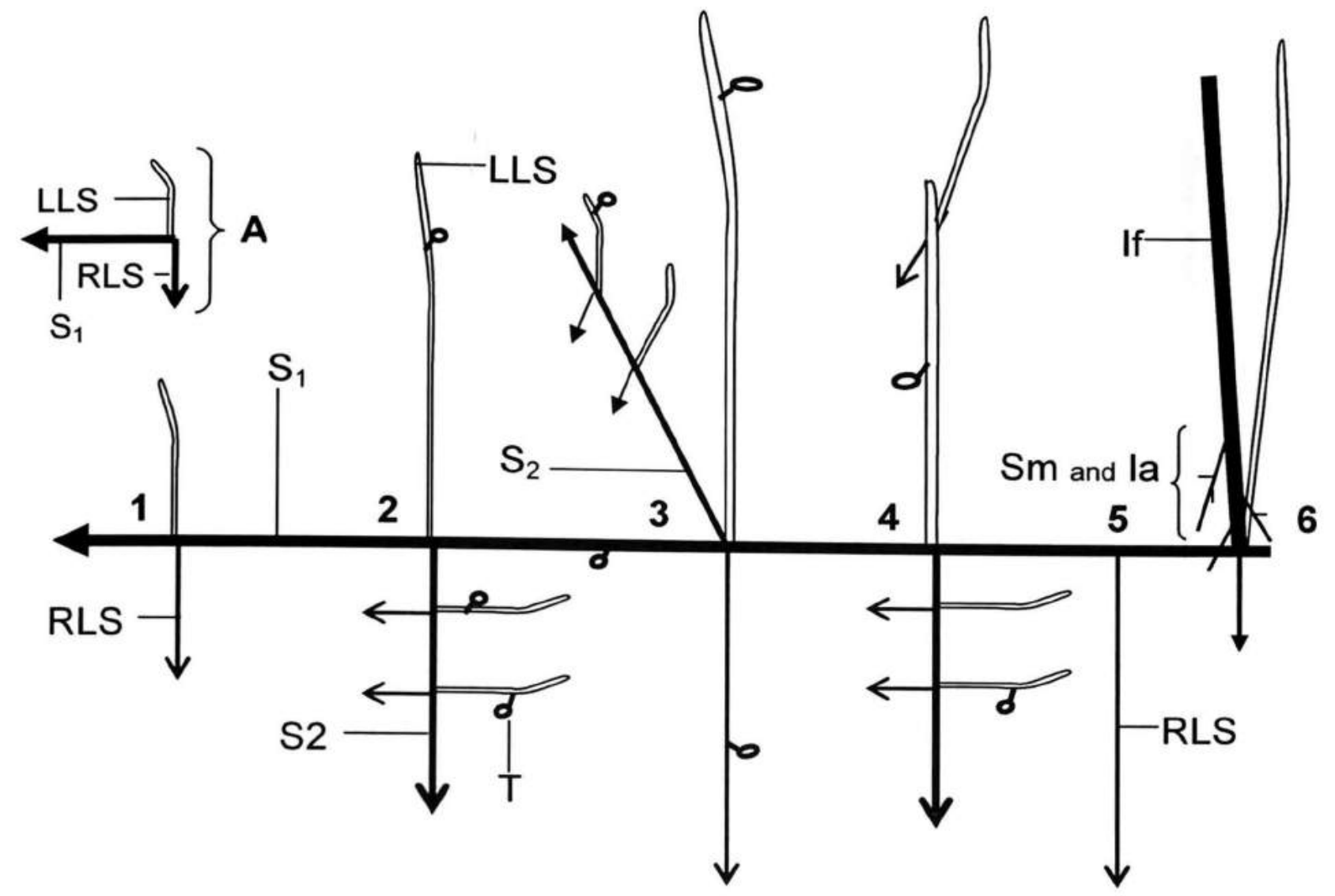

Figure 1.73. Model of Utricularia cornuta. A represents the simplest unit of $U$. cornuta in a plant segment. Multiples of these simple units combine together to make a plant segment. Steps 1-6 represent the possible modifications of unit A found in $U$. cornuta plants. The arrow points indicate the locations of plant apices and the direction of growth. The basic unit of the plant (A and step 1) consists of a primary stolon and one LLS and one RLS. Modifications include: a secondary stolon (S2) in (step 2), the presence of a secondary stolon (S2) in the LLS axis (step 3), the production of a LLS and/or RLS from another LLS (step 4), a RLS located in the internode region of the primary stolon (step 5), and the presence of an inflorescence in the axil of the LLS (step 6). Modified stolons arise from the base of the inflorescence peduncle and bear inflorescence appendages (Ia). 

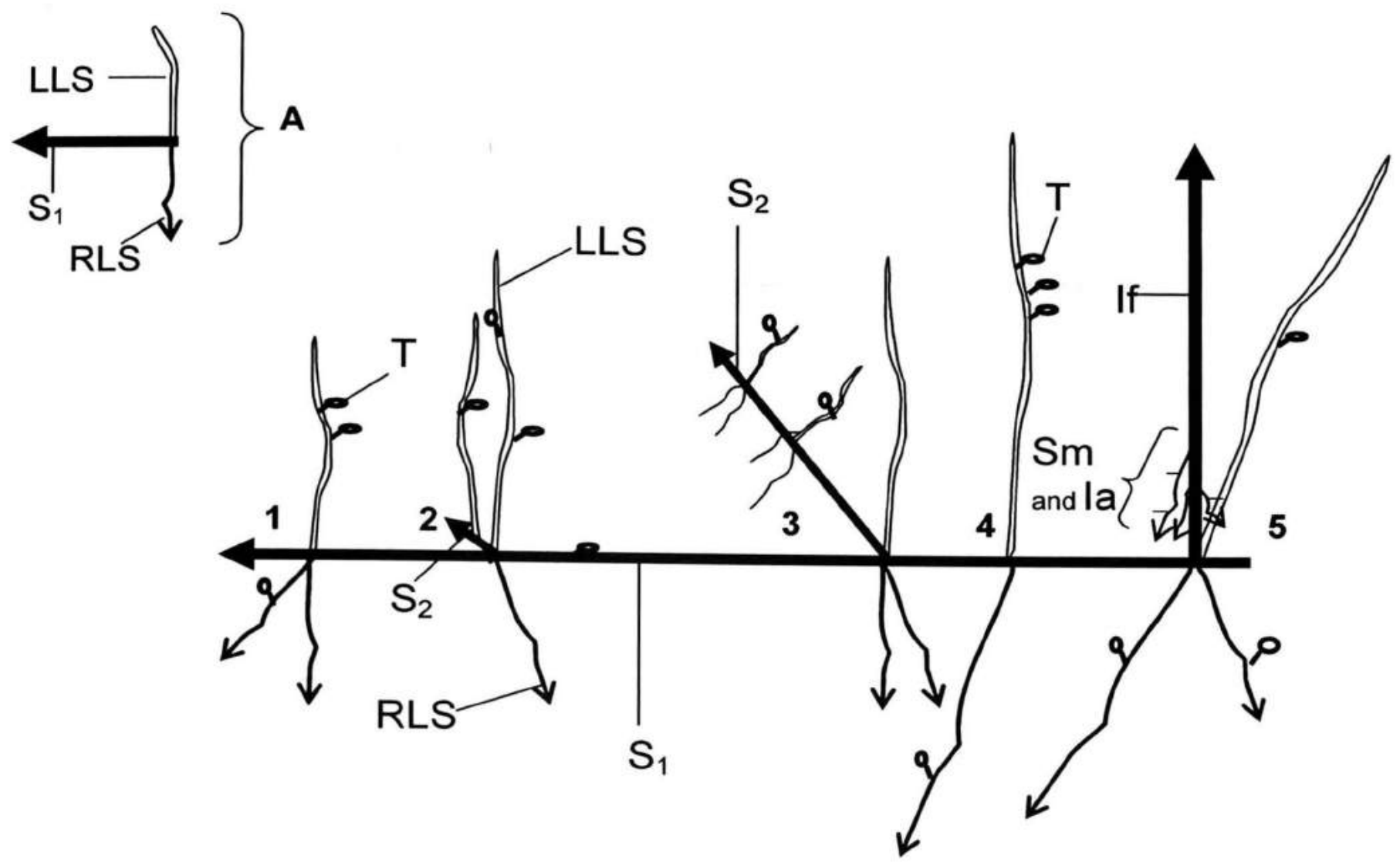

Figure 1.74. Model of Utricularia subulata. A represents the simplest unit of $U$. subulata in a plant segment. Multiples of these simple units combine together to make a plant segment. Steps 1-5 represent the possible modifications of unit A found in $U$. subulata plants. The arrow points indicate the locations of plant apices and the direction of growth. The basic unit of the plant (A) consists of a primary stolon and one LLS and one RLS. Modifications include: an additional rhizoid at present at the node (step 1), a secondary stolon (S2) located in the axil of the LLS (step 2 and 3), and the presence of an inflorescence in the LLS axil (step 5) Modified stolons (Sm) arise from the base of the inflorescence with inflorescence appendages (Ia). 

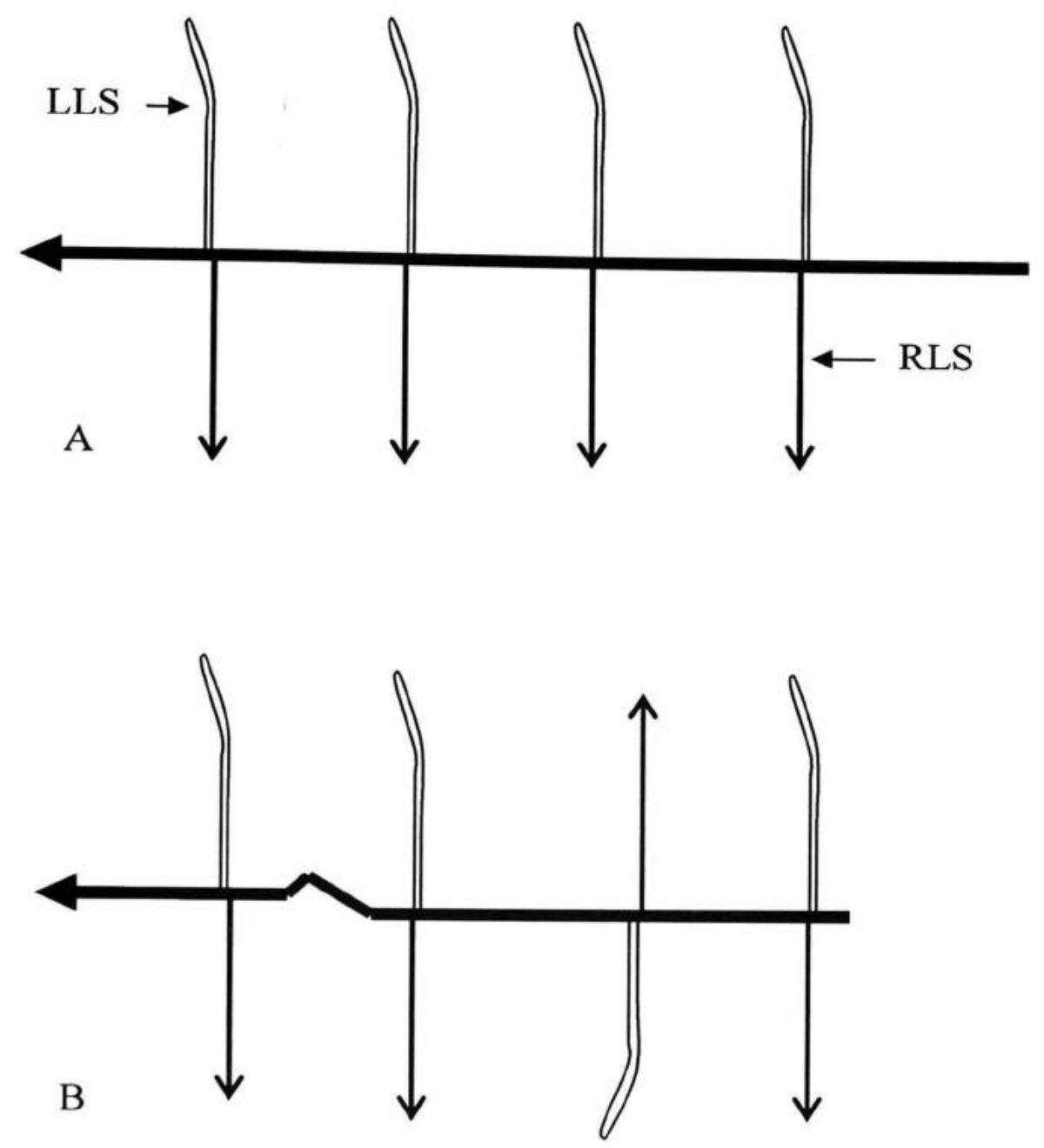

Figure 1.75. Hypothetical growth models for Utricularia cornuta

a. The primary stolon never twists and the LLS are always initiated on the side of the stolon facing towards the light. The fate of the organs is determined by

environmental variables. b. The LLS are initiated in with an alternating phylotaxis but the LLS grow toward the light, causing the stolon to twist (bend in stolon) and the LLS to appear on the side of the stolon facing the light. 


\section{LITERATURE CITED}

ARBER, A. 1920. Water Plants: a study of aquatic angiosperms. University Press, Cambridge, United Kingdom.

ALBERT, V. A., S. E. WILLIAMS, and M. W. CHASE. 1992. Carnivorous plants: phylogeny and structural evolution. Science 257: 1521-1525.

BERLYN, G. P. and J. P. MIKSCHE. 1976. Botanical microtechnique and cytochemistry. The Iowa State University Press, Ames, Iowa, USA.

BYRNE, M. E., C. A. KIDNER, and R. A. MARTIENSSEN. 2003. Plant stem cells: divergent pathways and common themes in shoots and roots. Current Opinion in Genetics \& Development 13: 551-557.

FINERAN, B. A. 1985. Glandular trichomes in Utricularia: a review of their structure and function. Israel Journal of Botany 34: 295-330

GREILHUBER, J. T. BORSCH, K. MÜLLER, A. WORBERG, S. POREMBSKI, and W. BARTHLOTT. 2006. Smallest angiosperm genomes found in Lentibulariaceae with chromosomes of bacterial size. Plant Biology 8: 770-777.

GODFREY, R. K. and J. W. WOOTEN. 1981. Aquatic and Wetland Plants of the Southeastern United States, 681-696. The University of Georgia Press, Athens, Georgia, USA.

GOEBEL, K. I. E. 1891. Morphologische und biologische Studien V. Utricularia. Annales du Jardin botanique de Buitenzorg 9: 41-119.

HARRIS, J. G. and M. W. HARRIS. 2001. Plant Identification Terminology: An Illustrated Glossary. Spring Lake Publishing, Payson, Utah, USA.

HARRISON, C. JILL, S. B. CORLEY, E. C. MOYLAN, D. L. ALEXANDER, R. W. SCOTLAND, and J. A. LANGDALE. 2005. Independent recruitment of a conserved developmental mechanism during leaf evolution. Nature 434: 509-514.

HOFER, J.M. C. W. GOURLAY, A. MICHAEL, and T. H. ELLIS. 2001. Expression of a class 1 Knottedl-like homeobox gene is down-regulated in pea compound leaf primordial. Plant Molecular Biology 45: 387-398.

JACKSON, D. B. VEIT, and S. HAKE. 1994. Expression of maize Knottedl related homeobox genes in the shoot apical meristem predicts patterns of morphogenesis in the vegetative shoot. Development 120: 404-413. 
JOBSON, R. W. and V. A. ALBERT. 2002. Molecular rates parallel diversification contrasts between carnivorous plant sister lineages. Cladistics 18: 127-136.

JOBSON, R. W., R. NIELSON, L. LAAKKONEN, M. WIKSTROM, and V.A. ALBERT. 2004. Adaptive evolution of cytochrome $c$ oxidase: Infrastructure for a carnivorous plant radiation. Proceedings of the National Academy of Sciences 101 52): 18064-18068.

JOBSON, R. W., J. PLAYFORD, K. M. CAMERON, and V. A. ALBERT. 2003. Molecular phylogenetics of Lentibulariaceae inferred from plastid $r p S 16$ intron and $t r n$ L-F DNA sequences: Implications for character evolution and biogeography. Systematic Botany 28(1): 157-171.

JUNIPER, B. E., R. J. ROBINS, and D. M. JOEL. 1989. The carnivorous plants, 3-353. Academic Press Ltd, London, United Kingdom.

KONDO, K. 1972. A comparison of variability of Utricularia cornuta and Utricularia juncea. American Journal of Botany. 59: 23-37.

KUMAZAWA, M. 1967. An experimental study on the seedling of Utricularia pilosa Makino. Phytomorphology. 17: 524-528.

LINCOLN, C. J. LONG, J. YAMAGUCHI, K. SERIKAWA, and S. A. HAKE. 1994. Knottedl-like homeobox gene in Arabidopsis is expressed in the vegetative meristem and dramatically alters leaf morphology when overexpressed in transgenic plants. Plant Cell 6: 1859-1876.

LLOYD, F. E. 1929. The mechanism of the water tight door of the Utricularia trap. Plant Physiology. 4(1): 87-102.

LLOYD, F. E. 1935. Utricularia rendlei, a new species from Victoria Falls. The Journal of Botany. 73: 40-42.

LLOYD, F. E. 1942. The Carnivorous Plants. Chronica Botanica, Vol. 9. Ronald Press, New York, USA.

MÜLLER, K., T. BORSCH, L. LEGENDRE, S. POREMBSKI, and W. BARTHLOTT. 2006. Recent progress in understanding the evolution of carnivorous Lentibulariaceae. Plant Biology 8: 748-757.

MÜLLER, K., T. BORSCH, L. LEGENDRE, S. POREMBSKI, I. THEISEN and W. BARTHLOTT. 2004. Evolution of carnivory in Lentibulariaceae and the Lamiales. Plant Biology 6: 477-520. 
MÜLLER, K. and T. BORSCH. 2005. Phylogenetics of Utricularia (Lentibulariaceae) and molecular evolution of the trnK intron in a lineage with high substitutional rates. Plant Systematics and Evolution 250: 39-67.

RICHARDS, J. H. 2001. Bladder function in Utricularia purpurea (Lentibulariaceae): is carnivory important? American Journal of Botany 88: 170-176.

RUTISHAUSER, R. and B. ISLER. 2001. Developmental genetics and morphological evolution of flowering plants, especially bladderworts (Utricularia): Fuzzy Arberian morphology complements classical morphology. Annals of Botany 88: 1173-1202.

RUTISHAUSER, R. and R. SATTLER. 1989. Complementarity and heuristic value of contrasting models in structural botany III. Case study of shoot-like 'leaves' and leaf-like 'shoots' in Utricularia macrorhiza and U. purpurea (Lentibulariaceae). Botanische Jahrbücher für Systematik, Pflanzengeschichte und Pflanzengeographie 111: 121-137.

SALMON. B. 2001. Carnivorous Plants of New Zealand. Ecosphere Publications, Auckland, New Zealand.

SATTLER, R. and R. RUTISHAUSER. 1990. Structural and dynamic descriptions of the development of Utricularia foliosa and $U$. australis. Candian Journal of Botany 68: 1989-2003.

SYDENHAM, P. H. and G. P. FINDLAY. 1973. The rapid movement of the bladder of Utricularia sp. Australian Journal of Biological Sciences 26: 1115-1126.

STOBER, Q. J., K. THORNTON, R. JONES, J. RICHARDS, C. IVEY, R. WELCH, M. MADDEN, J. TREXLER, E. GAISER, E. SCHEIDT and S. RATHBUN. 2001. South Florida Ecosystem Assessment: Phase I/II. Everglades stressor interactions: Hydropatterns, eutrophication, habitat alteration, and mercury contamination (Summary). United States Environmental Protection Agency, Region 4 Science and Ecosystem Support Division, Water Management Division and Office of Research and Development, Athens, Georgia, USA, EPA 904-R-01-002.

TAYLOR, P. 1989. The genus Utricularia. Kew Bulletin Series XIV. 1-724. Her Majesty's Stationery Office: London, Uni ted Kingdom.

THE INSTITUTE FOR REGIONAL CONSERVATION. Floristic inventory of South Florida Database Online. 2001. Institute for Regional Conservation. April 6, 2007. [http://regionalconservation.org/ircs/DatabaseChoice.asp]

USDA, NRCS. 2007. The PLANTS Database (http://plants.usda.gov, 19 May 2007). National Plant Data Center, Baton Rouge, LA 70874-4490 USA. 


\section{Chapter 2}

A key for the Utricularia species of southern Florida using vegetative and floral characteristics 


\section{INTRODUCTION}

Utricularia is a large genus of aquatic plants with a worldwide distribution and the ability to grow in various habitats. Taylor (1989) divides the genus into distinct habitat types: aquatic ( $27 \%$ of the species), terrestrial ( $67 \%$ of the species), and epiphytic, lithophytic, or rheophytic ( $13 \%$ of the species). There is some overlap between these potential habitats types, since some of the species are able to grow in multiple habitats. For example, a terrestrial species can usually grow in the benthos mimicking the habitat of a full aquatic or an aquatic species may be able to grow as an epiphyte in a moist, mossy area (Taylor 1989). A large number of the species within this genus are classified as terrestrials; a description that is somewhat misleading since these species still require moist soils to grow and can grow if submerged under water.

Eleven native species of Utricularia, including both aquatic and terrestrial representatives, are found in South Florida. The occurance of these species ranges from abundant to rare with one species, U. amethystina, possibly extirpated (IRC, 2007). The aquatic representatives can be found growing either as floating aquatics located on the water surface or as submerged aquatics growing below the water surface without being attached to the substrate. Some of aquatic species can also grow as attached or affixed aquatics. The aquatic species are found in, but are not necessarily limited to, deeper water, such as canals, sloughs, or lakes. The terrestrial are found growing embedded in moist soils and the periphyton mat and are typically located growing in moist, boggy, or swampy areas with shorter hydroperiods than the areas in which the aquatics taxa occur.

Utricularia species are known for their carnivorous ability and ambiguous morphology. None of the species has true roots, even in the embryonic stage, and the 
plant body is composed of a highly branched main axis (Lloyd 1942, Taylor 1989). This main axis grows horizontally and is often referred to as a stolon (Taylor 1989). Lateral structures resembling leaves arise from the primary stolon but cannot be labeled as true leaves because they often lack the necessary defining characteristics. However, some of the lateral structures are photosynthetic and have axillary buds causing them to resemble leaves somewhat in their structure and physiology. Thus, they are referred to as leaf-like structures in this key. The terrestrial species often have a second type of lateral structure that is non-photosynthetic and is referred to as rhizoid-like structures in this key. The aquatic species do not have rhizoid-like structures but instead have organs termed airshoots: long, non-photosynthetic, stem-like organs arising either at the node or along the internode structure (Taylor 1989, Richards 2001, Sattler and Rutishauser 1990).

Most of the species in southern Florida differ in the specific characteristics of the leaf-like structures and the rhizoid-like structures and therefore can be distinguished using these vegetative characteristics. The less frequently encountered Utricularia species are an exception and require floral or trap characteristics for identification. Utricularia floral characteristics are typical of angiosperms: the inflorescence is usually an axillary raceme, sometimes reduced to one flower; the flowers have a two-lobed corolla with the lower lip more complex than the upper as it has a spur of various shapes; and the calyx consists of two accrescent lobes in all Utricularia species, except the subgenus Polypompholyx (Taylor 1989). Each Utricularia flower is subtended by a bract, usually with species-specific morphology that makes it a feature often used in keys to distinguish between closely related species. The style is also bilabiate; usually an unevenly divided stigma and a pair of two curved stamens are present in all flowers 
(Taylor 1989). Taylor (1989) gives a more detailed description of all Utricularia species morphology.

Carnivory in Utricularia is made possible by complex suction traps located on the leaf-like structures in the aquatic species and reportedly on all organs in the terrestrial species (Lloyd 1942). The traps are small, globose structures that have various external appendages important for species identification. Each trap functions by actively expelling water to create an internal lumen with negative pressure. The traps are activated mechanically when small organisms strike external trigger hairs (Lloyd 1942).

Previous studies have documented that vegetative morphology varies with environmental conditions (Kondo 1972, Reut and Fineran 2000, Richards 2001), making it necessary to document local vegetative and floral characteristics for identification of each species. This key was created to supplement the current identification resources by providing species delimitation based primarily on the vegetative structures and using floral structures only when necessary. Its use is appropriate to facilitate correct identification of the Utricularia species found in southern Florida from Dade, Monroe, Collier, and Lee counties.

\section{MATERIALS AND METHODS}

Literature search: A literature search was done to compare the current morphological descriptions and keys available for Utricularia species. Three guides are available that describe the genus Utricularia in southern Florida. These include The Genus Utricularia, by Peter Taylor (1989); Aquatic and Wetland Plants of the Southeastern United States, by R. K. Godfrey and J.W. Wooten (1981); and a Guide to the Vascular Plants of Florida, by R.P. Wunderlin and B.F. Hansen (2003). 
Plant observations: Species were collected from or observed at several field locations (Table 2.1) and their morphological characters were recorded. Field collections, field observations, and/or herbarium specimen observations were made of $U$. cornuta, $U$. foliosa, U. gibba, U. inflata, U. purpurea, U. radiata, U. resupinata, and U. subulata. The characteristics of $U$. juncea, $U$. simulans, and $U$. amethystina were observed from herbarium specimens (FTG and NY). Characteristics of herbarium plants were recorded for all South Florida Utricularia taxa located at Fairchild Tropical Botanic Gardens herbarium (FTG). The structures observed on the field collected plants and the herbarium specimens were compared with written descriptions and phenotypic measurements were taken if necessary to distinguish between two species. Specifically, measurements were taken of specimens of $U$. radiata, $U$. inflata, $U$. cornuta, and $U$. juncea (FTG). Quantitative data taken included the number of flowers per inflorescence (U. cornuta and U. juncea) and the number of segments and the diameter of the whorl of inflated vegetative structures surrounding the inflorescence penduncle (U. radiata and $U$. inflata). The flowering times and county of collection for each specimen was recorded for all Utricularia specimens.

\section{RESULTS}

\section{A key for the Utricularia species of southern Florida using vegetative and floral characteristics}

1. Plants free-floating or partially submerged aquatics, primary stolon containing chloroplasts, green to brownish

2. aquatic, often floating, plants with a whorl of inflated, star-shaped floats around the inflorescence peduncle, primary plant axis producing feathery, leaf-like structures arranged alternately 
3. floating whorl $7-14 \mathrm{~cm}$ in diameter, each leaf-like structure divided into two primary segments and then further dichotomously divided numerous times, dichotomous branching into two equal divisions with further branching unequal

U. inflata

3. floats $3-5 \mathrm{~cm}$ in diameter, each leaf-like segment divided into two primary segments with equal divisions with continued dichotomous branching

$U$. radiata

2. floating plants lacking an inflated whorl of star-shaped floats, leaf-like structures arranged either in a whorl or alternately along the primary axis, plant apex circinnate or mucilaginous

4. leaf-like structures whorled, verticillate, and ultimate divisions terminating in a trap; mature plants often brownish or tan

U. purpurea

4. leaf-like structure does not terminate in a trap, traps dispersed along leaf-like structures

5. leaf-like structures dimorphic, one portion nonphotosynthetic and trap-bearing, one portion photosynthetic with many fewer traps, primary plant stolon flattened, $1-4 \mathrm{~mm}$ in diameter, plant mucilaginous and plants usually bright green in mature parts

U. foliosa

5. leaf-like structure not dimorphic, all dichotomously divided and bearing traps, traps green to black, plants light green to pale, occurring in intertwined mats to single thread-like filaments, primary stolon $0.2-0.4 \mathrm{~mm}$ in diameter, not mucilaginous

U. gibba

1. Plants terrestrial with main portion embedded in the soil or periphyton mat, most species with the primary stolon lacking chloroplasts

6. plants thread-like, apex circinnate, stolon and leaf-like structures with chloroplasts, leaf-like structures dichotomously divided, traps located only on the leaf-like structures

U. gibba

6. plants with primary stolon lacking chloroplasts, apex not circinnate, leaf-like structures the only part of the plant with chloroplasts 
7. traps lacking appendages surrounding the doorway, instead with an elongated lip, leaf-like structures linear and grass-like in appearance, plant body forming dense mat that can grow in moist soils or under shallow water, leaf-like structures linear

8. calyx $4.5-7 \mathrm{~mm}$, corolla $1.5-2 \mathrm{~cm}$, inflorescence 1-6 flowers

U. cornuta

8. calyx $2.5-4 \mathrm{~mm}$, corolla $.25-1.5 \mathrm{~cm}$, inflorescence $1-12$ flowers

U. juncea

7. traps with obvious, branched appendages at the doorway, plant body very small

9. flowers light to deep purple, rarely white, leaf-like structures circinnate with articulations or spatulate in shape

10. leaf-like structures with circinnate apex, joints or articulations along the leaf-like structure, often traps forming at the joint, flowers light to deep purple, upper and lower lobe appearing resupinate

resupinata

10. leaf-like structures without a circinnate apex, leaf-like structures lacking joints or articulations and spatulate in shape, flowers light purple to white

$U$. amethystina

9. flowers yellow, light yellow, or rarely white, leaf-like structures linear

11. plants minute, leaf-like structures linear to spatulate, often with anthrocyanins in the tip, traps with only one type of appendage around the doorway

U. subulata

11. calyx lobes fimbriate, traps with two different types of appendages around the doorway, one appendage bifid and central, one appendage conical and on the dorsal part of the doorway

U. simulans 


\section{Species description}

U. amethystina Salzm. ex A. St. Hil\& Firard. Florida Purple Bladderwort

Small to medium sized, terrestrial, growing embedded in soils or sandy areas, probably annual or possibly perennial, numerous rhizoids present; leaf-like structures: mostly seen forming a small rosette at the base of the inflorescence, occasionally seen spaced along the stolon, petiolate with a lamina, not linear, spatulate to orbicular, $2.5-3.5 \mathrm{~mm}$ in length; traps: present on all vegetative organs, trap appendages like thick horns covered in long, glandular hairs, the base of the stalk facing the doorway also covered with the long, glandular hairs; inflorescence: erect and surrounded by a rosette of leaf-like structures and rhizoids, $4.5-12.5 \mathrm{~cm}$ tall in Florida collections, several flowers per inflorescence; flowers: purple to white (possibly yellow), subtending bracts connate. Rare, possibly extinct in Florida, herbarium collections from 1916 indicate that it was found in pine rockland soils close to Ft. Meyers, last seen in Collier County, 1946 (Taylor 1989, Wunderlin and Hansen 2003)

\begin{tabular}{|l|l|l|l|l|l|l|l|l|l|l|l|l|}
\hline Flowering dates & J & F & M & A & M & J & J & A & S & O & N & D \\
\hline
\end{tabular}

\section{U. cornuta Michx. Horned Bladderwort}

Medium sized terrestrial, embedded in moist soils and/or the periphyton mat, perennial, plant segments composed of highly branched horizontal stolons, primary stolon lacking chloroplasts, numerous rhizoids and leaf-like structures, traps present on all organs; leaflike structures: linear, green and phototrophic with hair-like organs and traps at the base, appear opposite additional stolons or rhizoid-like structures, traps: lack branched appendages, instead having an elongated lip, lip often with anthrocyanins; inflorescence: axillary, erect with anthrocyanins in peduncle, 1-4-(6) flowers crowded at the apex, numerous rhizoid-like structures at the base, highly variable in length; flowers: yellow, bilabiate with a long spur, spurs $8-13 \mathrm{~mm}$ in length. (Godfrey and Wooten 1981, Kondo 1972, Taylor 1989, Wunderlin and Hansen 2003) (Figs. 2.4, 2.8)

\section{\begin{tabular}{|l|l|l|l|l|l|l|l|l|l|l|l|l|} 
Flowering dates & J & F & M & A & M & J & J & A & S & O & N & D \\
\hline
\end{tabular}}

\section{U. foliosa L. Leafy Bladderwort}

Large, floating aquatic, annual or perennial, stolons flattened, photosynthetic, and mucilaginous, air shoots present at nodes; leaf-like structures: alternately arranged along the primary stolon, dimorphic, one with feathery, pinnately divided segments and only a few traps, the other lighter green in color with only a few segments covered with traps; traps: simple, short, sometimes one-branched appendages; inflorescence: axillary, erect, 3-(20) flowers localized at the tip; flowers: yellow, bilabiate; seeds: lenticular with a light colored wing and a dark center, surface smooth. (Godfrey and Wooten 1981, Sattler and Rutishauser 1990, Taylor 1989, Wunderlin and Hanson 2003) (Figs. 2.2-2.3, 2.10-2.11, 2.18)

\begin{tabular}{|l|l|l|l|l|l|l|l|l|l|l|l|l|}
\hline Flowering dates & J & F & M & A & M & J & J & A & S & O & N & D \\
\hline
\end{tabular}


U. gibba L. Humped Bladderwort

Small to medium sized, floating or attached aquatic or embedded in the soil or periphyton mat, annual or perennial, stolons thread-like, traps dispersed along the leaf-like structures, single thread-like plants floating either along or on another aquatic plant, multiple plants forming dense mats either floating or benthic and attached to the substrate, circinnate vernation; leaf-like structures: alternately arranged along the primary stolon, dichotomously branched 1-4 times into slender segments, tip appearing determinate; traps: globose structures with long and slender branched appendages, often contain anthrocyanins and appearing purple to black; inflorescence: axillary, sometimes branched, 1-2 flowered, one per branch; flowers: yellow with a reddish to brown spot on the hump of the lower lip; fruit: capsules producing 10-50 seeds; seeds: disk-shaped or lenticular with wings, the surface uneven and papillose. (Godfrey and Wooten 1981, Lloyd 1942, Taylor 1989, Wunderlin and Hanson 2003) (Figs. 2.5-2.7, 2.9)

\begin{tabular}{|l|l|l|l|l|l|l|l|l|l|l|l|l|}
\hline Flowering dates & J & F & M & A & M & J & J & A & S & O & N & D \\
\hline
\end{tabular}

\section{U. juncea Vahl. Southern Bladderwort}

Medium sized terrestrial, perennial, embedded in moist soils and/or the periphyton mat, plant segments composed of branched horizontal stolons, primary stolon lacking chloroplasts, traps present on all organs; leaf-like structures: linear, green and phototrophic, traps: lacking branched appendages, instead having an elongated lip, lip often with anthrocyanins; inflorescence: axillary, erect, 1-9 flowers dispersed along the upper portion of the raceme, the bottom flowers opening earlier; flowers: yellow, bilabiate with a long spur, spurs 5-8-(10)mm in length. (Godfrey and Wooten 1981, Kondo 1972, Taylor 1989, Wunderlin and Hanson 2003)

\section{\begin{tabular}{|l|l|l|l|l|l|l|l|l|l|l|l|l|}
\hline Flowering dates & J & F & M & A & M & J & J & A & S & O & N & D \\
\hline
\end{tabular}}

\section{U. inflata Walter. Floating Bladderwort}

Large floating to suspended aquatic, perennial, plant segments composed of an apically growing segment lacking rhizoids, a whorl of 5-6-(10) floats 7-14mm in diameter approximately halfway along the peduncle, floats support the erect inflorescence, air shoots present; leaf-like structures: alternately arranged along the primary stolon, repeatedly unequally branched into feathery segments; traps: located on the leaf-like structures, appendages branched, traps often larger than $1 \mathrm{~mm}$; inflorescence: erect from the floating whorl, 4-8-(12) flowers per inflorescence; flowers: yellow with brown marks and brown nerves; seeds: formed in downward-facing, recurved capsules. (Godfrey and Wooten 1981, Taylor 1989, Wunderlin and Hanson 2003) (Figs. 2.12, 2.16-2.17)

Flowering dates

\begin{tabular}{l|l|l|}
$\mathbf{J}$ & $\mathbf{F}$ & $\mathbf{M}$ \\
\hline
\end{tabular}

\begin{tabular}{l|l|l|l} 
M & A & M \\
\hline
\end{tabular}

\begin{tabular}{|l|l|l|}
\hline & J & A \\
\hline
\end{tabular}

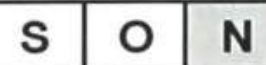




\section{U. purpurea Walter. Eastern Purple Bladderwort}

Medium to large, floating aquatics, perennials, plant segments composed of apically growing segments lacking rhizoids, apex of primary stolon and leaf-like structures strongly circinnate; leaf-like structures: whorls of leaf-like structures at every node, each whorl produces (4)-5-(6-7) leaf-like structures per whorl, ultimate leaflet segments terminate in traps; traps: only present in the terminal end of the leaflets, lack branched appendages but bearing long, glandular hairs at the door entrance, the hairs grouped into a fascicle; inflorescence: axillary, erect, 1-2 flowers at the apex; flowers: purple to white. (Godfrey and Wooten 1981, Richards 2001, Taylor 1989, Wunderlin and Hanson 2003) (Figs. 2.13-2.15)

Flowering dates
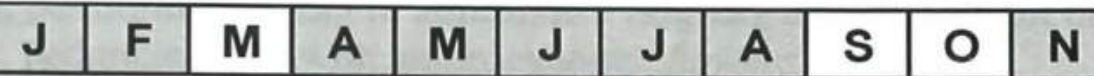

\section{D}

U. radiata Small. Little Floating Bladderwort

Small to medium, floating to suspended aquatics, annual or perennial, plant segments composed of an apically growing segment lacking rhizoids, a whorl of 4-8 floats 3-5mm in diameter, erect inflorescence supported by the whorl of floats; leaf-like structures: finely divided into two primary segments which are then dichotomously divided further; traps: only present on the leaf-like structures, with two long and branched door appendages; inflorescence: erect with approximately half of the peduncle above the floats and half of below the floats; flowers: 1-4 per inflorescence, yellow with brown marks on the lower lip. (Godfrey and Wooten 1981, Taylor 1989, Wunderlin and Hanson 2003)

\begin{tabular}{|l|l|l|l|l|l|l|l|l|l|l|l|l|}
\hline Flowering dates & J & F & M & A & M & J & J & A & S & O & N & D \\
\hline
\end{tabular}

U. resupinata B. D. Greene ex Bigelow. Lavender Bladderwort

Small to medium terrestrial, embedded in moist soils or periphyton mat, annual or perennial, plant segments composed of a horizontal stolon with leaf-like structures and numerous rhizoids; leaf-like structures: green, photosynthetic organs with circinnate vernation and articulations, or joints, along the length of the organ, traps often present growing at the joints or articulations; traps: trap appendages thin and branched several times; inflorescence: axillary with a purple peduncle, rarely more than one flower at apex, occasionally branched; flowers: solitary, dark purple, appearing resupinate, or with the upper corolla lip in the position of the lower lip (Godfrey and Wooten 1981, Taylor 1989, Wunderlin and Hanson 2003) (Figs. 2.19, 2.21, 2.24, 2.26)

\section{\begin{tabular}{|l|l|l|l|l|l|l|l|l|l|l|l|l|}
\hline Flowering dates & J & F & M & A & M & J & J & A & S & O & N & D \\
\hline
\end{tabular}}

\section{U. simulans}

Small to medium terrestrial, annual or perennial, embedded in the soil or periphyton mat, rhizoids present; leaf-like structures: green, photosynthetic, linear to spatulate, solitary or in small rosettes along the stolon, appearing opposite the rhizoids; traps: present on all vegetative organs with two appendages surrounding the doorway, one appendage bifid 
and ventral, and a second, short, conical dorsal appendage; inflorescence: axillary, 1-2(3-4) flowers; flowers: yellow, calyx and bracts fimbriate. (Godfrey and Wooten 1981, Taylor 1989, Wunderlin and Hanson 2003)

\section{\begin{tabular}{|l|l|l|l|l|l|l|l|l|l|l|l|l|} 
Flowering dates & J & F & M & A & M & J & J & A & S & O & N & D \\
\hline
\end{tabular}}

\section{U. subulata L. Zigzag Bladderwort}

Small terrestrials, annuals, embedded in the soil or periphyton mat, rhizoids present; leaflike structures: green, photosynthetic, linear to spatulate, anthrocyanins often present in the tip, the tip often curved; traps: two thick, sparsely branched appendages at the door of the traps, traps very small, present on all vegetative organs; inflorescence: solitary or occasionally branched, possibility zig-zag in appearance (zig-zag appearance not often seen in South Florida), peduncle often with anthrocyanins; flowers: yellow, clastogamous, or yellow-white to white, cleistogamous, small brown capsules produced with numerous seeds; seeds: oval, not flattened, with distinct ridges, very small, $\sim$ less than $2 \mathrm{~mm}$. (Godfrey and Wooten 1981, Taylor 1989, Wunderlin and Hanson 2003) (Figs. $2.20,2.22-2.23,2.25)$

\section{\begin{tabular}{|l|l|l|l|l|l|l|l|l|l|l|l|l|} 
Flowering dates & J & F & M & A & M & J & J & A & S & O & N & D \\
\hline
\end{tabular}}

\section{DISCUSSION}

Most of the Utricularia species present in southern Florida are clearly

distinguishable by their vegetative structures, floral characteristics, and trap appendages, however, there are a few species that can cause problems with identification. Utricularia gibba appears to have a highly plastic morphology and can grow as either a freely floating aquatic, a suspended aquatic, or an affixed aquatic. Taylor (1989) suggests that this species may not flower unless it is growing as an affixed aquatic, but during the present study fully aquatic specimens were observed flowering. Utricularia gibba plants can also form thick, floating mats composed of intertwining plant segments or of plant segments and floating periphyton mats.

Determination of the differences between $U$. cornuta and $U$. juncea is also complicated since the speciation between $U$. cornuta and $U$. juncea is questionable. This 
problem was addressed by Kondo (1972) and it was determined that these species are distinct because of their inability to hybridize. Their morphological characteristics appear to overlap, except that $U$. cornuta may have a tendency to have larger flowers. $U$. cornuta in South Florida should be able to self-pollinate, although no fruit with viable seeds were seen during this study. When $U$. cornuta is hand pollinated, it has a high rate of seed production (Kondo 1972). The seeming inability of $U$. cornuta to produce seed in natural populations may be due to the absence of a pollinator since neither I nor Kondo (1972) observed pollinators. Thus, $U$. cornuta may only propagate clonally; further pollinator studies are needed. These species may also be separated by range with $U$. cornuta extending farther north and south in North America and U. juncea more limited to the northern part of Florida. Herbarium specimens indicate that $U$. juncea has been collected more in the northern and central parts of the state, while $U$. cornuta occurs abundantly throughout (Fig. 2.1). Kondo (1972) also noted difficulty in quantifying the characteristics between the two species since they appeared to change with the surrounding environment or different cultures in the greenhouse. Therefore, intermediate forms may be a result of their environment.

Wunderlin (2003) separates these species by the length of the spur and the distribution of the flowers at the tip of the apex. In U. cornuta, the spur is longer, generally $10 \mathrm{~mm}$, but ranging from $8-13 \mathrm{~mm}$, while in $U$. juncea the spur is generally $6 \mathrm{~mm}$ and ranges from 5-8-(10)mm (FTG). Kondo's (1972) results agree with the separation in spur size, with the spur of $U$. juncea between $0.7 \mathrm{~mm}-2.4 \mathrm{~mm}$ and the spur of $U$. cornuta between $7.5 \mathrm{~mm}-13.8 \mathrm{~mm}$. The flowers of $U$. juncea in herbarium specimens appear slightly smaller and are spread out along the inflorescence tip, while the flowers of $U$. 
cornuta appear slightly larger and usually are more clustered at the tip of the inflorescence. However, this morphological variation could be a result of field conditions, latitude and longitude, clonal distribution, or simply of morphological variation within one species. Some confusion appears to exist in the flowering times of the two species. Wunderlin (2003) records flowering times for both as spring to fall. By contrast, Taylor (1989) indicates that their flowering times do not overlap, with $U$. cornuta flowering in the spring and summer and $U$. juncea flowering in the fall. Herbarium specimens (FTG) and field observations indicate that the flowering times do overlap and that a lack of overlap in flowering times is not the limiting factor for potential hybridization between the two taxa, but range could be (Fig. 2.1). The variation in observed flowering times could indicate that the flowering of these taxa may depend more on hydroperiod and temperature than time of year. This species pair is a good candidate for molecular studies to determine if the taxa are distinct, if molecular differences correlate with geographic distribution, and if intermediate specimens are a result of hybridization events.

Two other species that may be confused in southern Florida are U. resupinata and $U$. gibba since both can be found embedded in the substrate when $U$. gibba is found growing as an attached aquatic. These two species also have similar trap appendages, with $U$. resupinata's appendages resembling a shorter variation of $U$. gibba's. Additionally, both species have circinnate apices; $U$. gibba shows circinnate vernation at the stolon apices, while $U$. resupinata has leaf-like structures with circinnate tips. The vegetative morphology does provide a good way to distinguish the two species. Utricularia resupinata has joints or articulations along the green, leaf-like structures that are not found along the leaf-like structures or stolons of $U$. gibba. 
Besides U. cornuta and $U$. juncea, all Utricularia species in southern Florida should be able to be identified by their vegetative morphology if their reproductive organs are not present to be used for identification. Future studies on Utricularia species should characterize the molecular differences in relation to the morphology and ecological distribution of the taxa. 


\section{HERBARIUM SPECIMENS}

Utricularia amethystina JH Barnhart 1928-12-13 NY

U. amethystina JP Standley 1916-09-11 NY

U. amethystina JP Standley 1916-11-11 NY

$U$. amethystina JP Standley 1916-11-15 NY

U. cornuta CN Avery 884 FTG 9670

U. cornuta SR Hill 2759 FTG 24636

$U$. cornuta DW Black 155 FTG 36901

U. cornuta FC Carighead 1963-01-26 FTG 2431

U. cornuta FC Carighead 1965-10-10 FTG 8626

$U$. cornuta WT Gillis 11220 FTG 14634

U. cornuta J Popenone 499 FTG 29636

U. cornuta SL Orzell 16511 FTG 73640

U. cornuta SL Orzell 14157 FTG 65585

U. cornuta SL Orzell 14324 FTG 66514

U. cornuta SL Orzell 16824 FTG 74065

U. cornuta SL Orzell 16871 FTG 74064

$U$. cornuta SL Orzell 16568 FTG 74151

U. cornuta SL Orzell 16663 FTG 74150

U. cornuta SL Orzell 16989 FTG 74063

U. cornuta KA Bradley 1551 FTG 83376

U. cornuta SL Orzell 13347 FTG 68356

U. cornuta SL Orzell 19006 FTG 77567

U. cornuta KA Bradley 681 FTG 81914

U. cornuta KA Bradley 752 FTG 81815

U. cornuta GD Gann 649 FTG 81570

U. cornuta SL Orzell 19069 FTG 77565

U. cornuta SL Orzell 19091 FTG 77566

U. cornuta SL Orzell 18919 FTG 77568

U. cornuta KA Bradley 1587 FTG 83454

U. cornuta LA Biernacki 15 FTG 36331

U. cornuta J Popenone 1116 FTG 35266

U. cornuta V Dunevitz 1980-11-06 FTG 47207

U. cornuta WM Buswell 1936-05-03 FTG 90479

U. cornuta JK Small 1913-11-11 FTG 90471

U. cornuta WM Buswell 1941-05-04 FTG 90482

U. cornuta LM Garbarini 1967-11-20 FTG 90476

U. cornuta O Lakela 30187 FTG 90477

U. cornuta O Lakela 31359 FTG 90478

U. cornuta P Schmal 1967-11-20 FTG 90474

U. cornuta C Weymouth 1967-11-20 FTG 90473

U. cornuta WM Buswell 1930-02-15 FTG 90483

U. cornuta WM Buswell 1936-05-03 FTG 90480

U. cornuta IA Badia 48 FTG 90475

U. cornuta WM Buswell 1934-12-08 FTG 90481

U. cornuta E Skinner 1967-11-20 FTG 90472 
U. cornuta P Schmal 1967-12-08 FTG 100239

U. cornuta F Killmar 7 FTG 102523

U. cornuta TR Alexander 1973-05-23 FTG 102522

U. cornuta IA Badia 48 FTG 100241

U. cornuta IA Badia 48 FTG 100264

$U$. inflata J Kushlan JK 8 FTG 11979

U. inflata SR Hill 2869 FTG 25524

U. inflata J Kushlan 8A FTG 15191

$U$. inflata WT Gillis 11221 FTG 14633

U. inflata DS Correll 53502 FTG 58064

$U$. inflata D Tabb 1978-04-19 FTG 54734

$U$. inflata J Popenoe 2198 FTG 51679

U. inflata EL Bridges 24180 FTG 74933

U. inflata BF Hansen 6907 FTG 46971

U. inflata CR Jackson 1950-02-02 FTG 90494

U. juncea J Popenoe 769 FTG 29679

U. juncea D Tabb 1979-08-29 FTG 54736

U. juncea DS Correll 1981-10-31 FTG 51004

$U$. juncea AK Herdon 2103 FTG 64850

U. juncea J Popenoe 769 FTG 29679

U. juncea D Tabb 1979-08-29 FTG 75322

U. juncea SL Orzell 18069 FTG 75321

U. juncea SL Orzell 14441 FTG 68355

U. juncea SL Orzell 15369 FTG 68353

U. juncea SL Orzell 15614 FTG 68352

U. juncea SL Orzell 18580 FTG 77574

U. juncea SL Orzell 18786 FTG 77575

U. juncea SL Orzell 18634 FTG 77576

U. juncea SL Orzell 18331 FTG 77707

U. juncea SL Orzell 17313 FTG 77004

U. juncea SL Orzell 18257 FTG 77564

U. juncea DS Correll 53028 FTG 96252

$U$. juncea WM Buswell 1929-11-15 FTG 90495

$U$. juncea C Slaughter 13612 FTG 118330

U. radiata FC Craighead 1964-02-09 FTG 13371

$U$. radiata DS Correll 48110 FTG 30526

$U$. radiata FC Craighead 1964-02-09 FTG 15196

$U$. radiata FC Craighead 1966-03-10 FTG 15034

$U$. radiata RP Sauleda 8004 FTG 52808

$U$. radiata LC Anderson 10288 FTG 73289

$U$. radiata FC Craighead 1966-03-10 FTG 86386

$U$. radiata J Popenoe 1745 FTG 40064

U. radiata RO Woodbury 1942-03-07 FTG 90498

U. radiata RE Mossman 1218(2) FTG 100260 
Table 2.1. Field locations of Utricularia species in South Florida.

\begin{tabular}{|l|l|l|}
\hline Utricularia species & field location & herbaria \\
\hline U. amethystina & not found & NY \\
\hline U. cornuta & $\begin{array}{l}\text { 1) Singeltary, Florida City, FL } \\
\text { 2) Wildlife and Environmental Area, Homestead, FL }\end{array}$ & FTG \\
\hline U. foliosa & $\begin{array}{l}\text { 1) Singeltary, Florida City, FL } \\
\text { 2) Tamiami (C-4) Canal }\end{array}$ & \\
\hline U. gibba & $\begin{array}{l}\text { 1) Henington Pond, FIU, Miami, FL } \\
\text { 2) Singeltary, Florida City, FL } \\
\text { 3) Tamiami (C-4) Canal } \\
\text { 4) Wildlife and Environmental Area, Homestead, FL }\end{array}$ & \\
\hline U. juncea & not found & FTG \\
\hline U. inflata & $\begin{array}{l}\text { 1) observed at Janes Scenic Drive, Fakahatchee } \\
\text { Strand State Preserve }\end{array}$ & FTG \\
\hline U. purpurea & $\begin{array}{l}\text { 1) Henington Pond, FIU, Miami, FL } \\
\text { 2) Tamiami (C-4) Canal }\end{array}$ & \\
\hline U. radiata & 1) Singeltary, Florida City, FL & FTG \\
\hline U. resupinata & 1) Wildlife and Environmental Area, Homestead, FL & \\
\hline U. simulans & not found & FTG \\
\hline U. subulata & $\begin{array}{l}\text { 1) Singeltary, Florida City, FL } \\
\text { 2) Wildlife and Environmental Area, Homestead, FL }\end{array}$ & \\
\hline
\end{tabular}




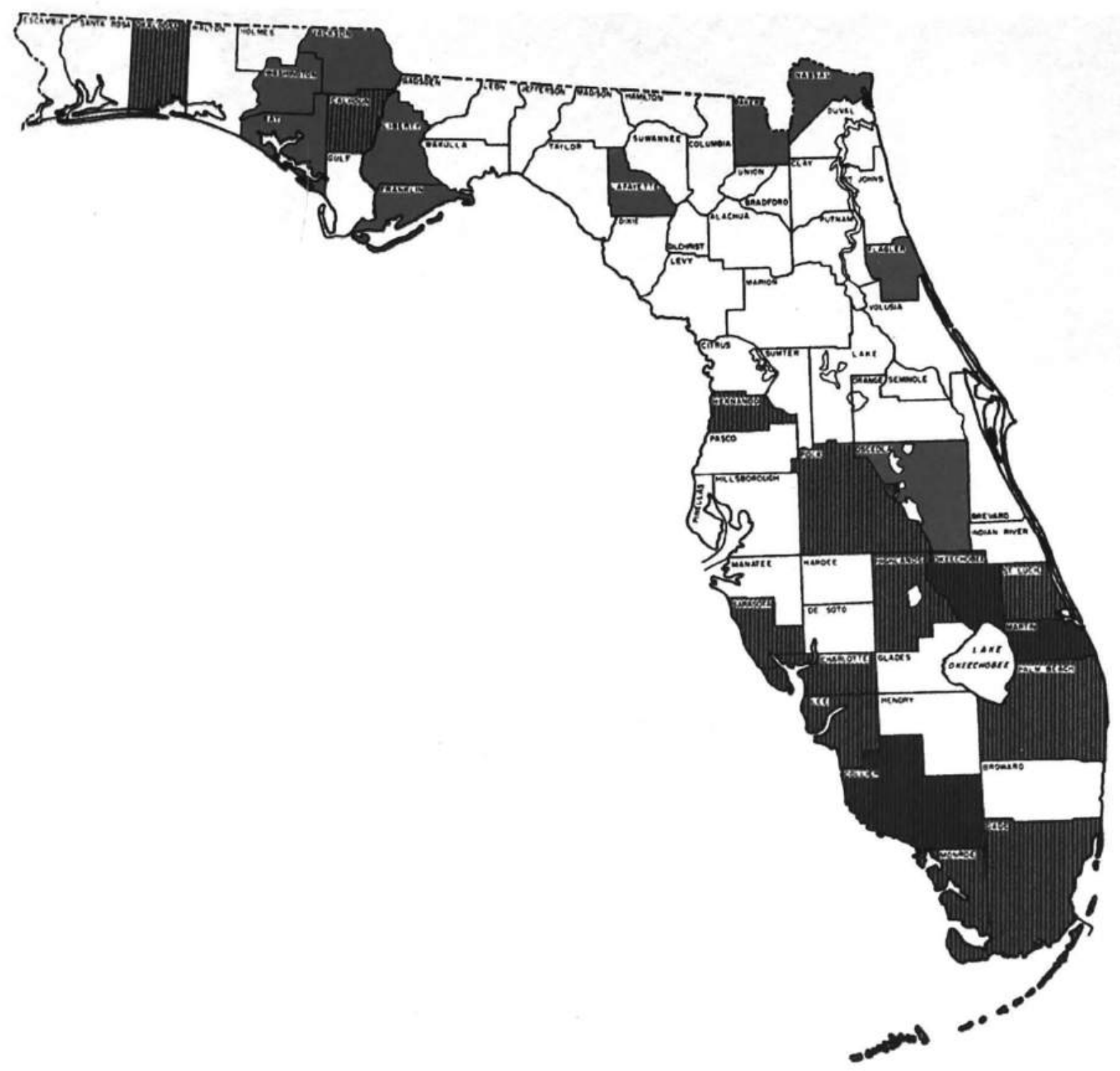

Figure 2.1. Map of the counties where $U$. cornuta and $U$. juncea have been collected in Florida. Grey shading indicates $U$.juncea, black and white herringbone indicates $U$. cornuta, and black and grey herringbone indicates both were collected in that county. Information compiled from field observations and herbarium specimens (FTG). 


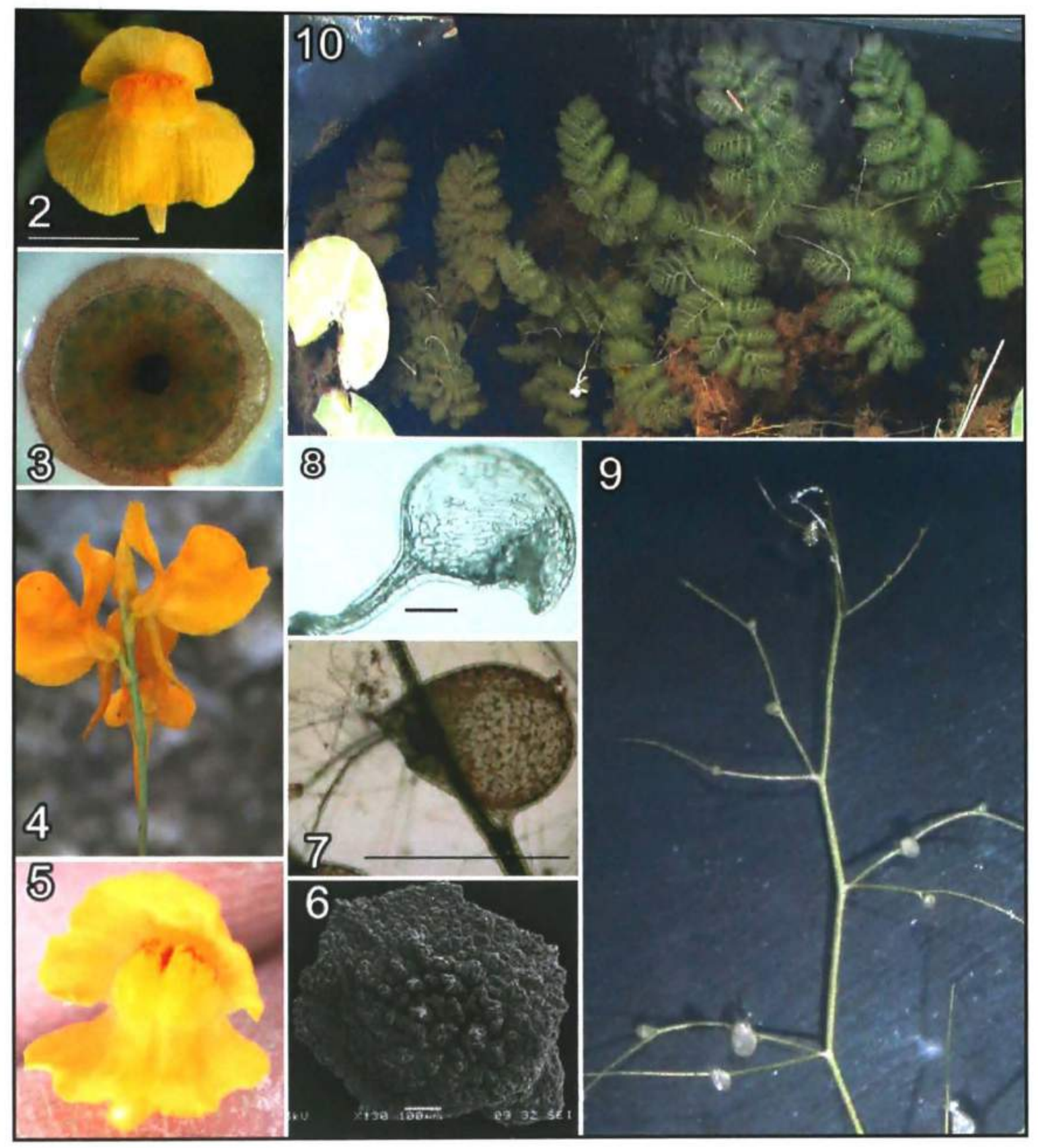




\section{Plate 2.1}

Figures 2.2-2.10. Utricularia species of South Florida. 2.2. U. foliosa flower. 2.3. U. foliosa seed. 2.4. $U$. cornuta flower. 2.5. $U$. gibba flower. 2.6. $U$. gibba seed. 2.7. $U$. gibba trap. 2.8. $U$. cornuta trap. 2.9. $U$. gibba plant stolon with circinnate tip. 2.10. $U$. foliosa plant segment. Fig. 2.2, bar $=1 \mathrm{~cm}$; Fig. 2.7, bar $=1 \mathrm{~mm}$; Fig. 2.8, bar $=0.05 \mathrm{~mm}$. 


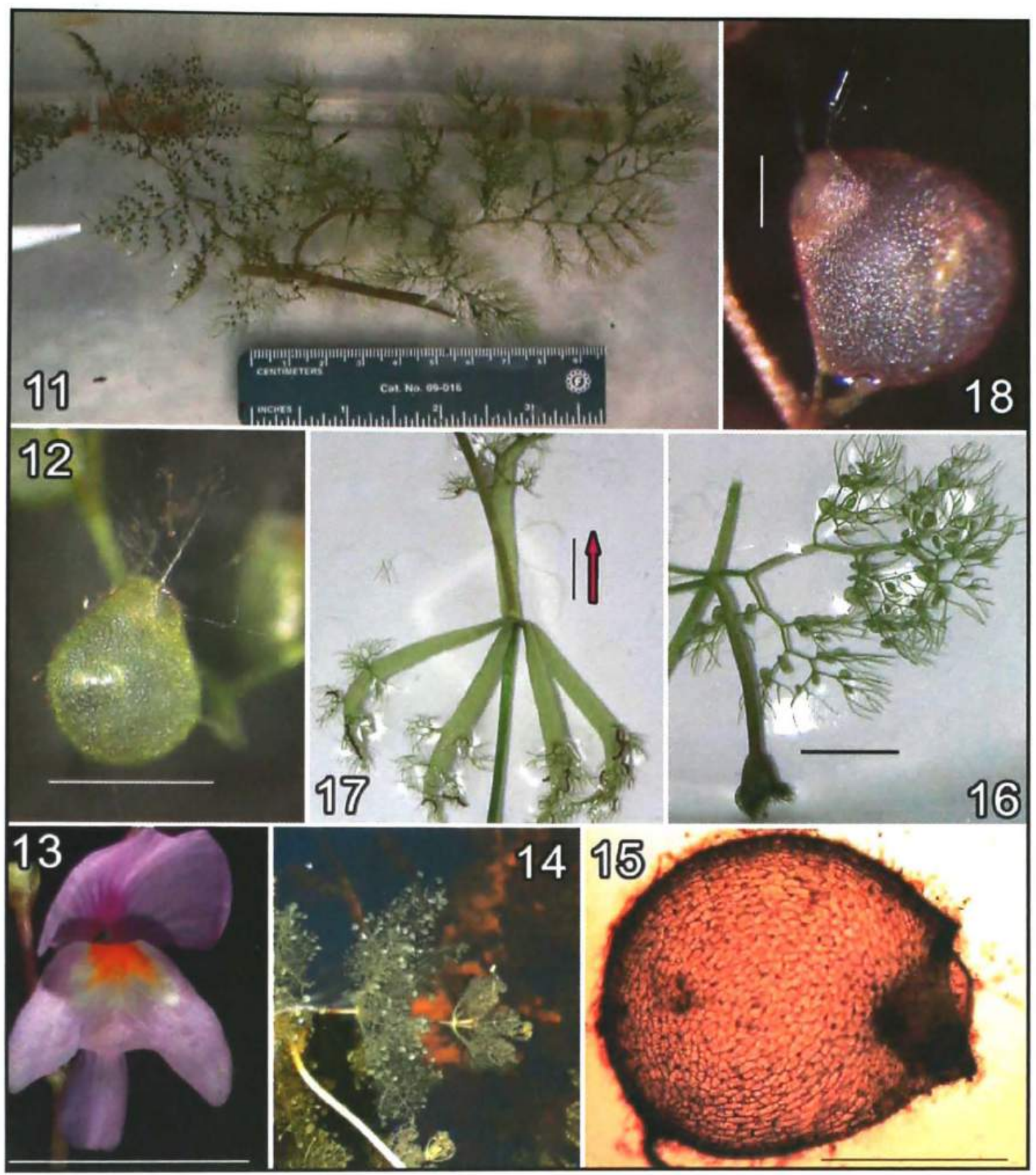




\section{Plate 2.2}

Figures 2.11-2.18. Utricularia species of South Florida. 2.11. U. foliosa dimorphic LLS. 2.12. $U$. inflata trap. 2.13. $U$. purpurea flower. 2.14. $U$. purpurea plant apex. 2.15. $U$. purpurea trap with glandular hairs (circled). 2.16. U. inflata LLS. 2.17. U. inflata inflated inflorescence whorl. Arrow indicates direction of scape growth. 2.18. U. foliosa trap. Fig. 2.12, bar $=2 \mathrm{~mm}$; Fig. 2.13, bar =1 cm; Fig. 2.14, bar =1mm; Figs. 2.16-2.17, bar =1 cm; Fig. 2.18 , bar $=1 \mathrm{~mm}$. 


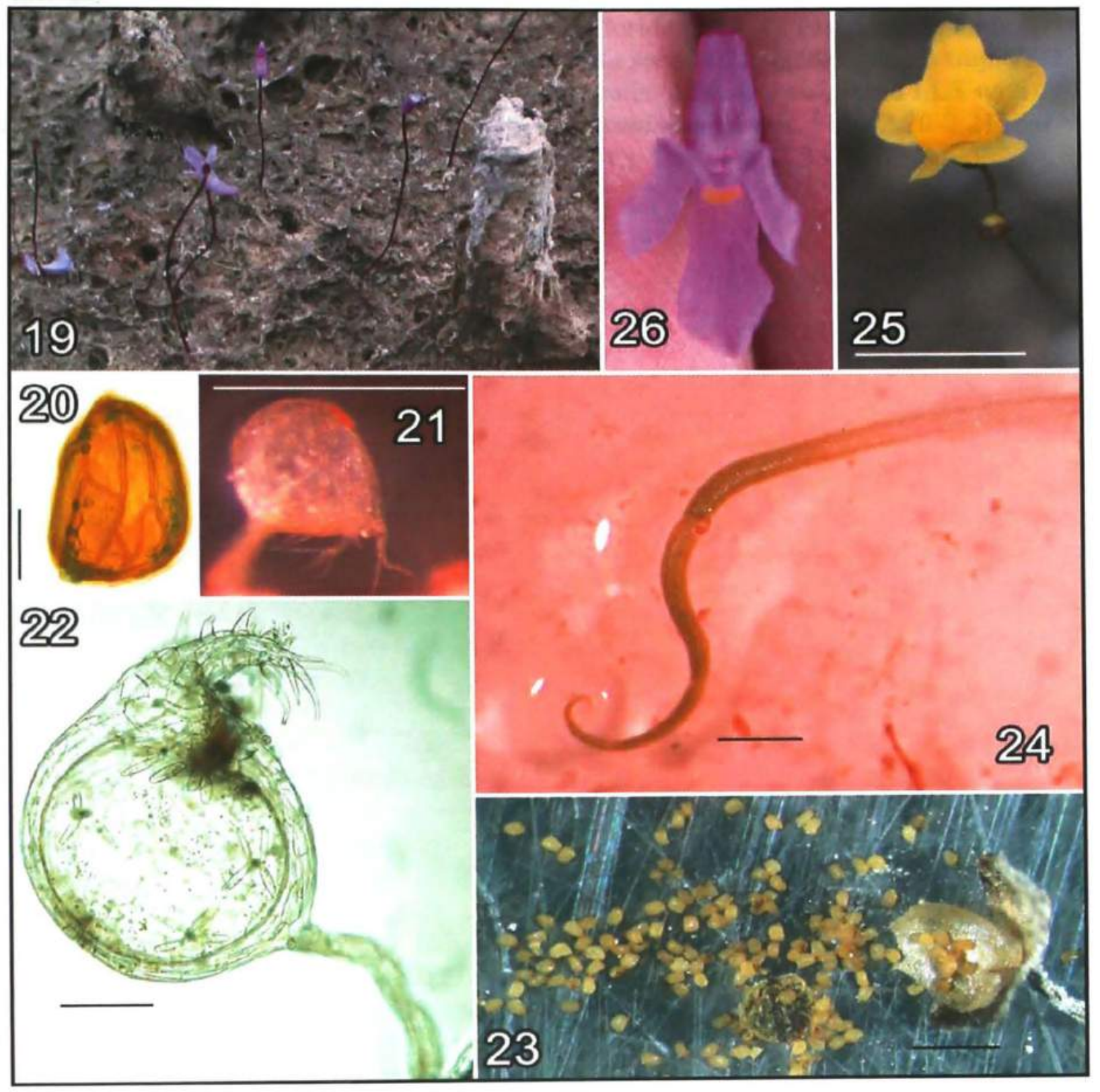




\section{Plate 2.3}

Figures 2.19-2.26. Utricularia species of South Florida. 2.19. U. resupinata plants embedded in the periphyton mat. 2.20. $U$. subulata seed. 2.21. $U$. resupinata trap. 2.22 . $U$. subulata trap. 2.23. U. subulata capsule and seeds. 2.24. U. resupinata LLS with articulation. 2.25. $U$. subulata flower. 2.26. $U$. resupinata flower. Figs. $2.20-2.21$, bar $=$ $1 \mathrm{~mm}$; Fig. 2.22, bar =0.5mm; Figs. 2.23-2.24, bar $=1 \mathrm{~cm}$; Fig. 2.25, bar $=8 \mathrm{~mm}$. 


\section{LITERATURE CITED}

GODFREY, R. K. and J. W. WOOTEN. 1981. Aquatic and Wetland Plants of the Southeastern United States, 681-696. The University of Georgia Press, Athens, Georgia, USA.

KONDO, K. 1972. Comparison of variability in Utricularia cornuta and Utricularia juncea. American Journal of Botany. 59: 23-37.

LLOYD, F. E. 1942. The Carnivorous Plants. Chronica Botanica, Vol. 9. Ronald Press, New York, USA.

REUT, M. S. AND B. A. FINERAN. 2000. Ecology and vegetative morphology of the carnivorous plant Utricularia dichotoma (Lentibulariaceae) in New Zealand. New Zealand Journal of Botany. 38: 433-450.

RICHARDS, J. H. 2001. Bladder function in Utricularia purpurea (Lentibulariaceae): is carnivory important? American Journal of Botany 88: 170-176.

SATTLER, R. and R. RUTISHAUSER. 1990. Structural and dynamic descriptions of the development of Utricularia foliosa and U. australis. Candian Journal of Botany 68: 1989-2003.

WUNDERLIN, R. P. and B. F. HANSEN. 2003. Guide to the Vascular Plants of Florida. 502-504. University Press of Florida, Gainsville, FL, USA.

TAYLOR, P. 1989. The genus Utricularia. Kew Bulletin Series XIV. 1-724. Her Majesty's Stationery Office: London, United Kingdom.

THE INSTITUTE FOR REGIONAL CONSERVATION. Floristic inventory of South Florida Database Online. 2001. Institute for Regional Conservation. May 16, 2007. [http://regionalconservation.org/ircs/DatabaseChoice.asp] 